Julián Andrés Ortiz González

Verificação da hipótese do $\Delta K_{e f}$ como a força motriz da propagação de trincas por fadiga

Tese de Doutorado

Tese apresentada como requisito parcial para obtenção do grau de Doutor pelo Programa de Pós-graduação em Engenharia Mecânica do Departamento de Engenharia Mecânica da PUC-Rio.

Orientador: Prof. Jaime Tupiassú Pinho de Castro 


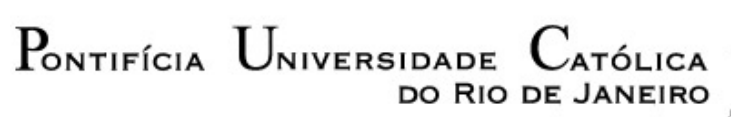

\section{Julián Andrés Ortiz González}

\section{Verificação da hipótese do $\Delta K_{\text {ef }}$ como a força motriz da propagação de trincas por fadiga}

Tese apresentada como requisito parcial para obtenção do grau de Doutor pelo Programa de Pós-graduação em Engenharia Mecânica da PUC-Rio. Aprovada pela Comissão Examinadora abaixo.

Prof. Jaime Tupiassú Pinho de Castro

Orientador

Departamento de Engenharia Mecânica - PUC-Rio

Prof. Marco Antonio Meggiolaro

Departamento de Engenharia Mecânica - PUC-Rio

Prof. José Luiz de França Freire

Departamento de Engenharia Mecânica - PUC-Rio

Prof. José Alexander Araújo Universidade de Brasília - UNB

Prof. Antonio Carlos de Oliveira Miranda

Universidade de Brasília - UNB

Rio de Janeiro, 13 de maio de 2019. 
Todos os direitos reservados. É proibida a reprodução total ou parcial do trabalho sem autorização da universidade, do autor e do orientador.

\section{Julián Andrés Ortiz González}

É formado em Engenharia Mecânica pela Universidade ECCI (2012). Possui Mestrado em Engenharia de Mecânica pela PUC-Rio, obtendo o título em 2015. Já realizou estudos sobre a produção de energia elétrica com fontes alternativas. Atualmente atua em pesquisa sobre a identificação da força motriz da propagação de trincas por fadiga.

Ficha Catalográfica

Ortiz González, Julián Andrés

Verificação da hipótese do $\Delta K_{e f}$ como a força motriz da propagação de trincas por fadiga / Julián Andrés Ortiz González; orientador: Jaime Tupiassú Pinho de Castro. - 2019.

93 f. : il. color. ; $30 \mathrm{~cm}$

Tese (doutorado)-Pontifícia Universidade Católica do Rio de Janeiro, Departamento de Engenharia Mecânica, 2019.

Inclui bibliografia

1. Engenharia Mecânica - Teses. 2. Propagação de trincas por fadiga. 3. Fechamento de trincas. 4. Carga de abertura de trinca. I. Mendes, Paulo Roberto de Souza. II. Pontifícia Universidade Católica do Rio de Janeiro. Departamento de Engenharia Mecânica. III. Título. 


\section{Agradecimentos}

O presente trabalho foi realizado com apoio da Coordenação de Aperfeiçoamento de Pessoal de Nível Superior - Brasil (CAPES) - Código de Financiamento 001.

O presente trabalho foi realizado com apoio do Conselho Nacional de Desenvolvimento Científico e Tecnológico - Brasil (CNPq).

O presente trabalho foi realizado com apoio da Fundação Carlos Chagas Filho de Amparo à Pesquisa do Estado do Rio de Janeiro- Brasil (FAPERJ).

Ao meu orientador Professor Jaime Tupiassú Pinho de Castro pelas indicações e bons conselhos na realização deste trabalho.

À PUC-Rio, pelos auxílios concedidos, sem os quais este trabalho não poderia ter sido realizado.

Ao meu colega Giancarlo Gomez Gonzáles pela ajuda na realização dos testes de laboratório.

A Mariana da Rocha Osborne pelas importantes contribuições no texto.

Aos meus colegas de laboratório Marco, Jorge e Vitor por todo o apoio.

Aos meus pais, pela educação e atenção de todas as horas.

Aos professores que participaram da Comissão examinadora.

A todos os professores e funcionários do departamento de engenharia mecânica pelos ensinamentos e ajuda.

A todos os amigos e familiares que de uma forma ou de outra me auxiliaram. 


\section{Resumo}

González, Julián Andrés Ortiz; Castro, Jaime Tupiassú Pinho. Verificação da hipótese do $\Delta K_{e f}$ como a força motriz da propagação de trincas por fadiga. Rio de Janeiro, 2019. 93p. Tese de Doutorado - Departamento de Engenharia Mecânica, Pontifícia Universidade Católica do Rio de Janeiro.

Medindo a rigidez de corpos de prova em testes de propagação de trinca por fadiga, Elber identificou que a ponta da trinca só está totalmente aberta durante uma parte do ciclo de carregamento, e nomeou o carregamento onde a trinca abre totalmente de carga de abertura $P_{a b}$. Baseado nisso, Elber assumiu que o dano à frente da trinca era induzido apenas pela fração do carregamento acima da $P_{a b}$, propondo que a força motriz na propagação de trincas por fadiga é a gama do fator de intensidade de tensões efetivo $\Delta K_{e f}$. Para verificar esta hipótese, neste trabalho foram examinados diferentes cenários em testes de propagação de trinca por fadiga. Primeiramente, em corpos DC(T) de aço AISI 1020 e em corpos DC(T) e C(T) de alumínio 6351-T6 foi propagada uma trinca com $\Delta K$ e $K_{\max }$ quase constantes, medindo $P_{a b}$ em campo próximo e em campo distante, com extensômetros e com um sistema 3D de correlação digital de imagens (DIC). Depois, usando novos corpos $\mathrm{DC}(\mathrm{T})$ de aço e de alumínio, foi propagada uma trinca com $\Delta K$ e $K_{\max }$ quase constantes, antes e depois de um evento de sobrecarga, medindo a $P_{a b}$ ao longo do teste, em campo próximo e campo distante. Cabe salientar que nesses testes as espessuras dos corpos de prova foram projetadas para que a trinca propagasse em tensão plana e em deformação plana. Finalmente, em testes de propagação de trinca com $\Delta K \mathrm{e}$ $K_{\max }$ quase constantes, em corpos DC(T) de aço e de alumínio foi medido o campo de deformação à frente da ponta da trinca com um sistema de microscópio estéreo DIC, para analisar o comportamento dentro da zona plástica, medindo também a $P_{a b}$ com os métodos mencionados anteriormente. Dos resultados dos testes três comportamentos foram particularmente relevantes. Nos primeiros testes de propagação com $\left\{\Delta K\right.$ e $\left.K_{\max }\right\}$ quase constantes, a razão $K_{a b} / K_{\max }$ diminuía enquanto a trinca propagava com uma taxa constante. Nos testes de sobrecarga o valor mínimo de $\Delta K_{e f}$ estava defasado em relação ao valor mínimo de taxa de propagação ( $\left.d a / d N\right)$. Já nos testes onde foi medido o campo deformação com o sistema de microscópio 
estéreo DIC, a deformação $0.1 \mathrm{~mm}$ à frente da ponta da trinca mostrou que existia dano para cargas abaixo da $P_{a b}$. Portanto, estes resultados não podem ser explicados pela hipótese de Elber, e contestam o $\Delta K_{e f}$ como a força motriz na propagação de trincas por fadiga.

\section{Palavras-chave}

Propagação de trincas por fadiga; fechamento de trincas, carga de abertura de trinca. 


\section{Abstract}

González, Julián Andrés Ortiz; Castro, Jaime Tupiassú Pinho (Advisor). Verification of the $\boldsymbol{\Delta} K_{\text {eff }}$ hypothesis as the driving force for fatigue crack growth. Rio de Janeiro, 2019. 93p. Tese de Doutorado - Departamento de Engenharia Mecânica, Pontifícia Universidade Católica do Rio de Janeiro.

Measuring the stiffness of a fatigue-cracked plate during its loading cycle, Elber discovered that this crack only completely opened after reaching the crack opening load $P_{o p}$. Based on this, Elber assumed that the damage ahead of the crack is induced by the loading part above the $P_{o p}$. In this way, he proposed that the range of the effective stress intensity factor $\Delta K_{\text {eff }}$ is the driving force in fatigue crack growth. In order to verify this hypothesis, this study investigated different scenarios in fatigue crack growth tests. For this, DC(T) specimens of AISI 1020 steel, and DC(T) and C(T) specimens of 6351-T6 aluminum were tested. The fatigue crack growth tests were performed under quasi-constant $\Delta K$ and $K_{\max }$ conditions. The $P_{o p}$ measurements in the near and far field were obtained from strain gage readings and 3D Digital Image Correlation (DIC) analysis. In addition, simple variable amplitude tests were performed in steel and aluminum $\mathrm{DC}(\mathrm{T})$ specimens. A single tensile overload was introduced in the fatigue crack growth experiments under quasi-constant $\Delta K$ and $K_{\max }$ conditions, also measuring the $P_{o p}$ throughout the test in the near and the far field. It is important to note that the thickness of the specimens was designed to perform a crack propagation in plane stress and plane strain conditions. Moreover, near tip strain measurements in steel and aluminum DC(T) specimens were obtained with a stereo microscope DIC system, to analyze the behavior within the plastic zone, also measuring the $P_{o p}$ with the methods previously mentioned. From the experimental results, three behaviors were particularly relevant. In the first fatigue crack growth tests with quasi-constant $\left\{\Delta K, K_{\max }\right\}$ conditions, the ratio $K_{o p} / K_{\max }$ decreased as the crack propagates under a constant rate. In the fatigue crack growth tests with overload application, the minimum value of $\Delta K_{\text {eff }}$ was lagged in relation to the minimum value of the propagation rate $(d a / d N)$. Finally, in the strain measurements performed with the stereo microscope DIC system, the deformation at $0.1 \mathrm{~mm}$ ahead of the crack tip showed the existence of damage in load 
values below $P_{o p}$. Therefore, these results cannot be explained by Elber's hypothesis, and question the $\Delta K_{\text {eff }}$ as the driving force in fatigue crack growth.

\section{Keywords}

Fatigue crack growth; crack closure; crack opening load. 


\section{Sumário}

1. Introdução 14

1.1. Objetivos 16

1.1.1. Objetivos específicos 16

1.2. Organização do trabalho 17

2. Fundamentos teóricos 18

2.1. Enfoque unificado do dano à fadiga 18

2.2. Fechamento de trincas por fadiga 20

2.2.1. Fechamento induzido por plasticidade 22

2.3. Modelo de dano crítico 23

2.4. Estado plano de tensão e estado plano de deformação 25

2.5. Dúvidas sobre a validade de $\Delta K_{\text {ef }} \quad 27$

2.5.1. Métodos de medição de carga de abertura $P_{a b}$

2.5.2. Fechamento total ou parcial da ponta da trinca 29

2.5.3. Efeitos do estado plano de tensões na propagação 33

2.5.4. Efeitos da razão de carga $R$ na propagação 35

2.5.5. Efeitos de sequência de carga na propagação 37

3. Materiais e métodos 43

3.1. Dimensões dos corpos de prova 43

3.2. Medição de deformação e deslocamento nos CPs 44

3.2.1. Medição do campo de deslocamento/deformação usando DIC 45

3.3. Medição do comprimento da trinca 48

3.3.1. Medição via variação da flexibilidade do CP 49

3.4. Procedimento de testes com $\Delta K$ e $K_{\max }$ quase constantes 50

3.4.1. Sistema de malha fechada para automatização dos testes $\quad 50$

3.5. Testes com $\Delta K$ e $K_{\max }$ quase constantes, com sobrecarga. $\quad 52$

3.6. Sistema de microscópio estéreo DIC 53

3.7. Processamento de dados 54 
3.8. Corpos de prova de aço AISI 1020

3.9. Corpos de prova de alumínio 6351-T6 57

3.9.1. Corpos de prova tipo $\mathrm{C}(\mathrm{T})$ de alumínio 58

3.10. Lista de todos os testes realizados 59

4. Resultados e discussão 61

4.1. Primeira etapa de testes 61

4.1.1. Resultados dos testes com $\Delta K$ e $K_{\max }$ quase constantes. Aço 63

4.2. Segunda etapa de testes 67

4.2.1. Testes sob $\Delta K$ e $K_{\max }$ quase constantes na liga de Al 6351-T6 68

4.3. Testes com sobrecarga em CPs de aço 74

4.4. Testes com sobrecarga em CPs de Alumínio 77

4.5. Testes com o sistema de microscópio estéreo DIC 78

4.5.1. Teste no CP de aço com o sistema microscópio estéreo + DIC 79

4.5.2. Teste no CP de Al com o sistema microscópio estéreo + DIC 82

4.6. Discussão 84

5. Conclusões 87

5.1. Trabalhos Futuros 88

5.2. Publicações 88

6. Referências Bibliográficas 90 


\section{Lista de símbolos}

A Constante da equação de Paris.

$A_{0-3} \quad$ Parâmetros do cálculo teórico da relação $K_{a b} / K_{\max }$.

$A_{e} \quad$ Constante da equação de Elber.

$A_{f n} \quad$ Constante da equação de Forman-Newman.

a Comprimento de trinca.

$a_{i} \quad$ Comprimento de trinca anterior.

$a_{i+1} \quad$ Comprimento de trinca atual.

$\Delta a \quad$ Aumento do comprimento de trinca.

$C_{i} \quad$ Flexibilidade do segmento $i$.

$\mathrm{CO}_{i} \quad$ Critério de flexibilidade da norma ASTM E647.

$C_{O P} \quad$ Flexibilidade da trinca totalmente aberta.

CP Abreviatura de Corpo de Prova.

$d_{\text {átomo }}$ Tamanho atômico.

$d a / d N$ Taxa de propagação de trinca por fadiga.

$d_{\text {grão }} \quad$ Tamanho de grão.

E Módulo de elasticidade.

$K \quad$ Fator de intensidade de tensões.

$K_{a b} \quad$ Fator de intensidade de tensões gerado pela carga de abertura.

$K_{C} \quad$ Fator de intensidade de tensões crítico.

$K_{I C} \quad$ Fator de intensidade de tensões crítico em modo I.

$K_{\max } \quad$ Fator de intensidade de tensões gerado pela carga máxima.

$K_{\text {max }_{t h}}^{*}$ Limiar máximo do enfoque unificado.

$K_{\min } \quad$ Fator de intensidade de tensões gerado pela carga mínima.

$\Delta K \quad$ Gama do fator de intensidade de tensões.

$\Delta K_{e f} \quad$ Gama efetiva do fator de intensidade de tensões.

$\Delta K_{t h} \quad$ Limiar de propagação de trinca.

$\Delta K_{t h}^{*} \quad$ Gama do limiar de propagação do critério unificado. 
$m \quad$ Constante da equação de Paris.

$m_{e} \quad$ Constante da equação de Elber.

$m_{f n} \quad$ Constante da equação de Forman-Newman.

$N \quad$ Número de ciclos.

$N_{i} \quad$ Número de ciclos anterior.

$N_{i+1} \quad$ Número de ciclos atual.

$N_{R} \quad$ Número de ciclos de retardo.

$P \quad$ Carga aplicada no corpo de prova.

$P_{a b} \quad$ Carga de abertura de trinca

$p_{f n} \quad$ Constante da equação de Forman-Newman.

$P_{\max } \quad$ Carga máxima aplicada.

$P_{\min } \quad$ Carga mínima aplicada.

$\Delta P \quad$ Gama da carga aplicada.

$q_{f n} \quad$ Constante da equação de Forman-Newman.

$R \quad$ Razão de carga $K_{\min } / K_{\max }$.

$S_{E} \quad$ Resistência ao escoamento.

SC Abreviatura de "sobrecarga".

$S_{F L} \quad$ Resistência (tensão) de fluxo do material.

$S_{R} \quad$ Resistencia à ruptura.

$t \quad$ Espessura do corpo de prova.

w Largura do corpo de prova.

zp Zona plástica.

$z p_{C} \quad$ Zona plástica crítica.

$z p_{\max } \quad$ Zona plástica máxima.

$z p_{r} \quad$ Zona plástica reversa.

$z p_{S C} \quad$ Zona plástica hipertrofiada pela sobrecarga.

$\alpha \quad$ Restrição 3D do protocolo de Forman-Newman.

$\delta \quad$ Abertura de boca de trinca.

$\delta_{c} \quad$ Abertura de boca de trinca crítica.

$\delta_{P} \quad$ Deslocamento do ponto de aplicação da força. 
$\varepsilon \quad$ Deformação.

$\Delta \varepsilon \quad$ Gama de deformação.

$v \quad$ Coeficiente de Poisson.

$\sigma \quad$ Tensão. 


\section{1. Introdução}

As estruturas, os equipamentos e os componentes mecânicos, na maioria dos casos, estão submetidos a carregamentos de amplitude variável que geram fadiga. Este processo de falha pode ser separado em três etapas: a iniciação de uma trinca, sua posterior propagação paulatina e finalmente a fratura brusca, que ocorre quando a trinca atinge seu tamanho crítico.

A etapa de propagação de trincas por fadiga é muito importante principalmente em dois casos : (i) quando uma peça ou equipamento não pode ser retirado de serviço facilmente logo após a detecção de uma trinca, seja por questões de custo, de produção ou por conveniência; ou (ii) no projeto de peças com alto risco e/ou baixo fator de segurança, onde se tem que garantir que uma trinca com o comprimento mínimo detectável não vai atingir o comprimento crítico antes da próxima inspeção (fato comum nas indústrias Aeronáutica, Nuclear, Aeroespacial...) [1].

A primeira abordagem exitosa do problema da propagação de trincas por fadiga foi proposta por Paris, Gomez e Anderson em 1961 [2]. Eles propuseram uma relação semi-empírica entre o fator de intensidade de tensões proposto por Irwin para analisar as trincas submetidas a cargas estáticas $(K)$ e a taxa de propagação de trincas por fadiga (da/dN). Depois disso, em 1963 no artigo de Paris e Erdogan [3], esta ideia reapareceu na forma de uma equação, relacionando a gama do fator de intensidade de tensões $(\Delta K)$, com a taxa de propagação de trincas por fadiga $(d a / d N)$. Cabe salientar que como esta equação mostrou bons resultados ao descrever a propagação estável das trincas por fadiga, na chamada Fase II da propagação, muitas formulações foram propostas baseadas nesta ideia, mas considerando os efeitos de outros parâmetros que podem afetar a propagação. Esses parâmetros comumente são: o fator de intensidade te tensões gerado pela carga máxima e pela carga mínima ( $K_{\max }$ e $\left.K_{\min }\right)$, a razão de carda $\left(R=K_{\min } / K_{\max }\right)$, o limiar de propagação $\left(\Delta K_{t h}\right)$, a tenacidade do material $\left(K_{c}\right)$, entre outros [4]. 
No final dos anos sessenta na sua tese de doutorado, Elber identificou que "como consequência do envelope de deformações residuais deixado em torno das faces da trinca, a parte elástica das peças trincadas tende a comprimir esta esteira plástica, forçando o fechamento das faces da trinca quando descarregadas" [5].

Já no seu artigo de 1971, Elber assumiu que as trincas só poderiam propagar depois que estivessem totalmente abertas, e propôs o fator de intensidade de tensões efetivo $\left(\Delta K_{e f}=K_{\max }-K_{a b}\right)$ como a força motriz da propagação de trincas por fadiga. A partir disso, como o $\Delta K_{\text {ef }}$ depende da carga de abertura de trinca $\left(P_{a b}\right)$, ou melhor, do fator de intensidade de tensões associado a esta carga $\left(K_{a b}\right)$, foi criado um novo enfoque no estudo da propagação de trincas por fadiga [6].

A hipótese de Elber é bastante popular e tem servido de fundamento para muitos modelos de previsão de vida residual em peças trincadas, um exemplo disso é o modelo de Forman-Newman implementado no programa NASGRO [7-9]. Porém, ainda existe uma discussão na literatura por alguns fenômenos na propagação de trincas por fadiga que está hipótese não consegue explicar [1] e concorre com modelos de propagação que usam parâmetros como $\Delta K, K_{\max }, K_{\min }, R=K_{\min } / K_{\max }$, $\Delta K_{t h}$ e $K_{c}$, e abordagens de acúmulo de dano à frente da ponta da trinca.

As formulações baseadas em modelos de acumulo de dano estimam as gamas de deformação atuantes à frente da ponta da trinca para calcular o dano. Com esta informação, são obtidos os incrementos de trinca cada vez que ocorre a falha de um corpo de prova virtual posicionado à frente da ponta, aplicando conceitos elastoplásticos $\varepsilon N$ tradicionalmente usados para prever iniciação de trincas $[1,10,11]$. Recentemente Ferreira et al. [12] apresentaram um modelo de acumulo de dano que leva em conta influência do fechamento das faces da trinca, sobre as deformações plásticas à frente de sua ponta, mostrando previsões de vida residual promissoras.

Esses são só alguns dos caminhos na procura da verdadeira força motriz na propagação de trincas por fadiga. Os modelos estão sendo estudados por vários autores e ainda geram bastante controvérsia, pelas eventuais diferenças que existem entre os princípios teóricos nos quais se fundamentam.

Por esta razão, é de vital importância oferecer evidências que levem à identificação da força motriz da propagação de trincas por fadiga, por meio de ensaios experimentais discriminatórios, que avaliem os princípios básicos dos modelos. Além disso, com resultados confiáveis, aumenta-se a compreensão do fenômeno da propagação de trincas por fadiga. 


\section{1.}

\section{Objetivos}

O objetivo primário deste trabalho é apresentar evidências experimentais confiáveis que contribuam para identificar a força motriz da propagação de trincas por fadiga. Para isso foram feitos ensaios discriminatórios que permitem identificar claramente os efeitos e parâmetros que são cruciais na propagação de trincas por fadiga. Essas evidências experimentais permitem que se apresentem sugestões acerca do uso de modelos de predição da vida residual em peças trincadas.

\subsection{1.}

\section{Objetivos específicos}

- Realizar testes de propagação de trinca sob $\Delta K$ e $K_{\max }$ quase constantes, obtendo simultaneamente as taxas de propagação de trinca e medições redundantes de carga de abertura $P_{a b}$.

- Reproduzir os testes de propagação sob $\Delta K$ e $K_{\max }$ quase constantes, alterando parâmetros de teste, como o valor do $\Delta K$, o material do corpo de prova e até mesmo sua geometria.

- Produzir resultados experimentais similares com eventos de sobrecargas, para avaliar os efeitos de retardo na taxa de propagação das trincas e sua relação com valores medidos de $P_{a b}$.

- Automatizar os testes com um sistema de malha fechada, para controlar as cargas aplicadas mantendo $\Delta K$ e $K_{\max }$ constantes, dependendo das mudanças no comprimento da trinca.

- Com base nos resultados experimentais, avaliar o comportamento de $\Delta K$ e de $\Delta K_{e f}$ como forças motrizes na propagação de trincas por fadiga. 
1.2.

Organização do trabalho

No Capítulo 2 é feita uma revisão das principais teorias que tentam descrever a propagação de trincas por fadiga, e a discussão que existe entre elas. No Capítulo 3 há uma descrição dos equipamentos e dos procedimentos utilizados nos ensaios experimentais. No Capítulo 4, primeiramente são mostrados os resultados experimentais obtidos e depois é feita uma análise deles, à luz dos modelos teóricos de propagação de trinca e de suas respectivas forças motrizes. Finalmente, no Capítulo 5 se encontram as conclusões e as propostas para trabalhos futuros. 


\section{2. \\ Fundamentos teóricos}

A propagação de trincas por fadiga pode ser descrita pela relação entre a taxa de propagação $d a / d N$ e a gama do fator de intensidade de tensões $\Delta K$. Esta ideia pioneira foi proposta pela primeira vez por Paris, Gomez e Anderson em 1961 [2], e depois consolidada em 1963, no artigo de Paris e Erdogan [3], onde foi proposta a famosa relação hoje conhecida como regra de Paris:

$$
\frac{d a}{d N}=A \Delta K^{m}
$$

onde $A$ e $m$, são constantes do material.

A Equação 2.1 pode ser plotada como uma reta num gráfico com escala logarítmica; $\log (d a / d N)=\log (A)+m * \log (\Delta K)$, onde $m$ é a sua inclinação. Esta equação permitiu que pela primeira vez se fizessem cálculos de vida residual à fadiga de estruturas trincadas, reconhecendo explicitamente o efeito da trinca.

As curvas de propagação de trincas por fadiga $d a / d N \times \Delta K$ são tipicamente sigmoidais e podem ser divididas em três fases. Elas iniciam no limiar de propagação $\Delta K_{\text {th }}$ e atingem seu limite superior no momento em que a peça fratura, quando fator de intensidade de tensões máximo atinge o valor da tenacidade do material, ou seja, $K_{\max }=K_{c}$ [13]. A regra de Paris só descreve a fase dois, como se pode observar na Figura 2.1, onde se relaciona a taxa de propagação de trinca típica das ligas metálicas sob $R$ constante, com parâmetros como o diâmetro atômico $d_{\text {átomo }}, \mathrm{o}$ tamanho de grão $d_{g r a ̃ o}$, a zona plástica reversa $z p_{r}$, e a abertura de boca de trinca crítica $\delta_{c}$.

\section{1 .}

\section{Enfoque unificado do dano à fadiga}

O enfoque unificado do dano à fadiga é um modelo mais recente, proposto por Vasudevan e Sadananda em 1993. O modelo propõe que a propagação não tem apenas uma força motriz, mas sim que o crescimento da trinca depende de dois 
parâmetros, $\Delta K$ e $K_{\max }$. Além disso, eles propõem que há, na realidade, dois limiares de propagação, o limiar da gama $\Delta K_{t h}^{*}$ e o limiar do máximo $K_{m a x}^{*}$.

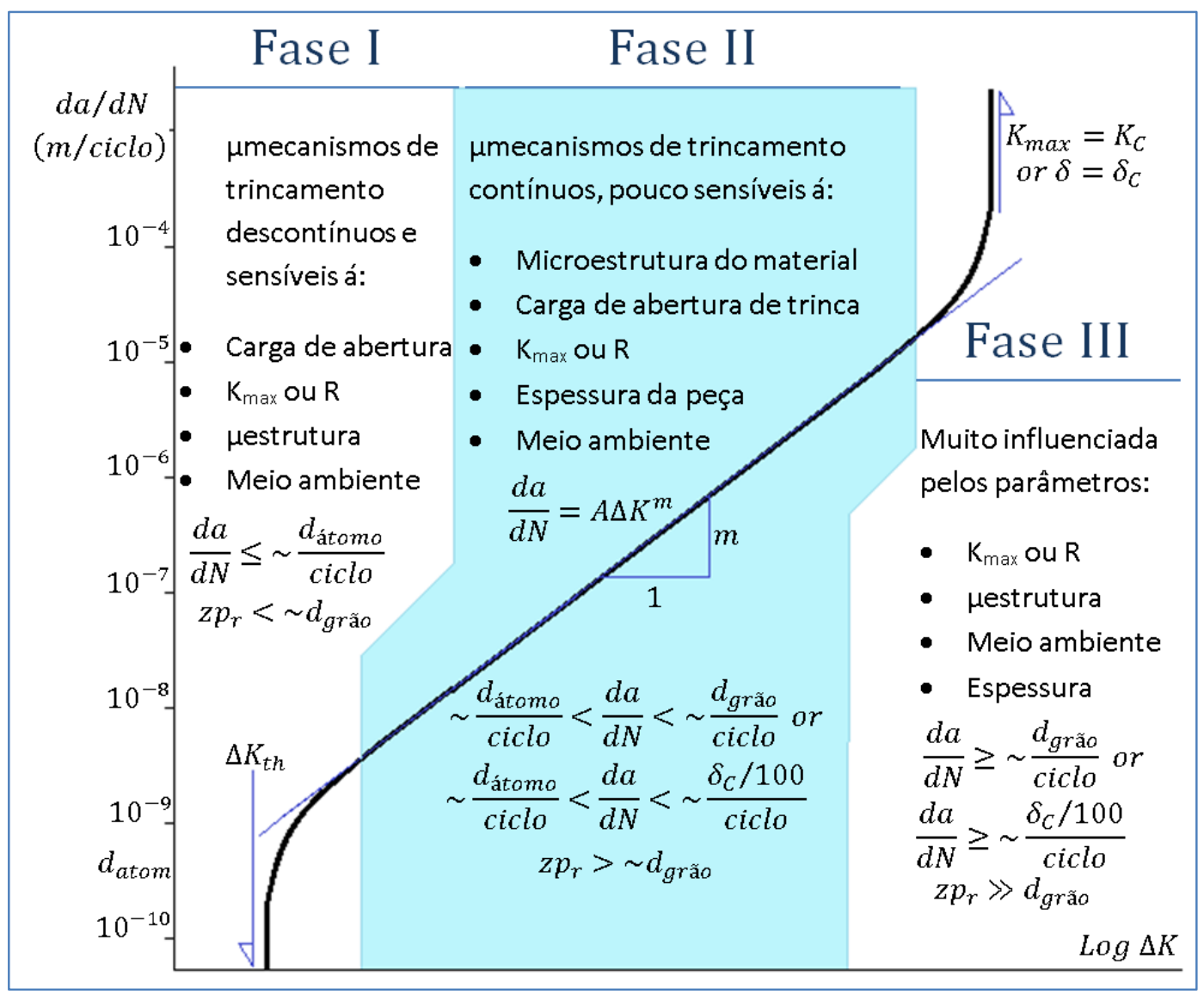

Figura 2.1: Curva sigmoidal típica que descreve a propagação de trincas por fadiga, com as três fases características (adaptado de [13]).

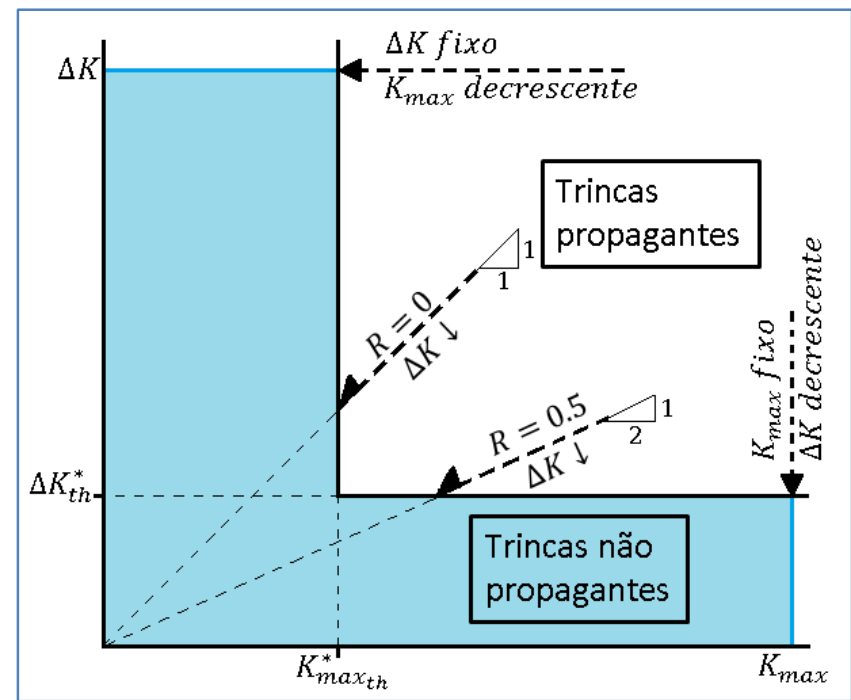

Figura 2.2: Avaliação do enfoque unificado dos dois limiares de propagação [13].

Além disso, o Enfoque Unificado afirma que estes limiares seriam propriedades mecânicas do material, independentes de qualquer outro parâmetro como a 
carga média, tamanho da peça ou da trinca e, em especial, do fechamento de trincas por fadiga (Seção 2.2). Deste modo as trincas só poderiam propagar por fadiga quando as condições descritas na Figura 2.2 e na equação 2.2 fossem satisfeitas [4]:

$$
\Delta K>\Delta K_{t h}^{*} \text { e } K_{\max }>K_{\max h}^{*}
$$

Por fim, esses dois limiares de propagação seriam independentes de $R$ no vácuo, “já que sua dependência em $R$ é causada pelo ambiente e não por efeitos mecânicos” [14]. As implicações desta afirmação são discutidas na Seção 2.5.4.

\section{2.}

\section{Fechamento de trincas por fadiga}

Medindo a rigidez (elástica) de uma placa trincada por fadiga, Elber descobriu que no ciclo de carregamento a trinca permanecia parcialmente fechada até que a carga $(P)$ atingisse o valor da chamada carga de abertura de ponta de trinca $\left(P_{a b}>\right.$ 0 ). Elber identificou que entre $0<P<P_{a b}$ a rigidez diminuía à medida que a carga crescia, até que em $P=P_{a b}$ a rigidez da placa trincada era atingida e permanecia constante para cargas $P>P_{a b}$. Por isso ele concluiu que a diminuição inicial da rigidez não era causada pela plastificação da placa [13]. A carga de abertura $P_{a b}$ identificada por Elber é medida no ponto inicial do trecho linear superior da curva $P$ vs. $\delta_{p}$, onde $\delta_{p}$ é o deslocamento do ponto de aplicação da carga, vide Figura 2.3 [6].

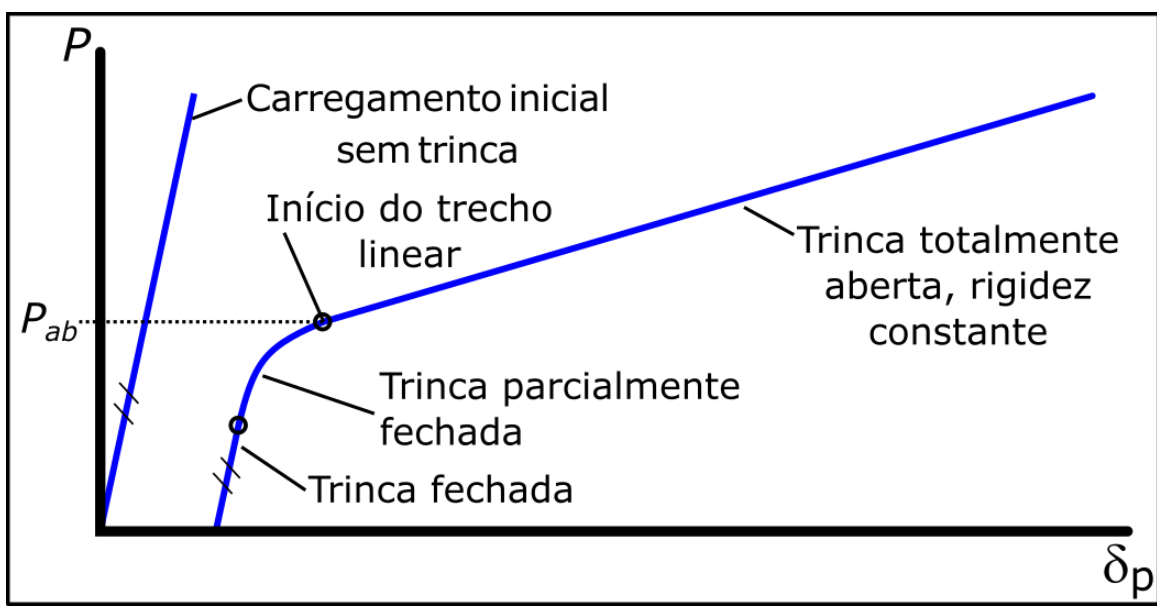

Figura 2.3: Curva $P$ vs. $\delta_{p}$ típica, que mostra a carga de abertura de trinca $\left(P_{a b}\right)$ durante o carregamento. 
Segundo Elber, o fechamento é devido ao envelope de deformações plásticas residuais trativas que rodeiam as trincas de fadiga, deixado pela zona plástica $(z p)$ que sempre acompanha a ponta da trinca. Desta forma, o fechamento é causado pela descarga elástica do ligamento residual, que ao tentar voltar ao estado original tende a comprimir aquele envelope e, portanto, também as faces da trinca. A Figura 2.4 mostra uma explicação deste comportamento.

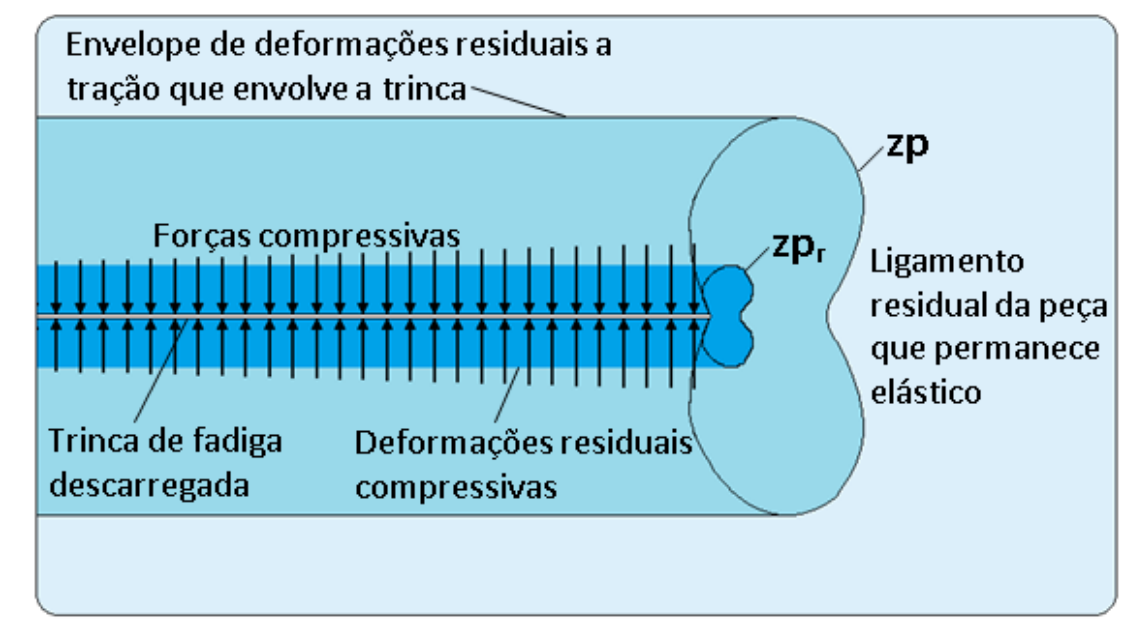

Figura 2.4: Compressão das faces da trinca quando a peça é descarregada, gerando o fechamento (adaptado de [13]).

Levando isso em conta, Elber também supôs que as trincas só poderiam crescer por fadiga após totalmente abertas, e desta forma a taxa $d a / d N$ não deveria ser controlada por toda a gama $(\Delta K)$ aplicada na peça, mas sim pela parte da gama na qual a trinca está aberta, chamada de gama efetiva $\Delta K_{e f}=K_{\max }-K_{a b}$, sendo $K_{a b} \mathrm{o}$ fator de intensidade de tensões causado pela carga de abertura $P_{a b}$.

Por outro lado, se $K_{\min }>K_{a b}$ então a trinca permanece aberta durante todo o ciclo, $\log 0 \Delta K_{e f}=K_{\max }-K_{\min }=\Delta K$. Deste modo, as taxas de propagação de trincas por fadiga, segundo Elber, deveriam ser modeladas da seguinte forma [6]:

$$
\frac{d a}{d N}=f\left(K_{\max }-K_{a b}\right)=f\left(\left(1-\frac{K_{a b}}{K_{\max }}\right) K_{\max }\right)=f\left(\Delta K_{e f}\right)=A_{e} \Delta K_{e f}^{m_{e}}
$$

onde $A_{e}$ e $m_{e}$, são constantes do material. 


\subsection{1.}

\section{Fechamento induzido por plasticidade}

O fechamento induzido por plasticidade é o modelo mais popular para estimar os efeitos de sequência de carga, já que ele pode justificar e quantificar muitos destes fenômenos $[15,16]$. Por isso, ele tem sido largamente usado na previsão de vida residual de peças trincadas submetidas a carregamentos reais de serviço. Segundo Elber, uma trinca só cresce após totalmente aberta sob cargas $P>P_{a b}$, que aliviam a compressão gerada pela parte elástica da peça trincada que tende a comprimir a esteira plástica que envolve as trincas de fadiga. Portanto, como a esteira plástica é gerada pelas sucessivas zonas plásticas que são deixadas para atrás durante a propagação, qualquer coisa que afete a zona plástica $z p$ também afeta $P_{a b}$ e, consequentemente, a taxa de propagação prevista por $\Delta K_{e f}$.

Elber justifica os retardos após sobrecargas supondo que quando a trinca penetra na zona plástica hipertrofiada pela sobrecarga $z p_{S C}$, a parte elástica da peça tente a aumentar a compressão sobre o envelope plástico que envolve as faces da trinca, forçando a carga de abertura $P_{a b}$ a aumentar e a gama efetiva $\Delta K_{e f}$ a diminuir. A Figura 2.5 ilustra a explicação elberiana do retardo gerado por uma sobrecarga $\left(K_{S C}\right)$ numa trinca que propaga sobre condições de $\Delta K$ e $K_{\max }$ constantes. A Figura 2.6 ilustra os efeitos esperados da sobrecarga no comportamento da taxa de propagação $d a / d N$ enquanto a trinca avança sob $\Delta K$ e $K_{\max }$ constantes.

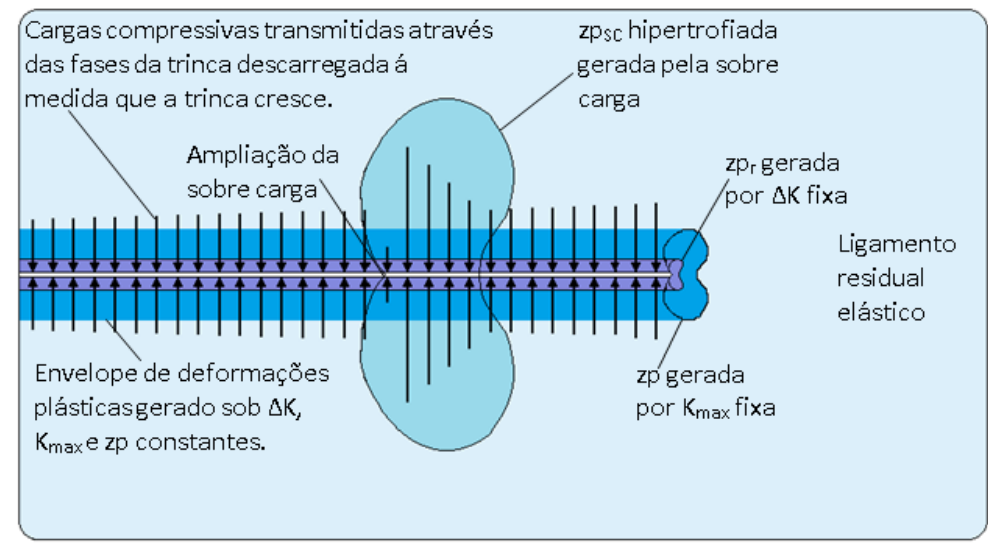

Figura 2.5: Explicação do mecanismo de retardo por sobrecarga, com o modelo de fechamento induzido por plasticidade, numa trinca que propaga com $\Delta K e K_{\max }$ constantes (adaptado de [13]).

Esta ideia também pode explicar as acelerações após subcargas compressivas $[1,9]$, levando em conta que elas diminuiriam as deformações residuais trativas que envolvem as faces das trincas de fadiga, o que geraria um aumento no $\Delta K_{e f}$. Além 
disso, esta teoria diz que o retardo máximo só acontece após a trinca ter crescido o necessário para que sua ponta possa ser influenciada pela $z p_{S C}$; e não no ciclo depois da sobrecarga, no qual se espera na realidade um aumento local na taxa de propagação devido ao cegamento da ponta da trinca que tende a diminuir $K_{a b}$, um fenômeno chamado de atraso no retardo (Figura 2.6). Por outro lado, como as deformações residuais dentro da $z p_{S C}$ decrescem a partir do ponto de aplicação da sobrecarga, os efeitos do fechamento na carga de abertura desaparecem de maneira gradual à medida que a trinca sai da $z p_{S C}$.

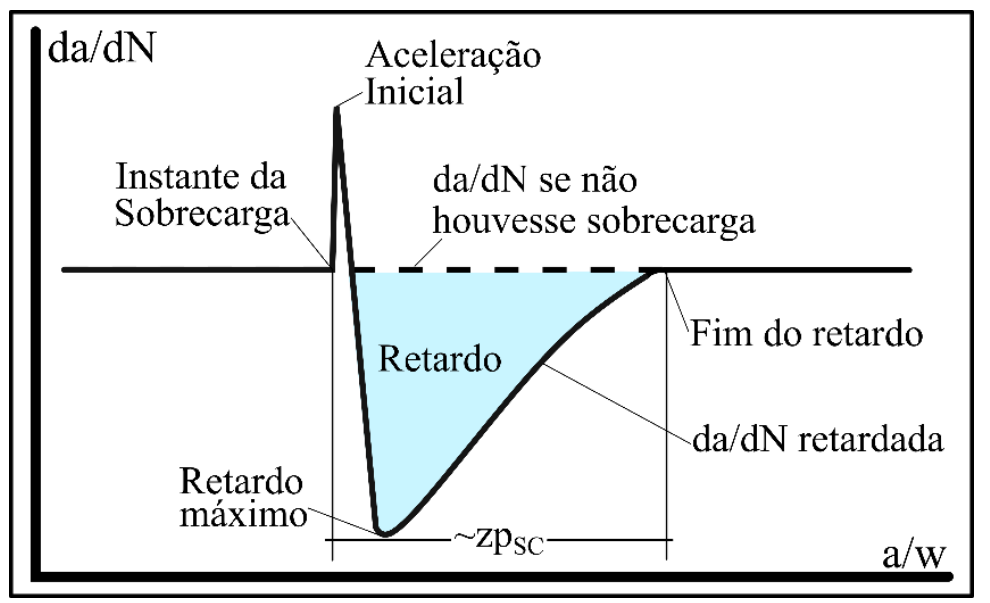

Figura 2.6: Comportamento da taxa de propagação $(d a / d N)$, antes e após um evento de sobrecarga, numa trinca que avança com $\Delta K$ e $K_{\max }$ constantes.

\section{3.}

\section{Modelo de dano crítico}

Os modelos de dano crítico propõem uma abordagem diferente para explicar a propagação de trincas por fadiga. Eles supõem que a trinca avança pela fratura sucessiva de pequenos elementos de volume que ficam à sua frente e que vão quebrando pelo acúmulo de dano causado pelas cargas cíclicas as que estão expostos [17].

A partir desta ideia, é possível usar as técnicas $\varepsilon N$ junto à Mecânica da Fratura para prever a propagação de trincas por fadiga, calculando o dano causado pelas tensões e deformações à frente da ponta da trinca [13]. A Figura 2.7 ilustra estes elementos à frente da ponta da trinca e como a gama de deformações $(\Delta \varepsilon)$ aumenta, à medida que a ponta da trinca se aproxima ao elemento que está sendo analisado. 
Para aplicar os modelos de dano crítico é necessário determinar os campos de tensão e de deformação à frente da ponta da trinca, sabendo que quando a trinca está aberta o raio dela tem que ser não nulo ou ela seria instável, já que as tensões e deformações na sua frente tenderiam a infinito. Estes modelos podem estimar $\Delta \varepsilon$ no elemento adjacente à ponta da trinca a partir do fator de concentração de tensões da trinca aberta e de uma regra de concentração de deformações.

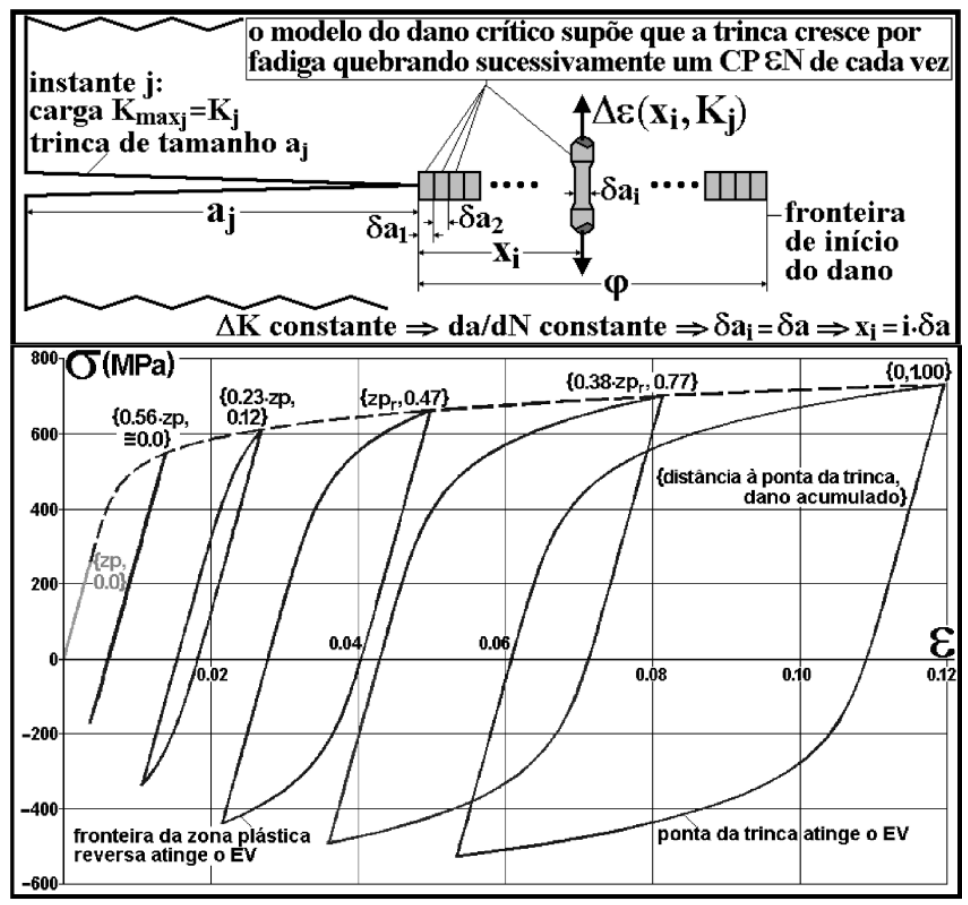

Figura 2.7: Exemplo de como a trinca propaga pela quebra sucessiva de pequenos elementos de volume ou "corpos de prova $\varepsilon N$ " [13].

Durante o avanço da trinca os vários elementos de volume à sua frente sofrem três diferentes fases de deformação: primeiro quando a distância do elemento até a ponta da trinca é maior do que a raio da zona plástica $(z p)$, as deformações nele são elásticas. Quando esta distância é maior do que a zona plástica reversa $\left(z p_{r}\right)$ e menor ou igual do que a zona plástica $(z p)$, ele escoa durante o carregamento, mas não sofre escoamento significativo na descarga. Já quando a distância é menor que a zona plástica reversa $\left(z p_{r}\right)$ o elemento sofre escoamento cíclico reverso.

Desta forma, o dano sofrido pelo elemento se acumula a cada ciclo de carga, até que ele acaba fraturando à frente da ponta da trinca, quando o dano atinge o valor crítico (Figura 2.7 e 2.8). Na maioria dos casos o dano fora da zona plástica reversa é desprezível (já que é dentro da $z p_{r}$ onde acontecem as maiores deformações). O uso desta metodologia é ilustrado na Figura 2.8. 


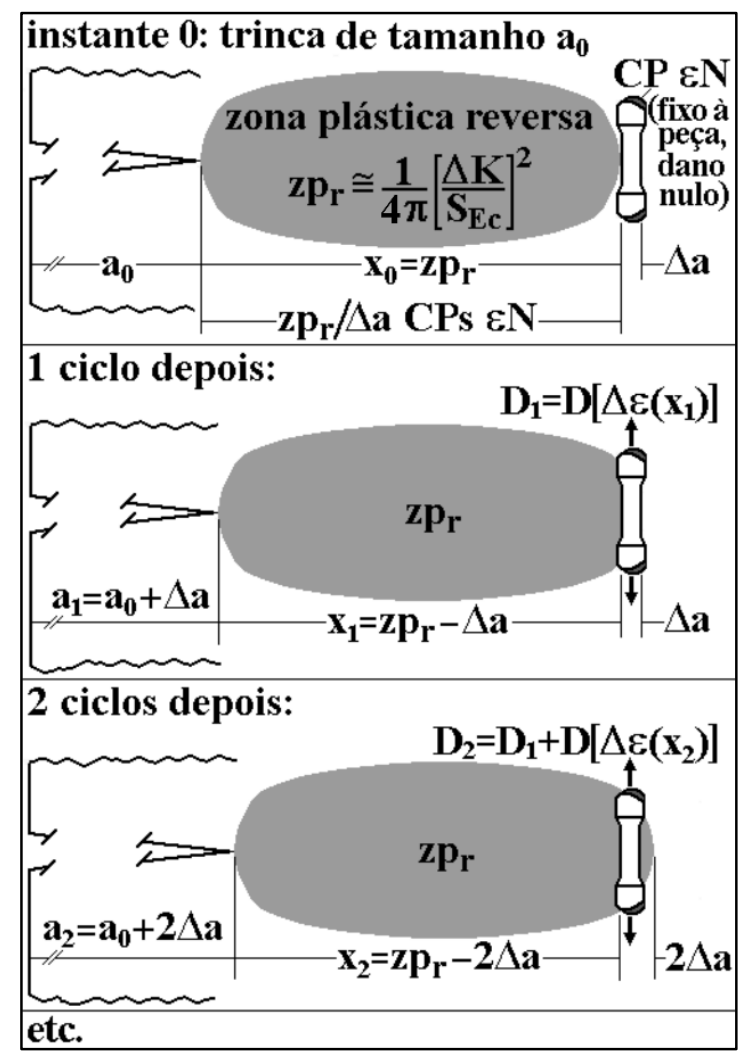

Figura 2.8: Exemplo de acúmulo de dano no elemento de volume [13].

\section{4 .}

\section{Estado plano de tensão e estado plano de deformação}

Assume-se que uma peça é fina quando a zona plástica é maior ou igual à espessura da peça $(t \leq z p)$, e que é grossa quando a zona plástica é bem menor do que a espessura da peça $(t>>p)$ [13]. Por isso, numa peça fina com uma trinca no plano normal ao vetor de aplicação da força, a tensão transversal na placa é aproximadamente igual à zero em torno da ponta da trinca ao longo de toda a espessura da peça, e assim a zona plástica é gerada em um estado plano de tensão dominante [1]. Quando estas condições ocorrem, falhas causadas por plasticidade, como a propagação de trincas por fadiga, apresentam-se num plano idealmente a $45^{\circ}$ em relação ao plano inicial da trinca, logo a superfície final da fratura é inclinada em relação à superfície da peça (Figura 2.9) [18].

Por outro lado, se a peça é grossa, a tensão em torno da ponta da trinca pode variar ao longo da espessura, devido a que a parte elástica da peça restringe o deslocamento transversal da zona plástica. Assim, esta tensão pode crescer de zero na superfície até atingir o valor máximo, em algum ponto da parte central da peça. Este valor limite é atingido quando a (grande) parte elástica da peça consegue forçar a 
região central da zona plástica à frente da trinca a se manter em um estado plano de deformações dominante (deformação transversal aproximadamente igual à zero) [19]. Então em estado de deformação plana a trinca cresce no plano normal ao vetor de aplicação da força (Figura 2.9).

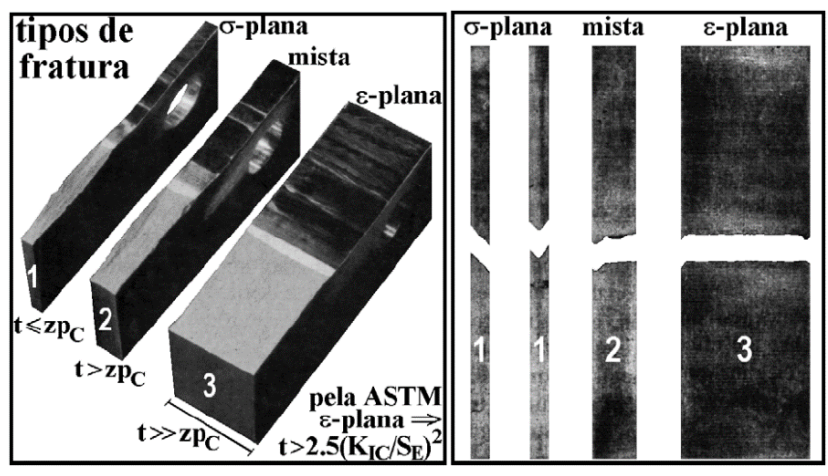

Figura 2.9: Classes de fraturas dependendo do estado plano no corpo de prova.

Na Figura 2.9 se pode observar como as trincas que propagam em tensão plana crescem em planos inclinados de $45^{\circ}$ aproximadamente, em relação ao plano normal ao vetor de aplicação da força. Por outro lado, quando a trinca propaga em estado plano de deformação, a trinca cresce no plano normal ao vector de aplicação da força, e nas peças cuja espessura é "média" a trinca cresce num estado misto, com lábios de cisalhamento da mesma ordem da região em tensão plana.

Um procedimento operacional para definir o estado plano à frente da trinca, é calcular o tamanho máximo da zona plástica $z p_{\max }$ (Equação 2.4) [20], para compará-lo com a espessura da peça $(t)$, assumindo que se $t \leq z p_{\max }$ a trinca propaga em estado plano de tensão. Se esse não for o caso, pode-se usar o protocolo da ASTM mostrado na Equação 2.5 [21], para saber se a trinca cresce em deformação plana. Finalmente, se nenhuma das duas condições é satisfeita, se diz que a trinca cresce num estado misto de tensão e deformação plana. Cabe salientar que a Equação 2.4 é a estimativa de Irwin para calcular o tamanho máximo da zona plástica.

$$
\begin{gathered}
z p_{\max }=\frac{K_{\max }^{2}}{\pi S_{E}^{2}} \\
t>2.5\left(\frac{K_{\max }}{S_{E}}\right)^{2} \text { Deformação plana }
\end{gathered}
$$

onde $z p_{\max }=$ tamanho máximo da zona plástica à frente da ponta da trinca; $K_{\max }=$ fator de intensidade de tensões máximo; $S_{E}=$ resistência ao escoamento do material; e $t=$ espessura do corpo de prova. 


\section{5.}

\section{Dúvidas sobre a validade de $\Delta K_{\text {ef }}$}

Na procura da verdadeira força motriz da propagação de trincas por fadiga, foram estudados vários cenários e identificadas situações que questionam seriamente a ideia de que a propagação das trincas por fadiga é de fato controlada pelo fator de intensidade de tensões efetivo $\Delta K_{e f}$. Por esta razão, a seguir é feito um pequeno resumo de alguns dos dados que contestam a real importância do fechamento elberiano na propagação de trincas por fadiga [22].

\subsection{1.}

\section{Métodos de medição de carga de abertura $P_{a b}$}

Quando Elber descobriu a carga de abertura de trinca $P_{a b}$, ele propôs que fosse medida através da rigidez do corpo de prova identificada em gráficos $P v s$. $\delta$, onde $P$ é a carga aplicada na peça trincada e $\delta$ o deslocamento do seu ponto de aplicação. Isso pode ser feito traçando uma linha tangencial na parte superior da curva de descarga da trinca totalmente aberta, e depois sobrepondo essa reta na curva de carga: no ponto inferior onde a reta e a curva se separam estaria o valor da carga de abertura de trinca (Figura 2.10a) [6]. Para facilitar a identificação de $P_{a b}$, Paris e Hermann propuseram um subtrator de linearidade que usa a inclinação da linha tangencial ( $\kappa$ na Figura 2.10a) para plotar uma nova curva $[P-\kappa \delta]$ vs. $\delta$, que permite que a carga de abertura seja mais facilmente localizada no ponto em que a horizontalidade da curva inicia (Figura 2.10b) [23].

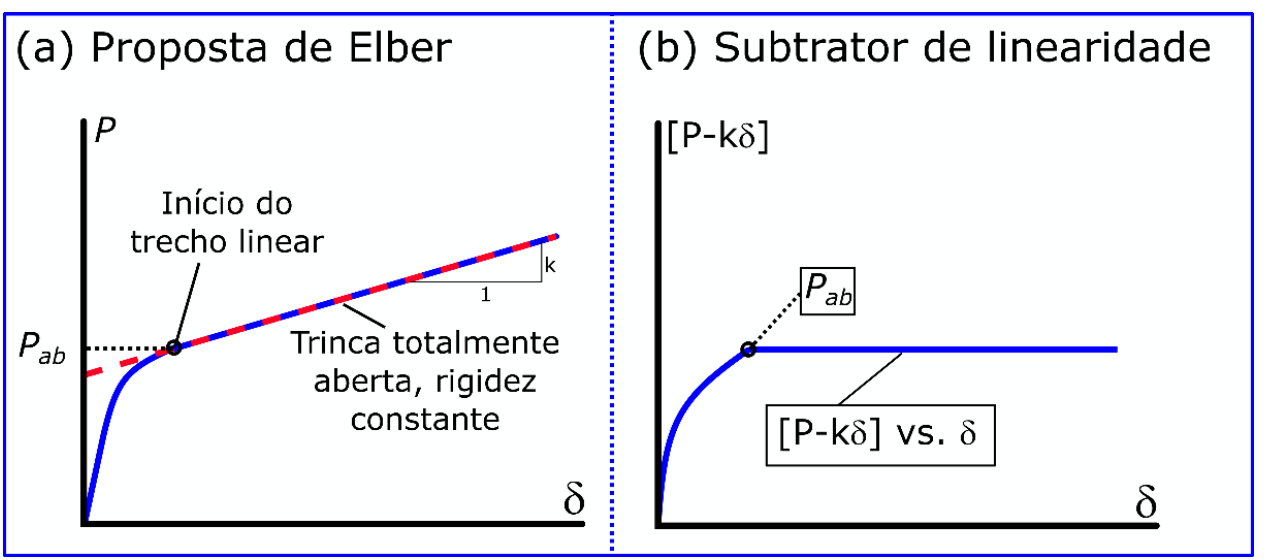

Figura 2.10: Métodos para medir a carga de abertura de trinca: (a) Método proposto inicialmente por Elber, (b) subtrator de linearidade de Paris e Hermann. 
Dentre os métodos que processam dados da curva de rigidez e entregam um valor de carga de abertura de trinca, aquele que tem maior aceitação (já que faz parte da norma ASTM E647) é o "Compliance Offset Method" [24]. Neste método são usadas as variações da inclinação da curva de flexibilidade do corpo de prova $(C=\delta / P)$, pegando trechos de $10 \%$ da curva de carga e avançando de cima para abaixo da curva a cada 5\% (Figura 2.11a), para assim calcular as inclinações de cada trecho da curva $\left(C_{1} \ldots C_{i}\right)$. Para determinar a flexibilidade do corpo de prova com a trinca totalmente aberta $\left(C_{o p}\right)$, se calcula a inclinação do $25 \%$ da parte superior da curva de descarga. A seguir, os valores $C_{1} \ldots C_{i}$ e $C_{o p}$ são usados para calcular o "Compliance Offset" para cada segmento $i$, com a equação: $C O_{i}=\left[\left(\operatorname{Cop}-C_{i}\right) *\right.$ 100 ]/Cop. Com estes dados se plota um gráfico $C O_{i}$ vs. $P$, se escolhe um critério de "Compliance Offset", e se determina o valor da carga de abertura de trinca $P_{a b}$, como se mostra na Figura 2.11b. A norma recomenda 2\% como critério, mas também aceita o uso de 1 e $4 \%$.

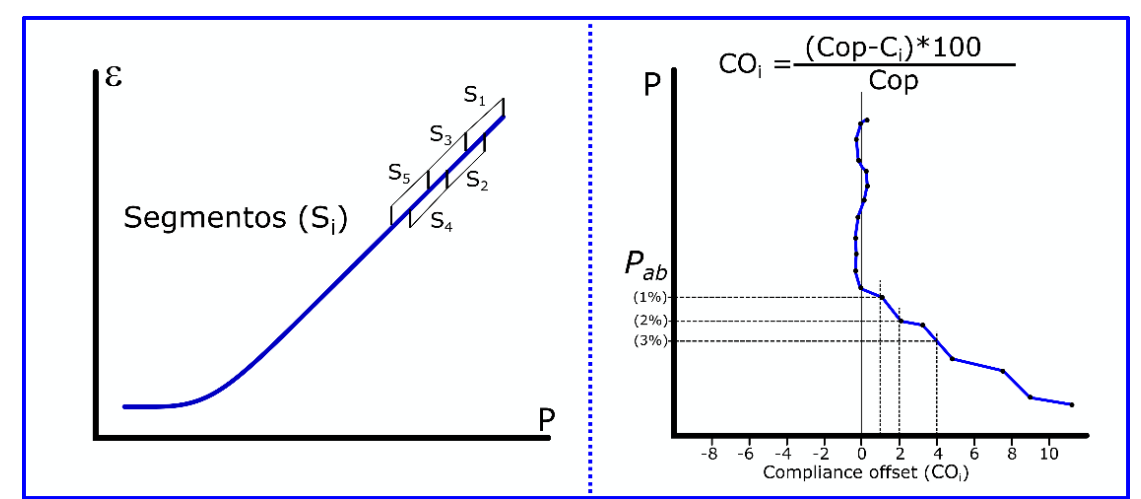

Figura 2.11: Método da ASTM E647 para determinar a carga de abertura de trinca $\left(P_{a b}\right)$; (a) curva de rigidez do corpo de prova (b) curva $\mathrm{CO}_{i}$ vs. $P$ onde se determina $\boldsymbol{P}_{a b}$.

Claramente estes métodos tentam medir a $P_{a b}$ respeitando a definição inicial de Elber (carga onde a trinca estaria totalmente aberta), mas depois de achar problemas no uso da teoria de fechamento de trincas, alguns autores criaram novas abordagens para medir a carga de abertura de trinca. Por exemplo, usando o gráfico de rigidez do material são determinadas três cargas; ajustando uma linha tangente na parte inferior da curva de rigidez, a primeira carga $\left(P_{l}\right)$ fica na parte superior onde a linha e a curva se separam; $P_{3}$ se determina com uma linha tangente na parte superior da curva de rigidez; e $P_{2}$ fica na interseção das duas linhas tangentes (Figura 2.12) [25]. 
Determinados os três valores de carregamento, será escolhido como a carga de abertura de trinca, aquele que agrupe melhor os dados das curvas $d a / d N$ vs. $\Delta K_{e f}$. Este procedimento gera muita controversa, já que a carga de abertura de trinca passa a ser praticamente um parâmetro ajustável, e não um parâmetro que possa ser medido para fazer predição de vida residual.

Além disso, outras propostas de métodos para medição de carga de abertura de trinca são: o método normalizado da ASTM criado por Song et al. [26], e o método "Q" proposto por Kujawski e Stoychev [27]. Estes métodos geram valores de carga de abertura de trinca menores (deixando $\Delta K_{\text {ef }}$ mais próximo de $\Delta K$ ), quando comparados com o método de Elber, e seus criadores os qualificam como melhores, baseados no agrupamento das curvas $d a / d N$ vs. $\Delta K_{e f}$. Cabe salientar que Kujawski concluiu, que as medidas de fechamento através da variação da rigidez da peça trincada não diferenciam os mecanismos de fechamento, logo não podem ser usadas para provar a validade da teoria de Elber [25].

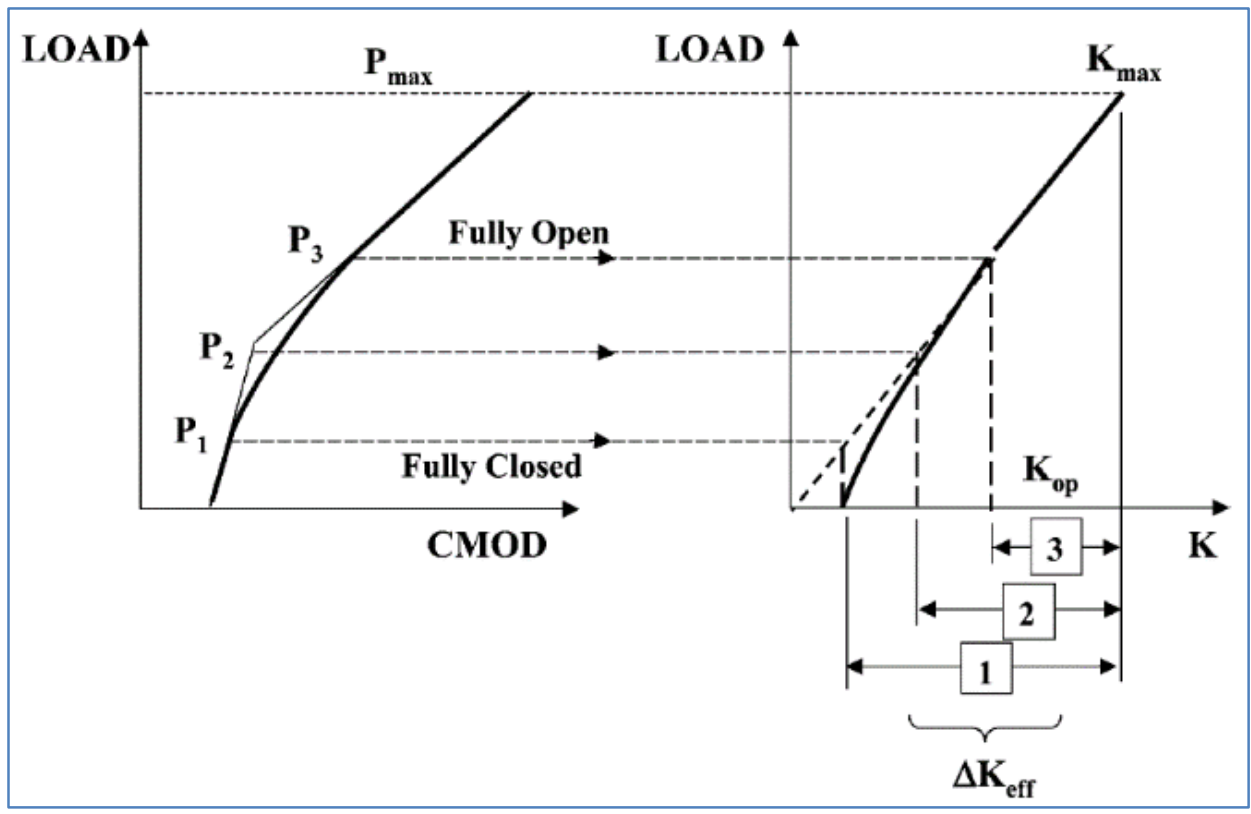

Figura 2.12: Diagramas do método com três níveis de fechamento para determinar a $\boldsymbol{P}_{a b}$ [25].

\subsection{2.}

\section{Fechamento total ou parcial da ponta da trinca}

A teoria de fechamento de Elber está fundamentada na hipótese de que o material à frente da ponta da trinca estaria protegido de qualquer dano adicional enquanto a peça trincada estiver submetida a cargas menores do que aquela necessária para abrir totalmente a trinca, $P_{a b}$. A Figura 2.13 mostra um esquema teórico de 
uma curva força vs. deformação na frente da ponta da trinca, (a) sem e (b) com o efeito de proteção para cargas abaixo da $P_{a b}[10]$.

Então, antes da trinca propagar, o material à sua frente estará submetido a ciclos de deformação elastoplástica, assim na Figura 2.13a se mostra como seria este fenômeno olhando na curva $P$ vs. $\varepsilon$ sem a existência de carga de abertura. Já a Figura 2.13b mostra a mesma curva, porém com o efeito de fechamento, em que para cargas abaixo do valor de $P_{a b}$, não acontece deformação à frente da ponta da trinca, tanto na carga como na descarga.

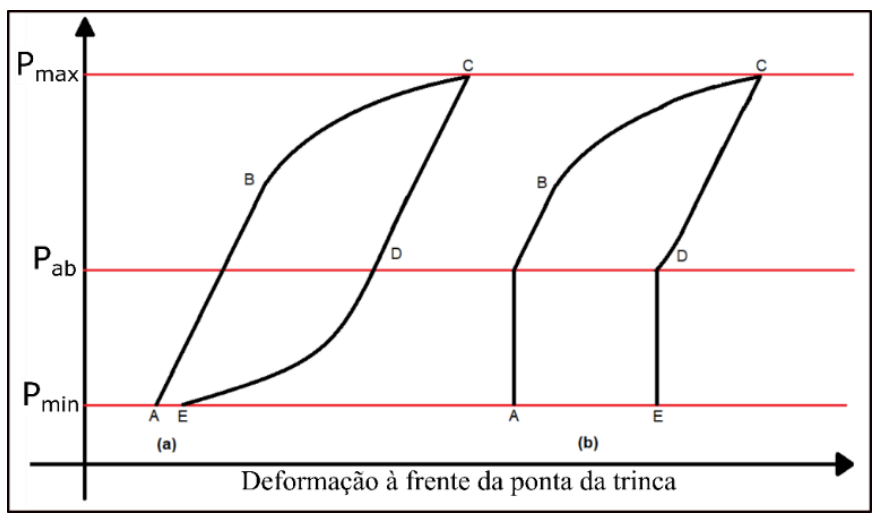

Figura 2.13: Esquema teórico das deformações à frente da ponta da trinca (a) sem e (b) com o efeito de proteção, para cargas abaixo da $P_{a b}[10]$.

Baseados nisso, Ferreira et al [12] mencionam que até mesmo os resultados apresentados por Elber poderiam ser usados para questionar a sua hipótese (de que o material à frente da trinca não sofre qualquer deformação ou dano adicional sob cargas $P<P_{a b}$ ), vide Figura 2.14. Estes resultados mostram curvas tensão vs. deslocamento antes (1-2), durante (2-3) e a após uma sobrecarga (3-1000), medidos por um Clip-Gage instalado à frente da ponta da trinca. Na Figura 2.14 os círculos representam o ponto de trinca totalmente aberta, logo há deslocamentos medidos no material abaixo da $P_{a b}$, tanto na carga (de 3 a $\overline{3}$ ), como na descarga (de $\overline{3}$ a 4 ).

Resultados que também levam a concluir que existe dano à frente da ponta da trinca mesmo em cargas abaixo da $P_{a b}$ foram publicados por Chen et al. [28]. Mantendo um $R=0.3$ fixo $\left(R=K_{\min } / K_{\max }\right)$, esses autores fizeram testes de propagação de trincas por fadiga diminuindo gradualmente o valor de $\Delta K$ até chegar no valor de $\Delta K_{\text {th }}$ (quando as taxas de propagação ficam menores que $10^{-12} \mathrm{~m} / \mathrm{ciclo}$ ), sob valores máximo e mínimo do fator de intensidade de tensões; $K_{\max }=3 M P a V_{m}$ e $K_{\min }$ $=0.9 \mathrm{MPa} \sqrt{\mathrm{m}}$. Por outro lado, o fator de intensidade de tensões gerado pela carga de abertura neste instante era $K_{a b}=2 M P a \sqrt{ }$. Depois, eles diminuíram $K_{\min }$ a zero 
e aplicaram novos ciclos de carga mantendo $R=0$. Isso provocou um aumento considerável na taxa de propagação, como mostrado na Figura 2.15a.

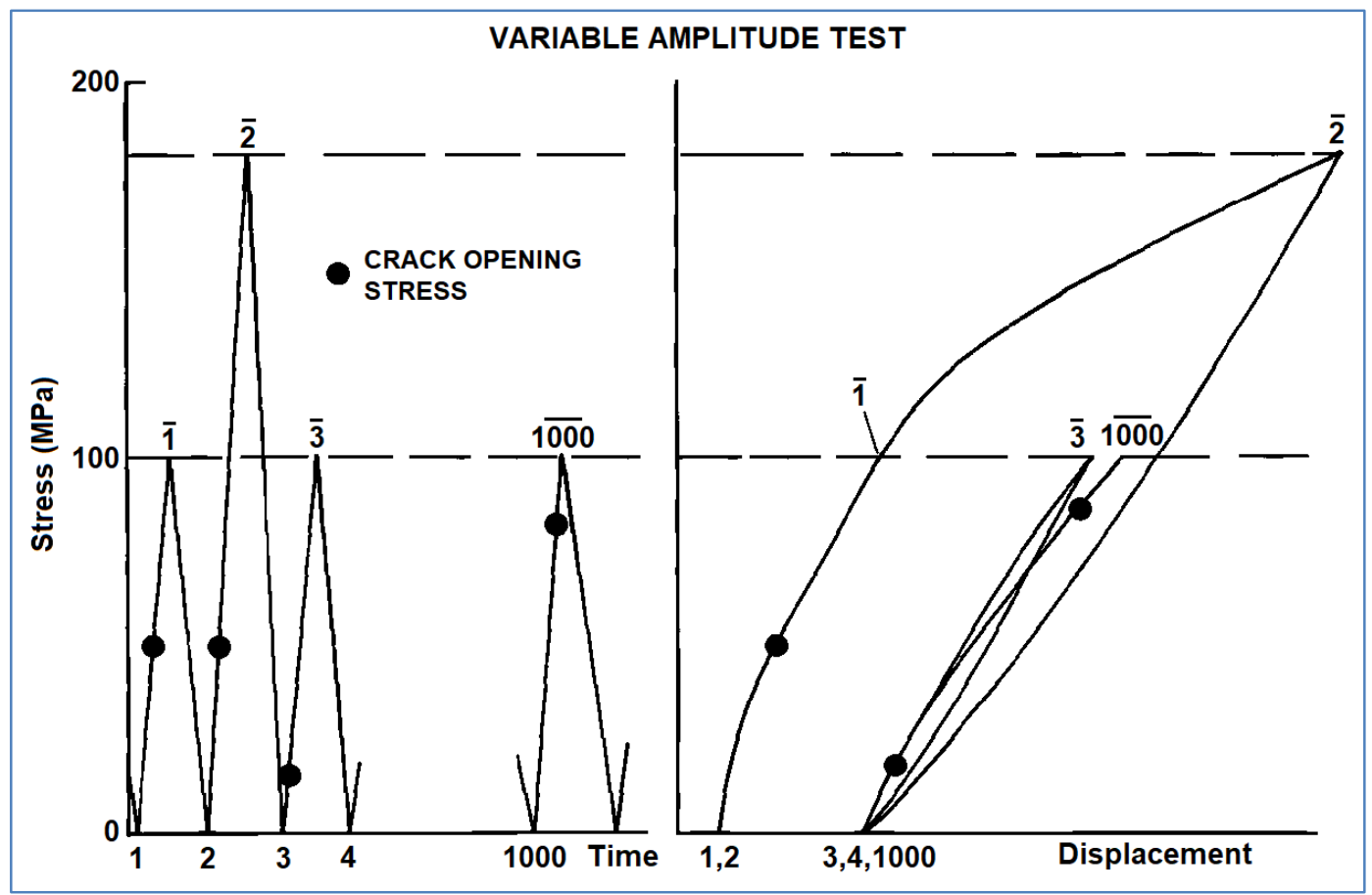

Figura 2.14: Resultados apresentados por Elber no seu artigo de 1971, que mostram a variação da tensão de abertura depois de uma sobrecarga [6].
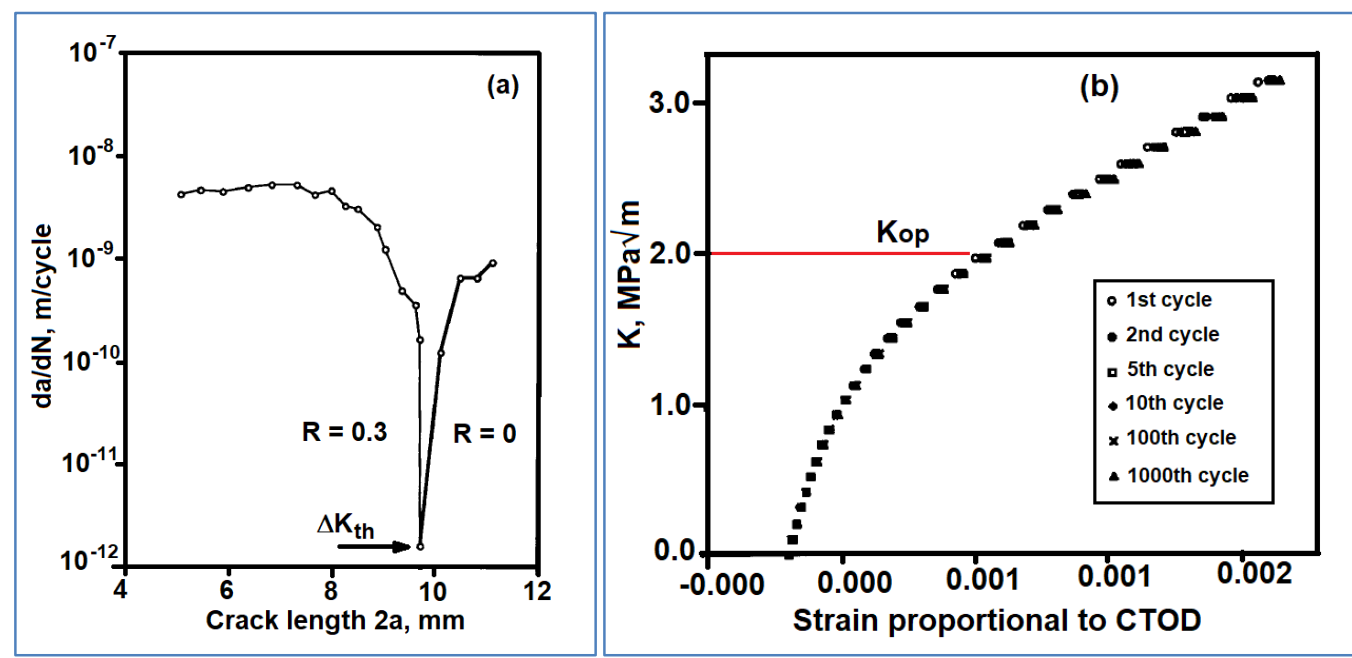

Figura 2.15: (a) Curva que mostra o aumento de $d a / d N$ após a mudança de $R$ e (b) os sucessivos valores de $K_{a b}$, para os diferentes instantes do teste [28].

Esses resultados não podem ser explicados pela teoria de Elber, já que como $K_{a b}=2 M P a \sqrt{ } m$ continuou igual (Figura 2.15b) e o $\Delta K_{e f}$ não foi alterado, o fato da taxa ter aumentado mostra uma contribuição das cargas abaixo da $P_{a b}$ no dano à frente da ponta da trinca. Este dano pode estar relacionado ao aumento do tamanho da zona plástica reversa, devido a uma maior amplitude do ciclo (aumento do $\Delta K$ ), o que teria aumentado a gama de deformação elastoplástica à frente da trinca. 
Baseado na ideia de que a trinca não estaria totalmente blindada contra o dano quando está submetida à cargas abaixo da $P_{a b}$, Paris et al. [29] criaram um modelo de fechamento parcial simulando uma cunha de espessura constante $(2 t)$, inserida dentro das faces de uma trinca, a uma distância $d$ da sua ponta, vide Figura 2.16a.

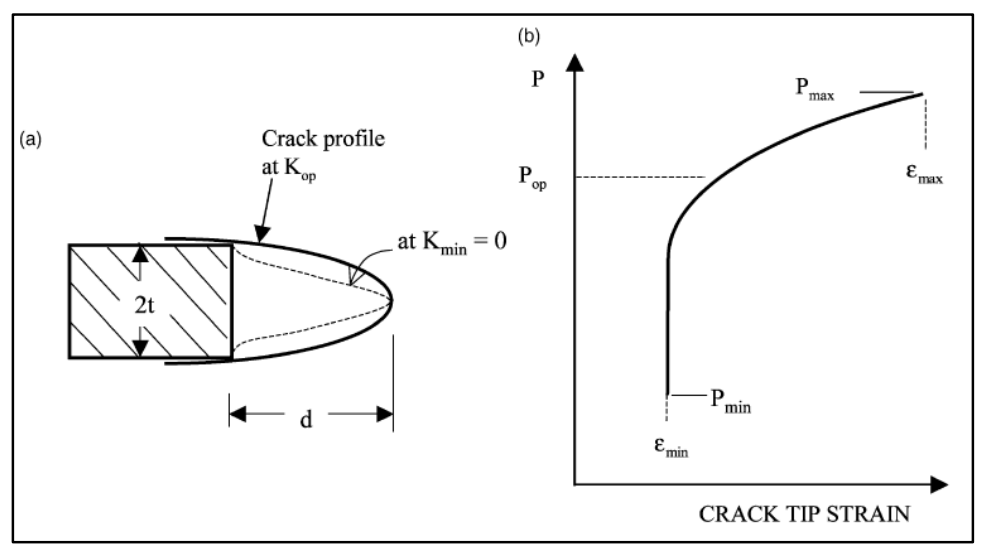

Figura 2.16: Modelo de fechamento parcial (a) trinca com cunha inserida, (b) curva de deformação na ponta da trinca simulada [29].

Analisando as deformações na trinca simulada, eles notaram que existe dano na ponta quando acontece a transição de um perfil arredondado para um afiado, em cargas abaixo da $P_{a b}$ (Figura 2.16a). Isso contradiz a ideia inicial de Elber que diz que só vai existir dano na ponta da trinca quando ela estiver totalmente aberta. $\mathrm{Na}$ Figura 2.16b se mostra a curva força vs. deformação na ponta da trinca resultante deste modelo. Com tudo isso, eles propuseram um novo fator de intensidade de tensões efetivo $\left(\Delta K_{2 / \pi}\right)$, usando a formulação a seguir:

$$
\begin{aligned}
\Delta K_{2 / \pi}=K_{\text {max }}-\frac{2}{\pi} K_{a b} & \text { se } \frac{2}{\pi} K_{a b}>K_{\text {min }} \\
\Delta K_{2 / \pi}=K_{\text {max }}-K_{\text {min }} & \text { se } \frac{2}{\pi} K_{a b} \leq K_{\text {min }}
\end{aligned}
$$

Além disso, como este modelo assume material idealmente plástico, eles propuseram para seu uso em materiais elastoplásticos um parâmetro obtido por métodos numéricos $\beta$ [25]. Esta proposta leva em conta que em um material real existe o dano gerado pela zona plástica reversa na descarga. Com isso, a formulação fica:

$$
\begin{array}{lr}
\Delta K_{\beta}=K_{\text {max }}-\beta K_{o p} & \text { se } \beta K_{a b}>K_{\text {min }} \\
\Delta K_{\beta}=K_{\text {max }}-K_{\text {min }} & \text { se } \beta K_{a b} \leq K_{\text {min }}
\end{array}
$$


Então, tanto com dados experimentais quanto com dados numéricos, vários autores têm contestado a hipótese de que a ponta da trinca está blindada contra o dano em cargas abaixo da carga de abertura de trinca. Isso gera sérias dúvidas sobre o uso de $\Delta K_{e f}$ para fazer previsões de vida residual à fadiga na prática.

\subsection{3.}

\section{Efeitos do estado plano de tensões na propagação}

Outro ponto de discussão entre os modelos é se existe ou não um efeito da espessura na taxa de propagação de trincas por fadiga. Segundo Elber, a carga de abertura varia com o tamanho da zona plástica $(z p)$, que depende do estado plano dominante na ponta da trinca, que por sua vez, está relacionado com a espessura da peça trincada. Assim, as predições da taxa $d a / d N$ baseadas em $\Delta K_{e f}$ são afetadas pela espessura (Figura 2.19). Todavia, isso contradiz procedimentos aceitos pela norma ASTM E647 para medir as curvas de propagação de trincas por fadiga, já que a norma diz textualmente que "o conceito da similitude é assumido, o que significa que trincas de tamanhos diferentes sujeitas a uma mesma gama $\Delta K$ nominal (e não a uma mesma gama efetiva $\Delta K_{e f}$ ), avançarão por incrementos iguais por ciclo" [24]. A norma reconhece que a espessura pode ter algum efeito ao dizer que "a influência potencial da espessura do espécime deve ser considerada ao gerar dados para pesquisa ou projeto"; no entanto, reconhece também que "taxas de propagação de trincas por fadiga (medidas) numa vasta faixa de $\Delta K$ aumentaram, diminuíram ou não foram afetadas pela espessura do espécime" e que "esta condição (considerar o efeito da espessura) deve ser invalidada nos testes que obedecem aos quesitos dos tamanhos listados na norma" [12].

Para cada um destes pontos de vista, têm sido publicados resultados experimentais que os sustentam [1]. Como exemplo, a Figura 2.17 mostra dados de crescimento de trincas por fadiga com três espessuras diferentes, que evidenciam um efeito da espessura na propagação [30]. Já a Figura 2.18 mostra resultados de testes em corpos de prova em tensão plana $(t=2.5 \mathrm{~mm})$ e testes em espécimes em deformação plana $(t=25 \mathrm{~mm}$ ), que não mostram efeito da espessura aparente na taxa de propagação de trincas por fadiga [31].

O efeito da espessura está incluso nas formulações mais avançadas que aplicam a ideia de Elber [32]. Uma das mais conhecidas é a de Forman-Newman, que 
vem sendo utilizada no programa de fadiga e fratura da NASA chamado NASGRO, com a equação a seguir [8]:

$$
\frac{d a}{d N}=A_{f n}\left(K_{\max }-K_{a b}\right)^{m_{f n}} \frac{\left(1-\frac{\Delta K_{t h}}{\Delta K}\right)^{p_{f n}}}{\left(1-\frac{K_{\max }}{K_{c}}\right)^{q_{f n}}}
$$

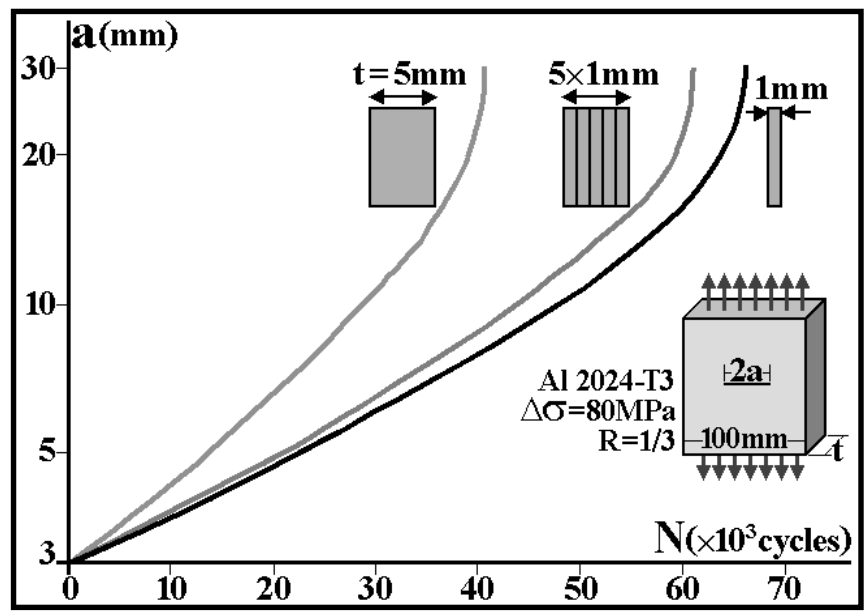

Figura 2.17: Dados experimentais que mostram efeito da espessura na taxa de propagação de trincas por fadiga numa liga de Al 2024 T3 [30].

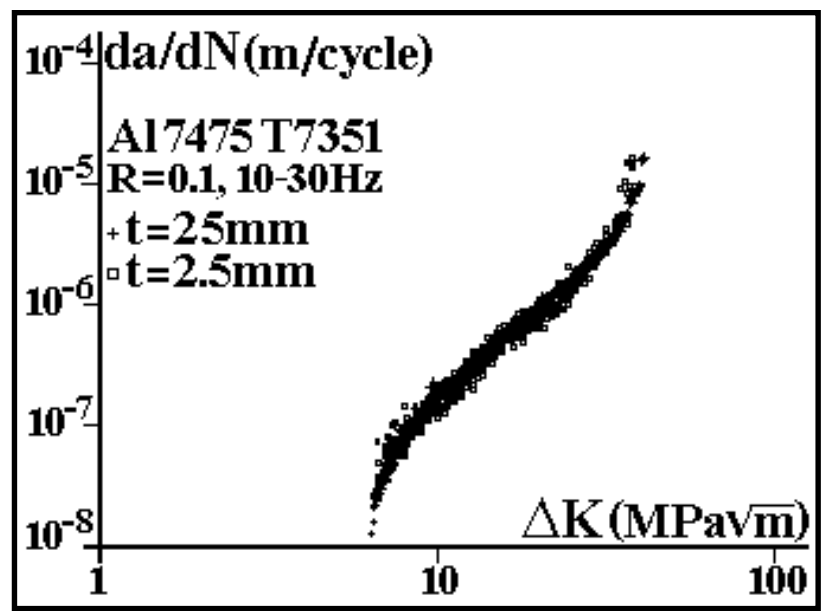

Figura 2.18: Resultados experimentais que não mostram efeitos da espessura na taxa de propagação de trincas por fadiga numa liga de Al 7475 T7351 [31].

A equação de Forman-Newman tem quatro parâmetros ajustáveis $\left(A_{f n} ; m_{f n}\right.$; $\left.p_{f n} ; q_{f n}\right)$, emprega o limiar de propagação $\Delta K_{t h}$ e a tenacidade do material $K_{C}$. Já para calcular o $K_{a b}$ os criadores de NASGRO propõem a seguinte rotina:

$$
\begin{gathered}
\frac{K_{a b}}{K_{\max }}=\left\{\begin{array}{c}
\max \left[R,\left(A_{0}+A_{1} R+A_{2} R^{2}+A_{3} R^{3}\right)\right], R \geq 0 \\
A_{0}+A_{1} R,-2 \leq R<0
\end{array}\right. \\
A_{0}=\left(0.825-0.34 \alpha+0.05 \alpha^{2}\right) \cdot\left[\cos \left(\pi \sigma_{\max } / 2 S_{F L}\right)\right]^{\frac{1}{\alpha}}
\end{gathered}
$$




$$
\begin{gathered}
A_{1}=(0.415-0.071 \alpha) \frac{\sigma_{\max }}{S_{F L}} \\
A_{2}=1-A_{0}-A_{1}-A_{3} \\
A_{3}=2 A_{0}+A_{1}-1 \\
S_{F L}=\frac{S_{R}+S_{E}}{2}
\end{gathered}
$$

A razão $\sigma_{\max } / S_{F L}$, que influi pouco em $K_{a b} / K_{\max }$, é às vezes substituída pela constante 0.3. Já $\alpha$ é a restrição transversal 3D, dada pela razão entre a tensão uniaxial que escoaria a peça (por Tresca ou Mises) e $S_{E}$. Então a restrição transversal varia entre $\alpha=1$ em tensão plana e $\alpha=1 /(1-2 v)$ em deformação plana $(2<\alpha<$ 3 em metais) e, portanto, depende do estado de tensão dominante na ponta da trinca, $\operatorname{logo}$ da espessura $(t)$ da peça. Na Figura 2.19 foi plotado um resultado da equação de Forman-Newman, para verificar a influência que ela prevê para o efeito do estado plano dominante, obtendo uma variação entre tensão e deformação plana não desprezível [13].

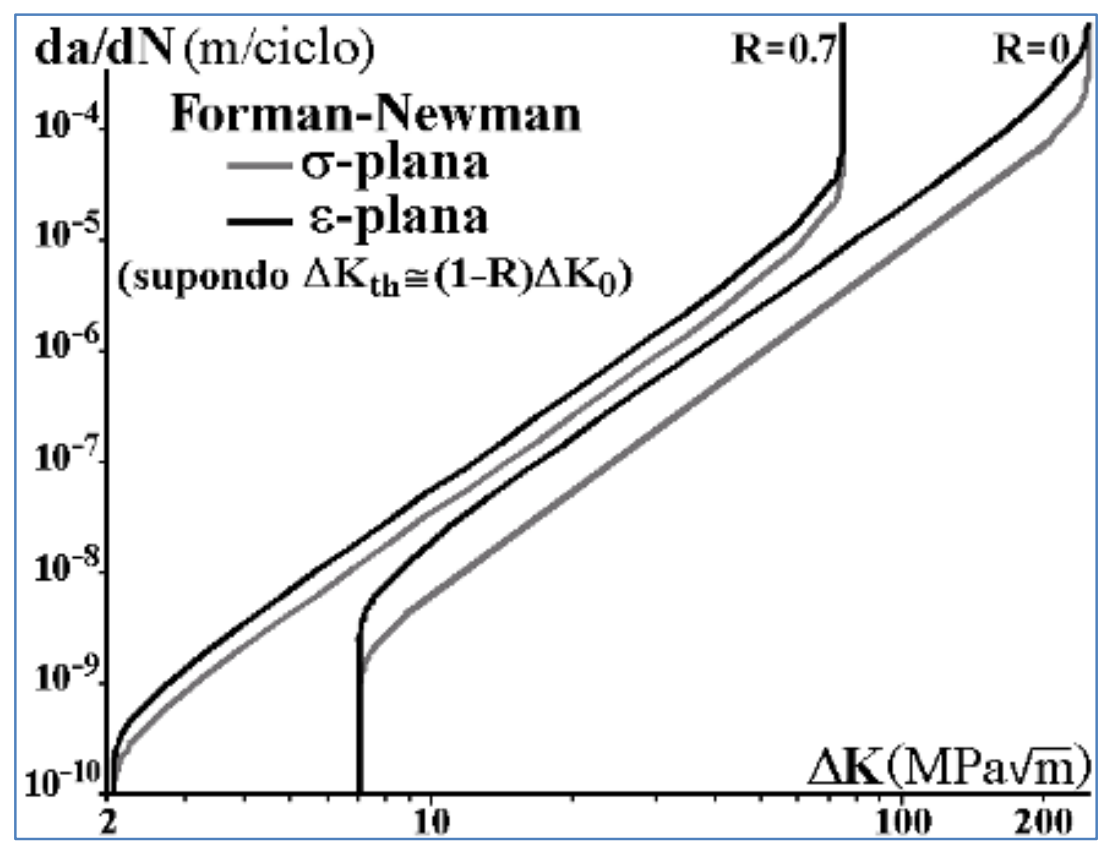

Figura 2.19: Efeito do estado plano na taxa de propagação de trincas por fadiga, previsto pela equação de Forman- Newman [13].

\subsection{4.}

\section{Efeitos da razão de carga $R$ na propagação}

Como a razão de carga é $R=K_{\min } / K_{\max }$ e o fator de intensidade de tensões efetivo é $\Delta K_{e f}=K_{\max }-K_{a b}$ se $K_{a b}>K_{\min }$, é razoável supor que trincas que propagam 
por fadiga em $R$ alto $(R>0.7)$ permaneceram totalmente abertas durante os ciclos de carga. Esta hipótese tem sido usada para explicar a queda no limiar de propagação de trincas por fadiga $\Delta K_{\text {th }}$ quando $R$ aumenta. Todavia, Vasudevan et al. [14] compararam valores de $\Delta K_{\text {th }}$ medidos em vácuo de alta qualidade sob vários valores de $R$ (vide Figura 2.20), que mostram que nesses casos $\Delta K_{t h}$ é independe de $R$. Isso indica que o efeito do fechamento induzido por plasticidade é desprezível nos testes em vácuo. Entretanto, como o vácuo elimina os efeitos do ambiente, mas não os do fechamento induzido por plasticidade, então o fato do $\Delta K_{\text {th }}$ ser independente de $R$ nestes resultados, contradiz a teoria de Elber. Vasudevan et al. argumentam que na propagação de trincas no ambiente existe uma difusão de elementos químicos (como o hidrogênio), que entram no material pelas faces da trinca aumentando o dano na sua ponta, e que portanto, os efeitos de $R$ nas taxas $d a / d N$ seriam causados pelo meio e não pelo fechamento elberiano.

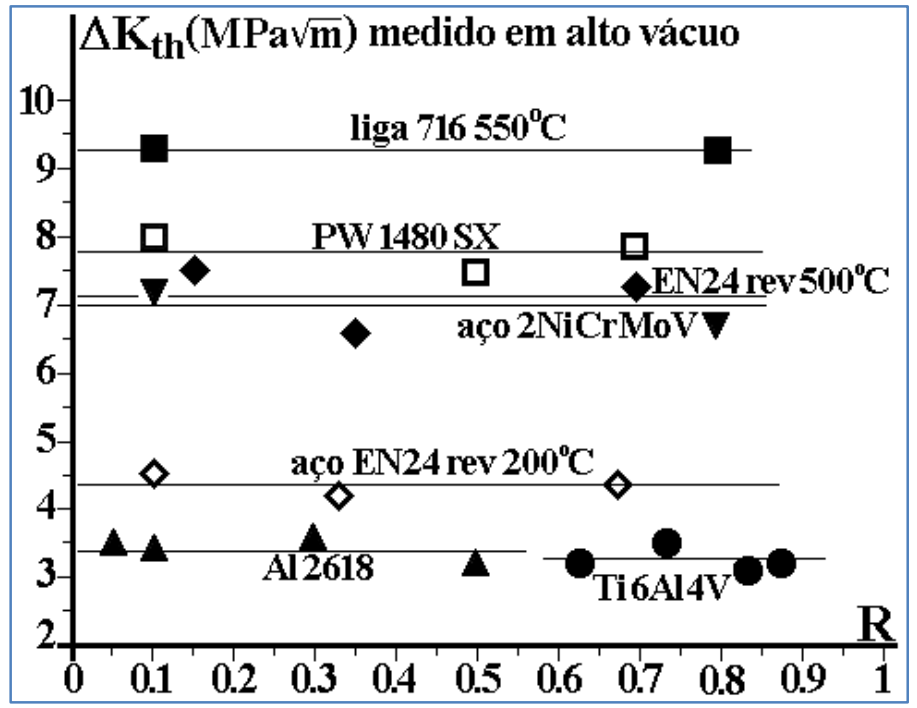

Figura 2.20: Medições do limiar $\Delta K_{\text {th }}$ sob alto vácuo que não dependem da razão $R$ [13].

Quando Elber propôs o fator de intensidade de tensões efetivo $\Delta K_{e f}$ como a força motriz na propagação de trincas por fadiga, uma das evidências que ele usou foram curvas $d a / d N$ vs. $\Delta K_{e f}$ para diferentes valores de $R$ que se agrupavam em uma curva só na Fase II de Paris (Figura 2.21b) [6]. A partir disso, Kujawski analisou dados de uma liga de Alumínio 2324 T39 medidos em 5 razões $R$ diferentes [33]. Com estes dados ele plotou vários gráficos: $d a / d N$ vs. $\Delta K$, mostrando a separação tradicional dos dados (Figura 2.21a); $d a / d N$ vs. $\Delta K_{e f}$, que agrupava melhor a região de Paris das diversas curvas (Figura 2.21b); e $d a / d N$ vs. $\Delta K_{2 / \pi}$, usando a formulação de fechamento parcial de Paris et al [34] mostrada anteriormente (Figura 2.21c). 
Por outro lado, pegando os pontos da Fase II das curvas, Kujawski e Dinga [33] propuseram um agrupamento ainda melhor dos dados fazendo uma transformação matemática da equação de Paris $d a / d N=A(\Delta K)^{m}$. Eles criaram dois novos parâmetros e reescreveram a equação de Paris como $d a / d N=A^{\prime}\left(\Delta K^{\prime}\right)^{m}$, onde $\Delta K^{\prime}$ e $A^{\prime}$ são o gama do fator de intensidade de tensões de referência e a intercepção da curva $d a / d N$ vs. $\Delta K$, onde todos os dados com diferentes $R$ podem ser agrupados. Para um dado valor de $d a / d N$, as duas equações se igualam se $A^{\prime}\left(\Delta K^{\prime}\right)^{m}=A(\Delta K)^{m}$, e com isso o FIT de referência fica $\Delta K^{\prime}=\Delta K\left(A / A^{\prime}\right)^{1 / m}$. Por fim, os dados de propagação da Fase II, plotados em gráficos $d a / d N$ vs. $\Delta K^{\prime}$, são melhor agrupados (Figura 2.21d), quando comparado aos agrupamentos conseguidos por $\Delta K_{e f}$ ou por $\Delta K_{2 / \pi}$. Desta análise Kujawski concluiu que o agrupamento de dados medidos em $R$ diferentes em função de $\Delta K_{e f}$ não prova que a gama efetiva controla a propagação [25].

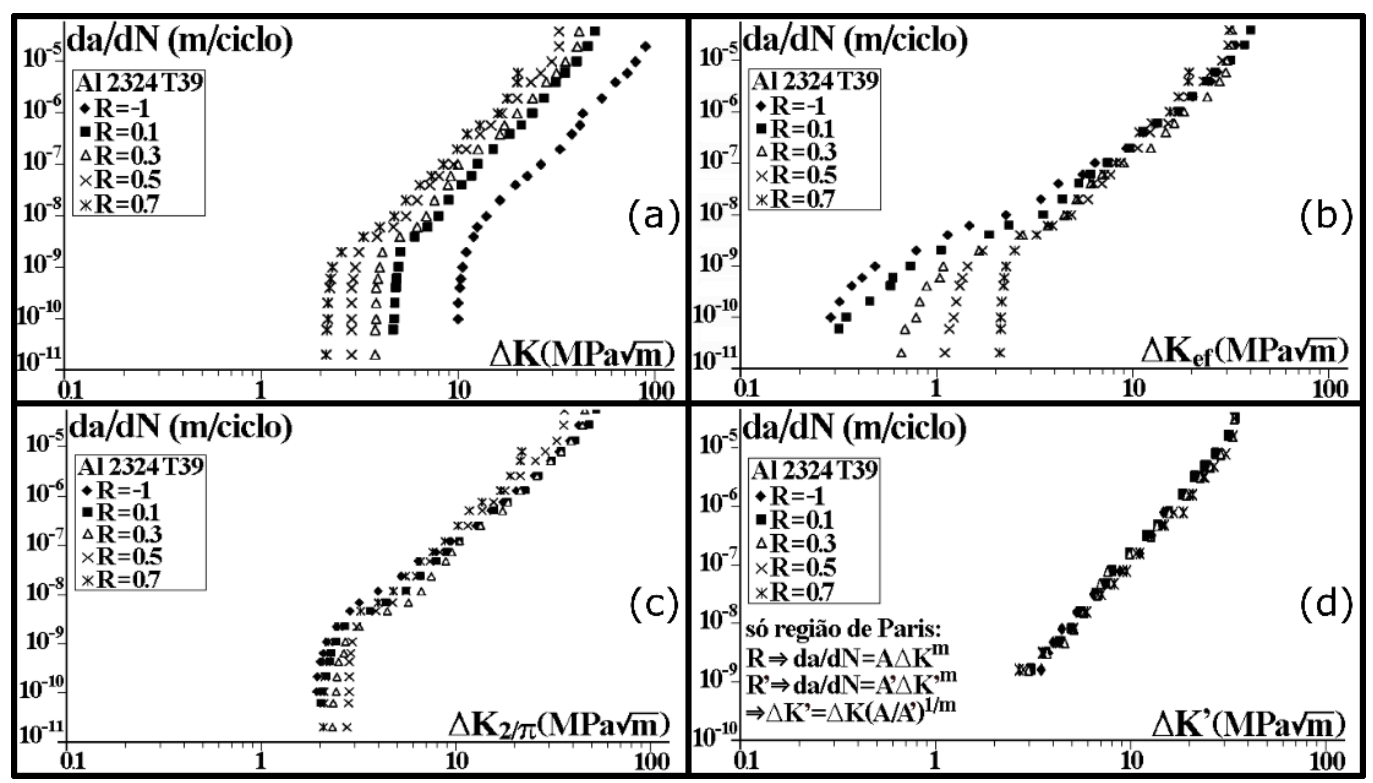

Figura 2.21: Dados do Al 2324T39, de taxa de propagação de trinca $d a / d N$ vs. (a) $\Delta K$; (b) $\Delta K_{e f} ;(\mathrm{c}) \Delta K_{2 / \pi} ;$ (d) $\Delta K^{\prime}[25]$.

\subsection{5.}

\section{Efeitos de sequência de carga na propagação}

No estudo dos efeitos de sequência de carga, a teoria de Elber é a mais popular para descrever as variações na taxa de propagação da trinca após mudanças bruscas no carregamento da peça $[15,16,35]$. Apesar disso, existem alguns questionamentos em casos específicos, onde o $\Delta K_{e f}$ não explica de forma razoável o comportamento da trinca. 
Fleck [36] fez testes de propagação de trinca por fadiga sob $\Delta K=25 \mathrm{MPa} \sqrt{ }$ e $R=0.05$ quase constantes, medindo a taxa de propagação antes e após a aplicação de uma sobrecarga em corpos de prova C(T) de aço BS4360 50B sob tensão e deformação plana, com espessuras de $3 \mathrm{~mm}$ e $24 \mathrm{~mm}$, respectivamente.

Para medir a carga de abertura de trinca, ele usou um transdutor de abertura de boca de trinca (COD), um extensômetro na face traseira do corpo de prova, um Clip-Gage na face do CP atrás da ponta da trinca, e nos corpos de prova de $24 \mathrm{~mm}$, um extensômetro tipo "pushrod" furando no meio da parte superior do CP, até chegar na face da trinca, $1 \mathrm{~mm}$ atrás do ponto de aplicação da sobrecarga. Apesar de que o uso do extensômetro tipo "pushrod" poder ser um pouco complexo e invasivo, Fleck afirmou que não foi verificada qualquer influência do método no comportamento da carga de abertura. A Figura 2.22 mostra as taxas de propagação para os corpos de prova fino e grosso, em tensão e deformação plana respectivamente.

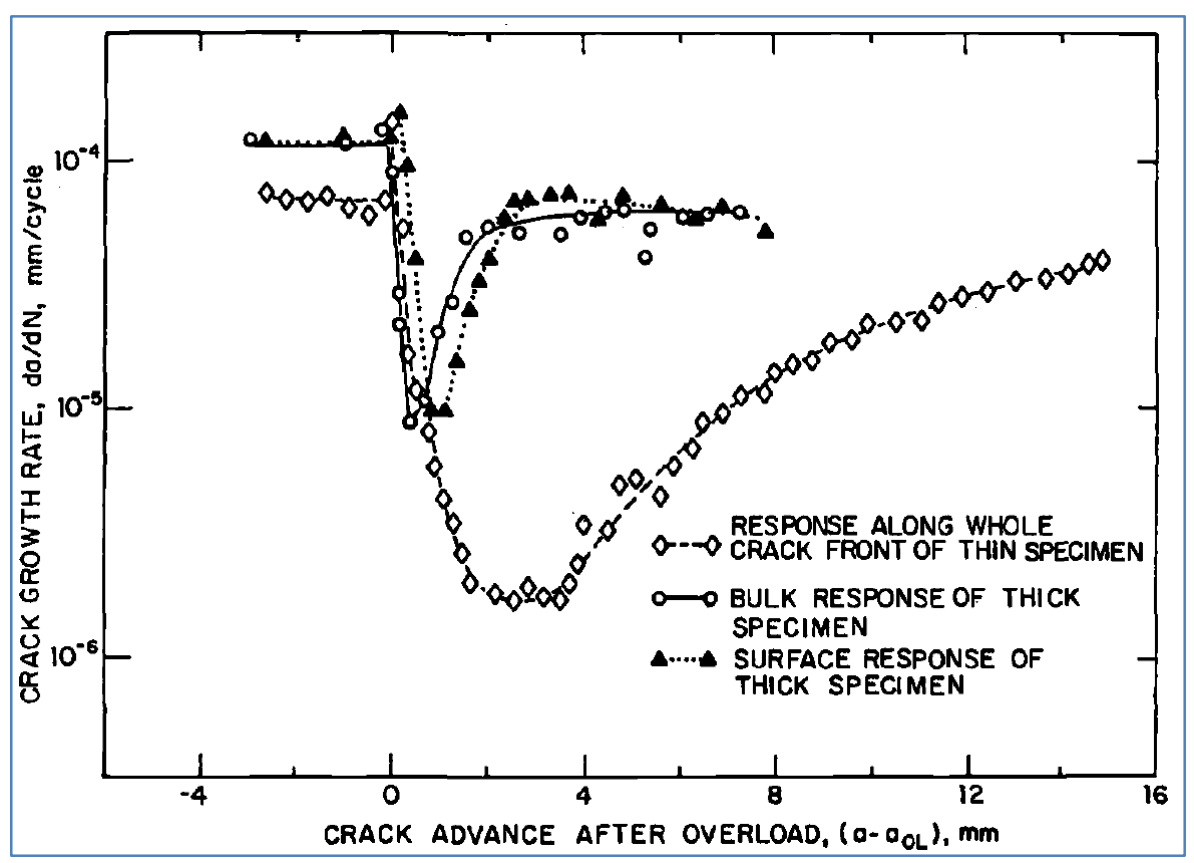

Figura 2.22: Taxa de propagação após sobrecarga em tensão e deformação plana [36].

A medição das taxas de propagação foi feita por queda de potencial e por um microscópio acompanhando a ponta da trinca na face do corpo de prova. No CP grosso foram obtidas duas taxas diferentes e no $\mathrm{CP}$ fino se mediu a mesma taxa com os dois métodos. Na Figura 2.23 estão as medidas de carga de abertura, representadas pela razão de fechamento proposta por Elber; $U=\left(K_{\max }-K_{o p}\right) /\left(K_{\max }-K_{\min }\right)$. Neste caso existiu uma diferença nas medidas de carga de abertura feitas na face do 
CP grosso, quando comparadas com as medidas obtidas pelos métodos de flexibilidade global (extensômetro na face traseira e transdutor "pushrod").

Analisando a Figura 2.22 e a Figura 2.23, pode-se perceber como no CP grosso, $K_{a b}$ caiu próximo do valor $K_{\min }(\mathrm{U} \approx 1)$ após a aplicação da sobrecarga, mas não se gerou um aumento proporcional na taxa de propagação. Além disso, da posição $2 \mathrm{~mm}$ até a posição $8 \mathrm{~mm}$ de incremento de trinca o $K_{a b}$ foi diminuindo gradualmente, mas a taxa ficou constate a partir dos $3 \mathrm{~mm}$, sobre uma condição de $\Delta K_{\text {ef }}$ variável. Já no $\mathrm{CP}$ fino, o $\Delta K_{\text {ef }}$ permaneceu aproximadamente constante entre a posição $2 m m$ e $6 m m$, mas a taxa de propagação começou a aumentar antes de $4 m m$ de incremento de trinca. Este tipo de inconsistências entre $d a / d N$ e $\Delta K_{e f}$ contestam a teoria de Elber, mas o autor atribuiu estes problemas ao chamado "fechamento descontínuo". Fleck explicou esse fenômeno afirmando que pela aplicação da sobrecarga se gera uma "corcova" de material deformado, a qual se torna principal ponto de contato entre as faces da trinca ao longo da propagação. Esta "corcova" atua como uma mola, permitindo geração de dano à frente da ponta da trinca, para cargas abaixo de $K_{a b}$.

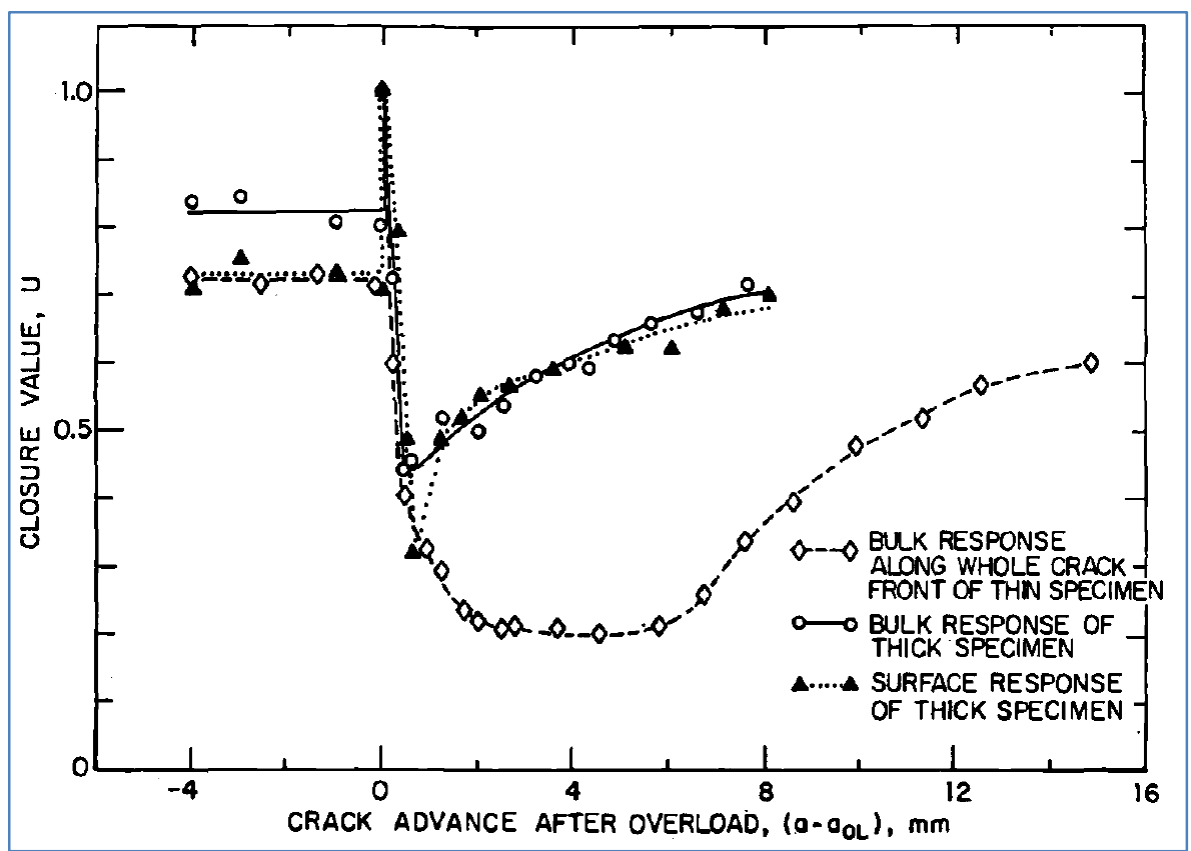

Figura 2.23: Razão de fechamento $U=\left(K_{\max }-K_{o p}\right) /\left(K_{\max }-K_{\min }\right)$ dos testes de sobrecarga em tensão e deformação plana [36].

Em outro trabalho, Castro et al. [13] relatam testes de propagação de trincas sob carga quase constante $\{\Delta K=10 \mathrm{MPa} \sqrt{ } \mathrm{e}$ e $R=0.7\}$ em corpos de prova $\mathrm{C}(\mathrm{T})$ de $12 \mathrm{~mm}$ de espessura de aço A542/2 2.25Cr1Mo, nos quais, após a aplicação de 
uma sobrecarga de $50 \%\left(K_{S C}=1.5 \cdot K_{\max }\right)$, foram medidos retardos significativos, vide Figura 2.24. Como a trinca se propagou em $R$ alto, ela de fato permaneceu totalmente aberta durante todo o ciclo de carga, antes e após a sobrecarga, como comprovado através de medidas de flexibilidade, obtidas com um extensômetro colado na fase traseira do CP, vide Figura 2.25. Portanto, durante todo o teste $K_{\min }>$ $K_{a b}$ e $\Delta K_{e f}=\Delta K$, e sendo assim nestes testes os efeitos das sobrecargas não podem ser explicados pelo mecanismo de fechamento induzido por plasticidade, simplesmente porque não se observa fechamento nem antes, nem após a sobrecarga.

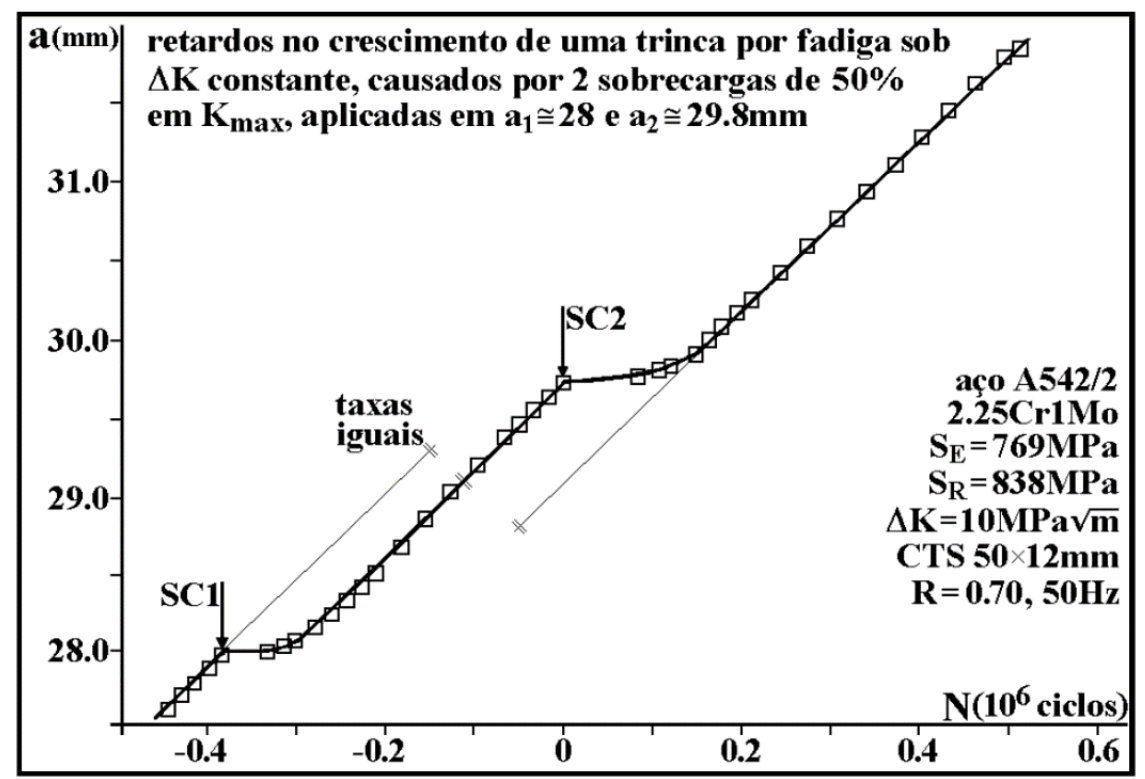

Figura 2.24: Retardo no $d a / d N$ gerado por 2 sobrecargas de $50 \%$ de $K_{\max }$, em uma trinca que propaga com $\triangle K=10 M P a{ }_{m}$ e $R=0.70[13]$.

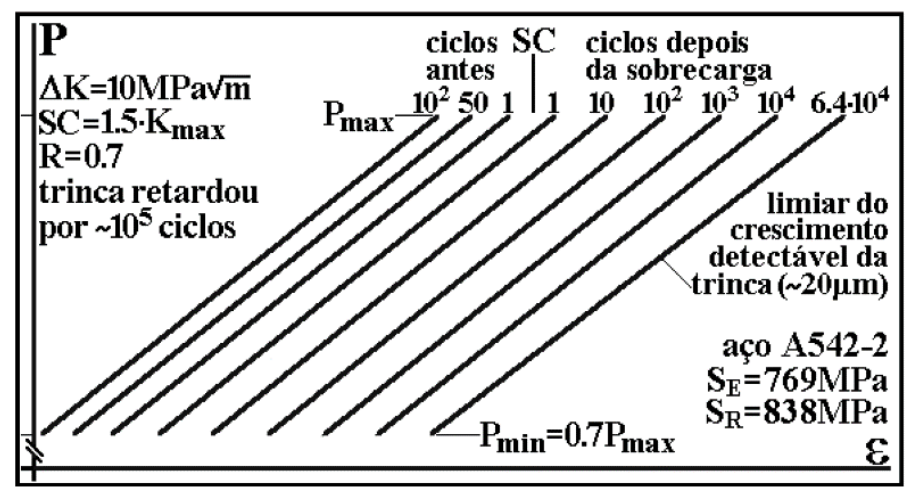

Figura 2.25: Curvas de flexibilidade antes e após a sobrecarga (SC), que apresentam ausência de fechamento $\left(P_{a b}<P_{\min }\right)[13]$.

Nesta mesma linha, Yamada e Newman usaram extensômetros à frente da ponta da trinca e na face traseira do CP para medir $P_{a b}$ em testes de propagação com sobrecarga para diferentes $R$, em corpos de prova $\mathrm{C}(\mathrm{T})$ de Inconel-718 [37]. Então, usando o subtrator de linearidade de Paris e Hermann para medir $P_{a b}$, eles acharam 
que nos testes de $R$ alto só o extensômetro perto da ponta da trinca registrou fechamento (com medições um pouco ruidosas). Com estes dados, eles afirmaram que os testes em $R$ alto tinham fechamento e que o $\Delta K_{\text {ef }}$ explicava o comportamento da trinca quando submetida a uma sobrecarga em $R$ alto. Mas se os extensômetros de campo próximo e de campo distante no teste de $R$ baixo mostraram os mesmos valores de $P_{a b}$, por que em $R$ alto não foram iguais? Pode significar que a trinca em $R$ baixo propaga numa condição de fechamento global e em $R$ alto numa condição fechamento altamente localizado nas faces do $\mathrm{CP}$, o que cria um $\Delta K_{e f}$ variável na frente da ponta da trinca. Porém, pensando numa propagação sobre esta condição de $\Delta K_{e f}$ variável em três dimensões, a trinca deveria propagar mais rápido no meio do que nas bordas do $\mathrm{CP}$, alterando a frente da trinca e deixando estrias não paralelas, que não foram reportadas pelos autores. Levando em conta isso, outra conclusão sobre estes resultados poderia ter sido que o fechamento em $R$ alto foi desprezível, já que não se evidenciou variação nas estrias deixadas pela trinca (tunelamento), apesar de ter uma condição de $\Delta K_{e f}$ variável na sua frente. Isso mostra como é difícil fazer testes de propagação de trinca que não deixem nenhuma dúvida e como os mesmos resultados podem ser interpretados de maneiras diferentes.

Para verificar se uma trinca com fechamento variável ao longo de sua frente propaga em taxas diferentes mudando sua forma, Corbani et al [38] fizeram testes de propagação de trinca em corpos de prova $\mathrm{SE}(\mathrm{T})$. Nestes CPs, primeiro foi propagada uma trinca em modo I, sob cargas tensão-tensão e $R=0.05$, criando frentes de trinca aproximadamente paralelas. A seguir, o CP trincado foi reposicionado numa montagem de flexão de quatro pontos, passando a trabalhar num sistema de viga com uma trinca lateral, vide Figura 2.26.

Nesta montagem de flexão de quatro pontos, uma parte da frente da trinca trabalha sob tensão-tensão e a outra sob compressão-compressão, criando um cenário de fechamento variável ao longo da frente da trinca. Então, as frentes das trincas quase paralelas que tinham sido criadas numa montagem de tensão pura, foram distorcidas pelo carregamento de flexão transversal (Figura 2.27). De fato, as sucessivas frentes de trinca que aparecem na Figura 2.27 mostram claramente que, apesar da frente da trinca ser inicialmente quase linear, ela lentamente assumiu uma forma em L cada vez mais alongada, após se propagar em duas dimensões parcialmente 
fechada, submetida a carregamentos cíclicos em flexão transversal. Este é o comportamento esperado de uma frente de trinca que propaga por fadiga, dependendo do valor local da força motriz da trinca ao longo da sua frente.

Em outras palavras, esses testes confirmam a ideia (razoável) de que a propagação de trincas por fadiga é um fenômeno local, e como tal, a propagação com frentes de trincas paralelas requer uma força motriz constante ao longo delas [1].

Consequentemente, se as frentes de trincas são submetidas a gradientes de força motriz, então as frentes subsequentes devem se distorcer. Se não se distorcem, então sua força motriz deve ser constante ao longo de suas frentes, sem grande diferença entre as regiões em tensão plana e deformação plana, devido ao fechamento induzido pela plasticidade ou qualquer outro motivo.

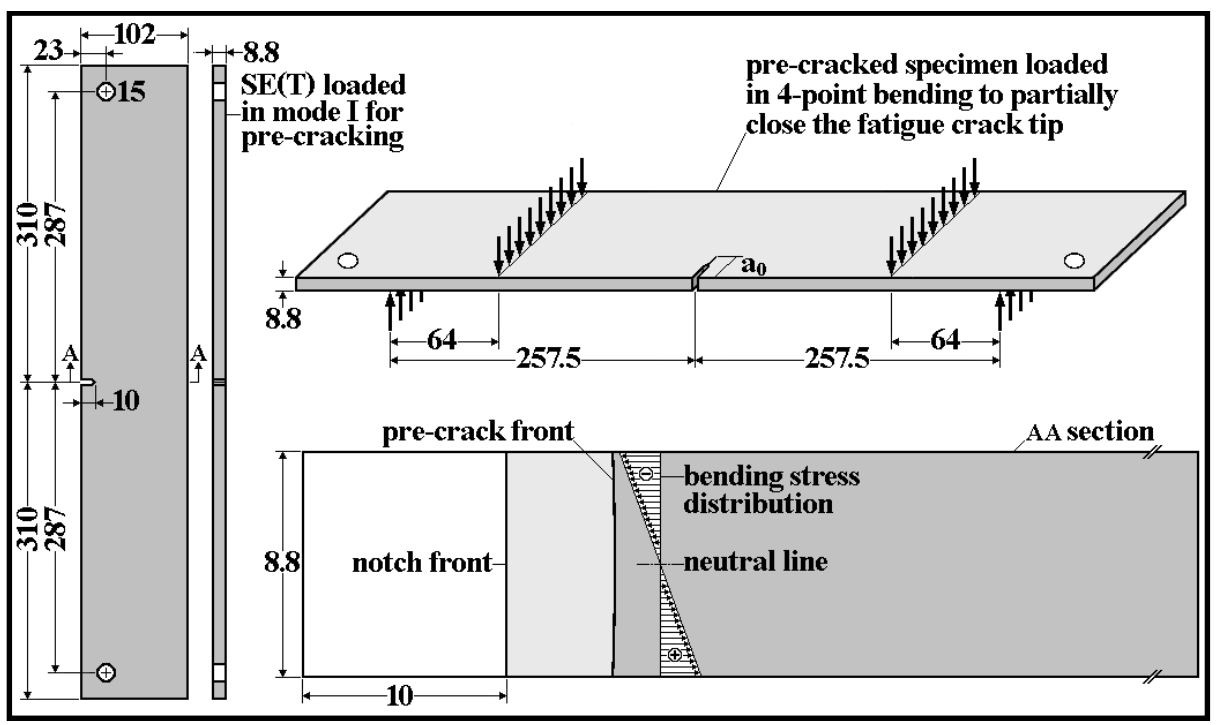

Figura 2.26: Corpo de prova SE(T) pré-trincado, carregado em flexão transversal para fechar parcialmente a frente da trinca [38].

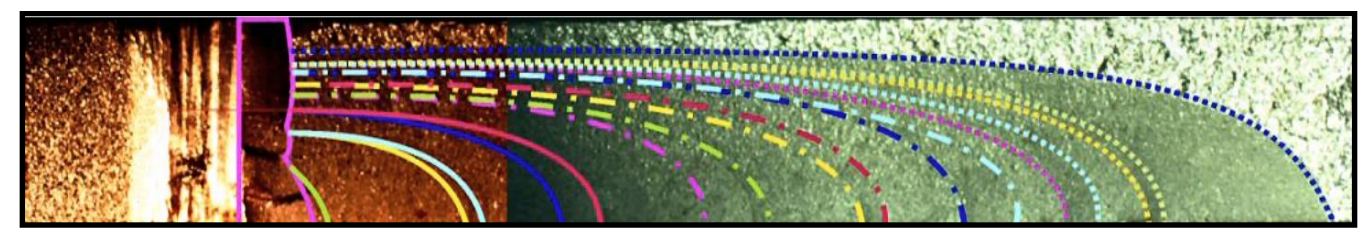

Figura 2.27: Frentes de trinca sucessivos, que propagaram em flexão transversal, a partir de uma trinca de frente linear [38]. 


\section{3. \\ Materiais e métodos}

\section{1.}

\section{Dimensões dos corpos de prova}

Para realizar os testes de laboratório foram escolhidos corpos de prova (CPs) tipo "Disk-Shaped Compact Tension" DC(T), que pelas suas características facilitam a usinagem de CPs com diferentes espessuras a partir de uma barra redonda, mantendo características homogêneas de material entre os CPs, com um baixo custo de fabricação [21]. Então para escolher o tipo de material e as espessuras dos CPs, foram estabelecidas as seguintes condições:

- $\Delta K>\Delta K_{\text {th }}$ e $K_{\max } \ll K_{C}$, para propagar a trinca longe da fase de fratura.

- Usar um valor de $R \leq 1$ para aumentar a possibilidade de ter fechamento.

- Manter dimensões razoáveis que facilitassem a montagem nas máquinas.

- Seguir as recomendações da ASTM, para este tipo de testes [21, 24].

Além disso, para que a trinca propagasse em tensão ou em deformação plana dominante (Seção 2.4), as espessuras dos corpos DC(T) e o material foram selecionados através de um processo iterativo usando as seguintes equações [13]:

$$
\begin{aligned}
& K=\frac{P}{t \sqrt{w}} * \frac{\left(2+\frac{a}{w}\right)\left[0.76+4.8 \frac{a}{w}-11.58\left(\frac{a}{w}\right)^{2}+11.43\left(\frac{a}{w}\right)^{3}-4.08\left(\frac{a}{w}\right)^{4}\right]}{\left(1-\frac{a}{w}\right)^{3 / 2}} \\
& z p_{\max }=\frac{K_{\max }^{2}}{\pi S_{E}^{2}}\left\{\begin{array}{c}
t \leq z p_{\max } ; \text { Tensão plana } \\
t>2.5\left(K_{\max } / S_{E}\right)^{2} \text { Deformação plana }
\end{array}\right. \\
& \Delta K=K_{\max }-K_{\min } \\
& R=K_{\min } / K_{\max } \\
& K_{\max }=\Delta K /(1-R)
\end{aligned}
$$

onde $K=$ fator de intensidade de tensões dos corpos de prova DC(T) [21]; $P=$ força aplicada; $t=$ espessura do CP; $w=$ largura do CP; $a=$ tamanho da trinca; $z p_{\max }=$ tamanho da zona plástica máxima (pela estimativa de Irwin); $S_{E}=$ resistência ao escoamento; $\Delta K=$ gama do fator de intensidade de tensões; $K_{\max } e K_{\min }=$ fatores de intensidade de tensões máximo e mínimo; e $R=K_{\min } / K_{\max }$. 


\section{2.}

\section{Medição de deformação e deslocamento nos CPs}

Para avaliar a hipótese de Elber, é indispensável medir a carga de abertura de trinca $P_{a b}$, medida tradicionalmente por meio de um gráfico $P$ vs. $\delta_{P}$, como explicado no Capitulo 2. Mas como o deslocamento do ponto de aplicação da força $\left(\delta_{P}\right)$ é difícil de medir com exatidão, recomenda-se usar medições de deformação e deslocamento do $\mathrm{CP}$, no campo próximo da ponta da trinca e na face traseira do $\mathrm{CP}$ [37].

Medidas redundantes de deformação foram feitas usando uma série de extensômetros colados ao longo do ligamento residual à frente da ponta da trinca (dez extensômetros), e por um extensômetro colado na face traseira do $\mathrm{CP}$, vide Figura 3.1. A Tabela 3-1 lista os tipos de extensômetros que foram usados:

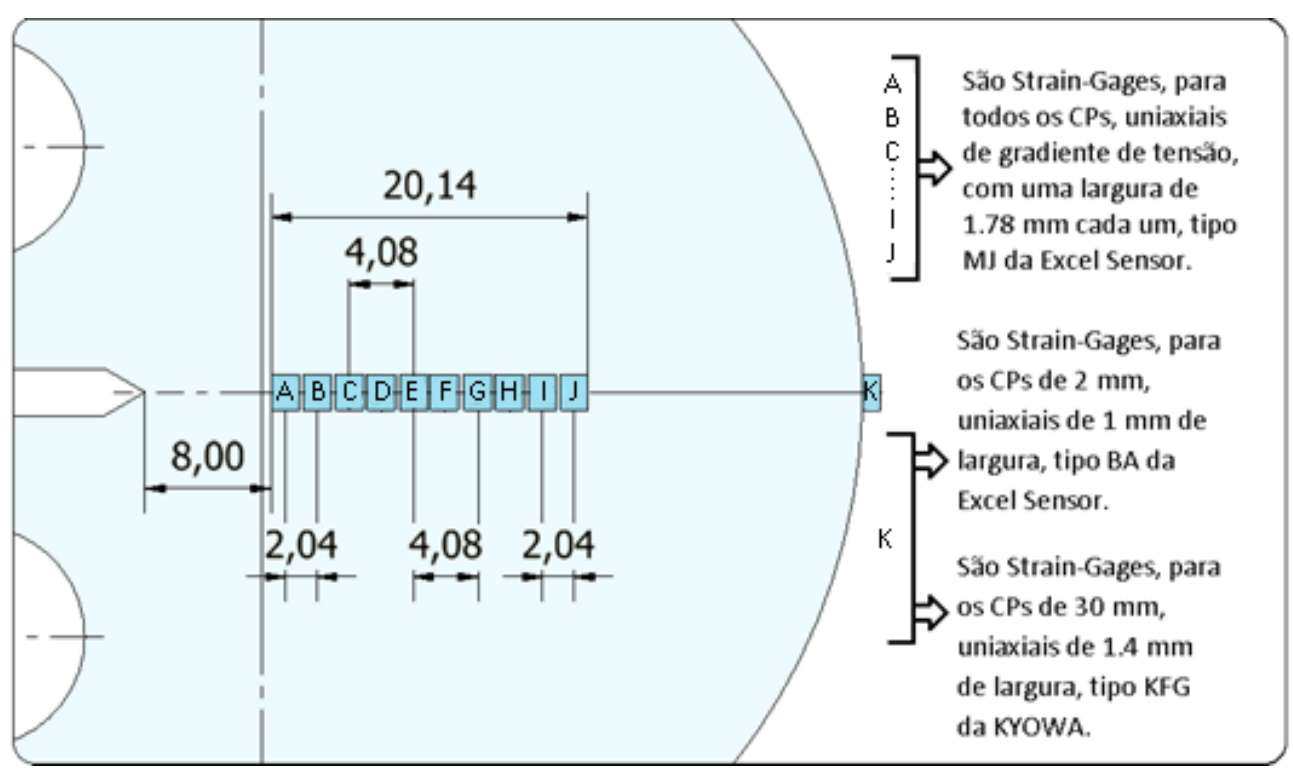

Figura 3.1: Distribuição e especificações dos extensômetros nos CPs (dimensões em mm).

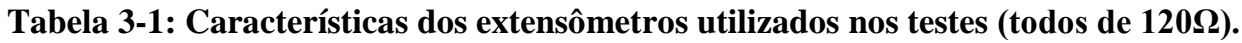

\begin{tabular}{|c|c|c|c|c|c|c|c|}
\hline \multirow{3}{*}{ Código } & \multirow{3}{*}{ Tipo } & \multicolumn{4}{|c|}{ Dimensỗes mm } & \multirow{3}{*}{ Fornecedor } & \multirow{3}{*}{$\begin{array}{l}\text { Espessura } \\
\text { do } \mathrm{CP} \\
(\mathrm{mm})\end{array}$} \\
\hline & & \multicolumn{2}{|c|}{ Grelha } & \multicolumn{2}{|c|}{ Base } & & \\
\hline & & $\mathbf{a}$ & b & c & d & & \\
\hline PA-06-031MJ-120 & Gradiente & 0.787 & 1.178 & 2.29 & 20.1 & Excel sensor & 2 e 30 \\
\hline PA-06-060BA-120 & Uniaxial & 1.0 & 1.0 & 6.0 & 5.0 & Excel sensor & 2 \\
\hline KFG-5-120-C1-11 & Uniaxial & 5.0 & 1.4 & 9.4 & 2.8 & KYOWA & 30 \\
\hline \multicolumn{4}{|c|}{ 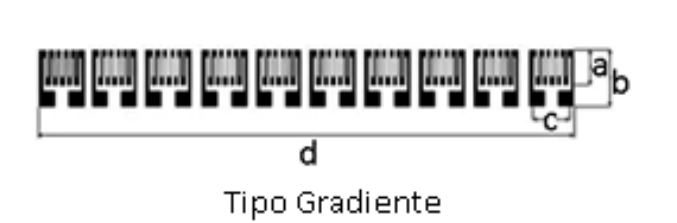 } & c & 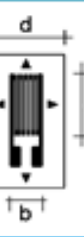 & \multicolumn{2}{|c|}{ Tipo uniaxial } \\
\hline
\end{tabular}


As Figuras 3.2, 3.3 e 3.4 mostram os extensômetros colados no campo distante e no campo próximo da trinca. Para a leitura dos onze extensômetros (um na fase traseira e dez à frente da ponta da trinca), na primeira etapa de testes foi usado o sistema de aquisição de dados ADS-2000 da LINX, com o software AqDados [39]. Já na segunda etapa de testes, foi desenvolvido um programa em Labview para aquisição de dados, usando o sistema NI cDAQ 9172 e os módulos NI 9235 e NI 9215, da National Instruments [40].

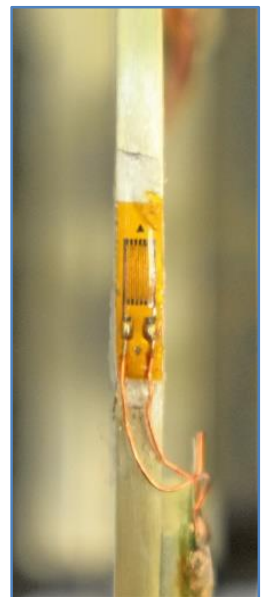

Figura 3.2: Extensômetro colado na face traseira do CP de $2 \mathrm{~mm}$.

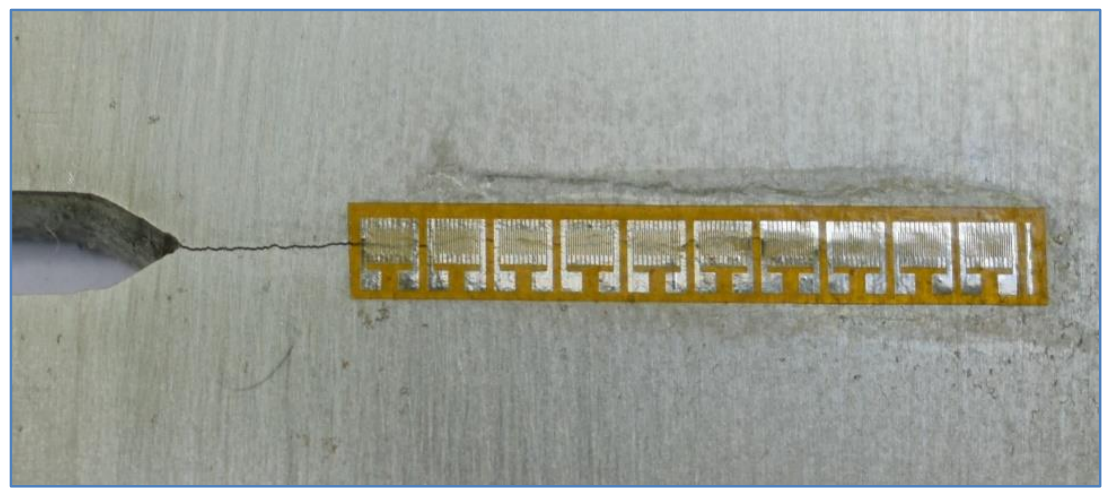

Figura 3.4: Extensômetros colados no campo próximo da ponta da trinca, igual para os dois tipos de CPs.

\subsection{1.}

\section{Medição do campo de deslocamento/deformação usando DIC}

A correlação digital de imagens (DIC) é uma técnica não invasiva que pode medir campos de deslocamento/deformação opticamente [41]. A técnica correlaciona sub-imagens de uma sequência de imagens, das quais uma é obtida antes do 
carregamento do corpo de prova (imagem referência) e as outras durante o carregamento. $\mathrm{O}$ estado de deformação do material pode ser obtido através do monitoramento dos deslocamentos de marcadores na superfície da amostra, acompanhando a mudança de posição de uma pequena região através dos valores do nível de tons de cinza da área em estudo. $\mathrm{O}$ acompanhamento da sub-imagem pode ser alcançado por meio da maximização do coeficiente de correlação cruzada (cc), para estabelecer as semelhanças existentes entre distintas regiões das imagens.

Então se os níveis de tons de cinza nos $n$ pixels de uma sub-imagem de amostra são representados pelo vetor $p=\left[p_{1} p_{2} \ldots p_{n}\right]^{t}$ e se os tons correspondentes a sub-imagem de busca forem $q=\left[\begin{array}{llll}q_{1} & q_{2} & \ldots & q_{n}\end{array}\right]^{t}$, então o coeficiente de correlação cruzada é [42]:

$$
c c=\frac{\sum_{i=1}^{n}\left(p_{i} q_{i}-n p_{m} q_{m}\right)}{\left[\sum_{i=1}^{n}\left(p_{i}^{2}-n p_{m}^{2}\right)\right] \cdot\left[\sum_{i=1}^{n}\left(q_{i}^{2}-n q_{m}^{2}\right)\right]}
$$

onde $p_{m}$ e $q_{m}$ são os valores médios para todos os $p_{i}$ e $q_{i}$, respectivamente. $\mathrm{O}$ coeficiente de correlação cruzada $(c c)$ oscila entre $-1 \mathrm{e}+1$. Quando $c c=1$ significa que as duas imagens são idênticas, já para $c c=0$ quer dizer que não há nenhuma correlação entre elas, e quando $c c=-1$ indica que as imagens são perfeitamente correlacionadas, mas uma é a inversa da outra. A Figura 3.5 mostra um esquema do funcionamento deste algoritmo.

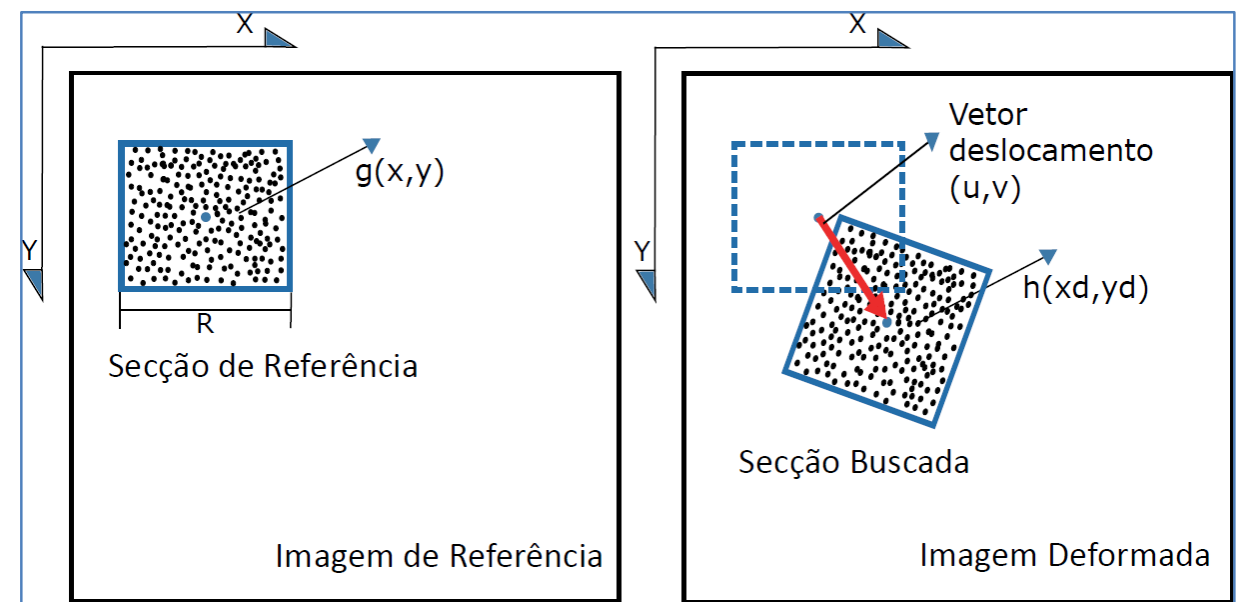

Figura 3.5: Esquema do método de correlação digital de imagens (DIC).

Atualmente existem muitos programas que aplicam esta rotina de correlação digital de imagens (DIC), e neste trabalho foram usados os programas comerciais da Correlated Solutions, VIC-Snap $2009^{\circledR}$ e VIC-3D $2010^{\circledR}$ [43]. 
Para medir os campos de deslocamento e deformação via DIC deve-se:

- Primeiro polir a superfície do CP com lixa, para eliminar imperfeições na região a ser analisada.

- Em seguida limpar a superfície com álcool, para poder aplicar o padrão de pintas ou "speckles" aleatórias, primeiro aplicando uma camada de tinta branca homogênea, e depois salpicos de tinta preta espalhados aleatoriamente na superfície do CP.

- Após o tempo de secagem da tinta, o CP é montado na máquina de ensaios mecânicos (Figura 3.6).

- Com o programa VIC-Snap, que permite a captura remota e a visualização das imagens, as câmeras são orientadas para que a área de interesse do CP apareça no campo de visão.

- Após o posicionamento das câmeras, deve-se ajustar a intensidade da fonte de luz para obter uma focagem adequada.

- Em seguida se escolhe uma placa de calibração (Figura 3.6) que seja compatível com o tamanho do campo de visão.

- A placa de calibração é posicionada no mesmo plano do $\mathrm{CP}$, dentro do campo de visão, para registrar entre 25 e 30 fotos da placa, em posições aleatórias.

- Com ajuda do módulo de calibração do programa VIC-3D, é feita a calibração das câmeras automaticamente. Este programa localiza na placa de calibração os pontos de referência, que possuem uma distribuição e tamanho conhecidos. Esta informação é utilizada para ajustar os modelos matemáticos, através dos quais é possível obter a reconstrução tridimensional da cena.

- Após executar estas etapas, o sistema está pronto para ser utilizado.

Durante o ensaio mecânico, imagens do corpo de prova são capturadas e posteriormente analisadas com o programa VIC-3D. O resultado desta análise é o campo de deslocamento e a partir dele, é calculado o campo de deformações da superfície do corpo de prova $[44,45]$.

Na Figura 3.6 é mostrada a montagem experimental utilizada para realizar as medições com DIC neste trabalho. 


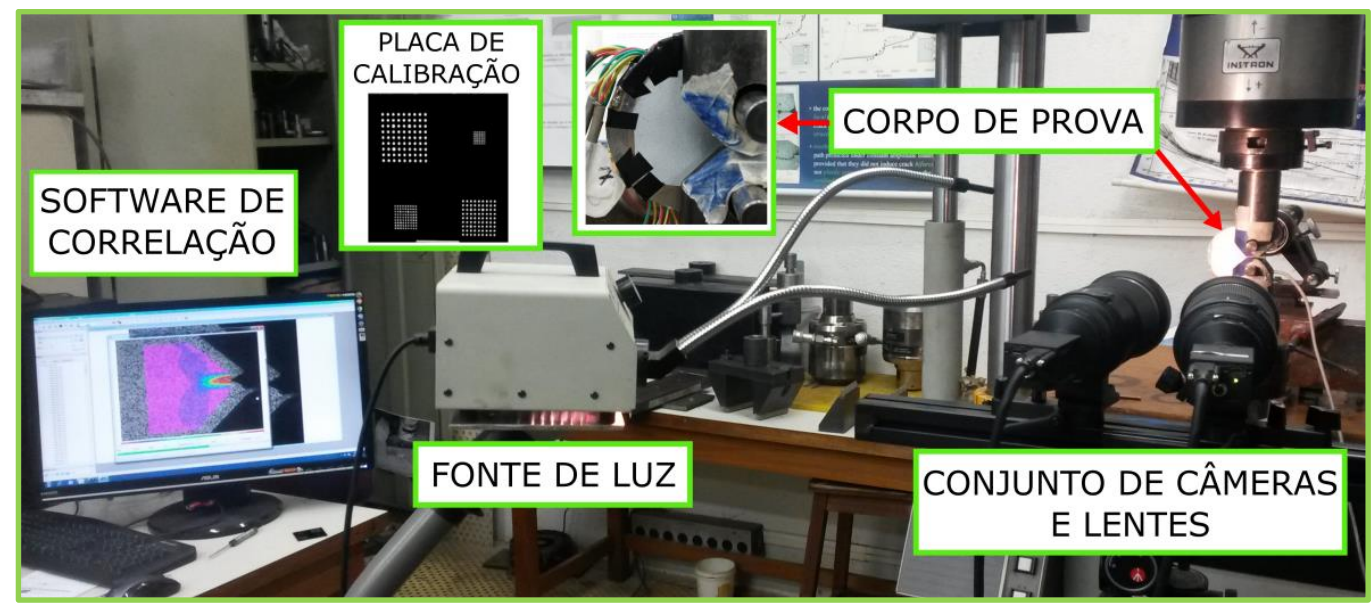

Figura 3.6: Montagem do corpo de prova e dos aparelhos necessários para fazer a medição com DIC.

Para usar DIC as fotos foram tiradas com duas câmeras de 5 megapixels CCD (Point Grey GRAS-50S5M), equipadas com lentes Tamron SP AF180mm F/3.5. As fotos foram posteriormente analisadas com o software VIC-3D para obter os campos de deslocamento e de deformação na face dos CPs. Os parâmetros para fazer a análise via DIC foram: Janela $=31 \times 31$ pixels, Paso $=7$ pixels, Janela de deformação $=15 \times 15$. Estes parâmetros determinam que a cada 7 pixels (passo), existe uma medição numa região de $31 \times 31$ pixels.

\section{3.}

\section{Medição do comprimento da trinca}

Para acompanhar e medir a trinca opticamente durante os ensaios, foi usado um microscópio montado numa mesa micrométrica com um aumento de $12 \mathrm{X}$ para localizar a ponta da trinca, vide Figura 3.7.

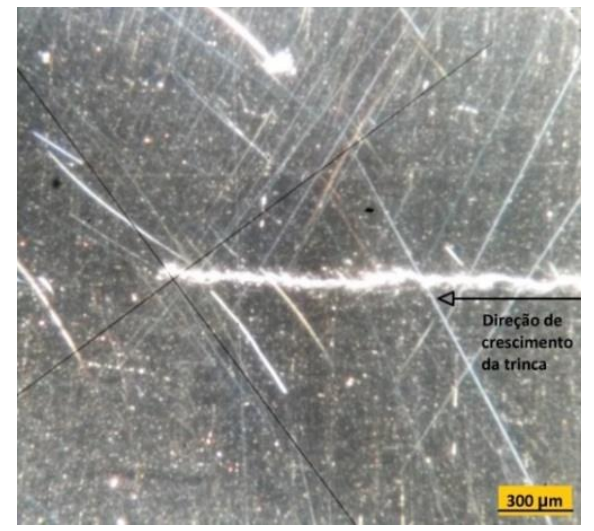

Figura 3.7: Região de ampliação da trinca feita com o microscópio. 


\subsection{1.}

\section{Medição via variação da flexibilidade do CP}

A flexibilidade pode ser definida como a facilidade com que se deforma uma estrutura submetida a um carregamento, ou de um jeito mais formal, pela deformação que sofre a estrutura dividida na magnitude da força aplicada $(C=\varepsilon / P)$.

Este conceito é muito útil quando se trabalha com corpos trincados submetidos a carregamentos em Modo I, já que existe uma relação entre a flexibilidade e a taxa de alivio de energia por unidade de área de avanço da trinca $G$ [46].

$$
\mathcal{G}=\left(\frac{P^{2}}{2 t}\right)\left(\frac{d C}{d a}\right)=\frac{K_{I}^{2}}{E}
$$

onde $d C / d a$ é a taxa de variação de flexibilidade em relação ao aumento do tamanho da trinca, $P$ é a carga aplicada, $t$ é a espessura do espécime, $E$ é o módulo de elasticidade e $K_{I}$ é o fator de intensidade de tensões em Modo I.

Baseadas neste princípio, há relações entre o comprimento da trinca e a deformação do corpo de prova medida na fase traseira do CP (Figura 3.1). Estas formulações dependem do fator de intensidade de tensões, que no caso do corpo de prova $\mathrm{DC}(\mathrm{T})$ se calcula com a equação 3.1. Uma expressão que relaciona o comprimento da trinca usando a deformação da fase traseira do corpo de prova $\mathrm{DC}(\mathrm{T})$ é dada por:

$$
\begin{gathered}
\frac{a}{w}=\varphi_{0}+\varphi_{1} U+\varphi_{2} U^{2}+\varphi_{3} U^{3}+\varphi_{4} U^{4}+\varphi_{5} U^{5}+\varphi_{6} U^{6} \\
U=\frac{1}{\sqrt{-E \cdot t(\varepsilon / P) w}+1}
\end{gathered}
$$

Tabela 3-2: Constantes da equação que relaciona a deformação da fase traseira do corpo de prova tipo DC(T), com o comprimento da trinca
\begin{tabular}{|c|c|c|c|}
\hline $\boldsymbol{i}$ & Constante $\boldsymbol{\varphi}_{\boldsymbol{i}}$ & $\boldsymbol{i}$ & Constante $\boldsymbol{\varphi}_{\boldsymbol{i}}$ \\
\hline $\mathbf{0}$ & 0.796239 & $\mathbf{4}$ & -2603.44 \\
\hline $\mathbf{1}$ & 5.40205 & $\mathbf{5}$ & 4829.01 \\
\hline $\mathbf{2}$ & -103.821 & $\mathbf{6}$ & -3578.51 \\
\hline $\mathbf{3}$ & 714.676 & & \\
\hline
\end{tabular}

Na equação 3.8, $w$ é a largura do corpo de prova, $a$ é o comprimento da trinca e $\varphi_{i}$ são as constantes ajustadas numericamente para o cálculo do tamanho da trinca (Tabela 3-2), com a deformação da fase traseira $(\varepsilon)$ do corpo DC(T) [47]. 


\section{4 .}

\section{Procedimento de testes com $\Delta K$ e $K_{\max }$ quase constantes}

Ensaios com $\Delta K$ e $K_{\max }$ constantes [30] permitem estudar o comportamento da trinca com uma quantidade mínima de variáveis, facilitando a análise da $P_{a b}$, algo indispensável neste trabalho. Para isso é necessário recalcular a gama da carga $(\triangle P)$ a cada aumento no tamanho da trinca $\Delta a$ (Equação 3.10). Depois, com $R$ fixo, recalcula-se a carga mínima $P_{\min }$ (Equação 3.11), para mudar a magnitude das cargas aplicadas no $\mathrm{CP}$ através do controlador da máquina de ensaios mecânicos.

$$
\begin{gathered}
\Delta P=\frac{\left(1-\frac{a}{w}\right)^{3 / 2} *(t \sqrt{w}) * \Delta K}{\left(2+\frac{a}{w}\right)\left[0.76+4.8 \frac{a}{w}-11.58\left(\frac{a}{w}\right)^{2}+11.43\left(\frac{a}{w}\right)^{3}-4.08\left(\frac{a}{w}\right)^{4}\right]} \\
P_{\min }=\frac{R * \Delta P}{1-R}
\end{gathered}
$$

A equação 3.10 é para corpos de prova DC(T). Para usar outros tipos de CPs, basta trocá-la pelo fator de intensidade de tensões do tipo de CP que se quer testar. Na primeira etapa de testes o ajuste nos carregamentos para manter $\Delta K$ e $K_{\max }$ quase constantes foi feito manualmente a cada $0.1 \mathrm{~mm}$ de aumento no comprimento da trinca aproximadamente, medindo a trinca com o microscópio e com o método de variação de flexibilidade, para recalcular $P_{\max }$ e $P_{\min }$.

\subsection{1.}

\section{Sistema de malha fechada para automatização dos testes}

Depois de que foi confirmado o bom funcionamento da formulação para medir o comprimento da trinca pela técnica da variação de flexibilidade (comparando com o comprimento de trinca medido com o microscópio), foi desenvolvido um programa em Labview [48] para medir a trinca e calcular a taxa de propagação em tempo real (Seção 3.3.1).

Ampliando este programa, foi criado um sistema de malha fechada que mede o aumento no comprimento da trinca, recalcula os carregamentos para manter o $\Delta K$ e o $K_{\max }$ constantes, e muda as cargas que a máquina aplica no CP automaticamente, vide Figura 3.8. 


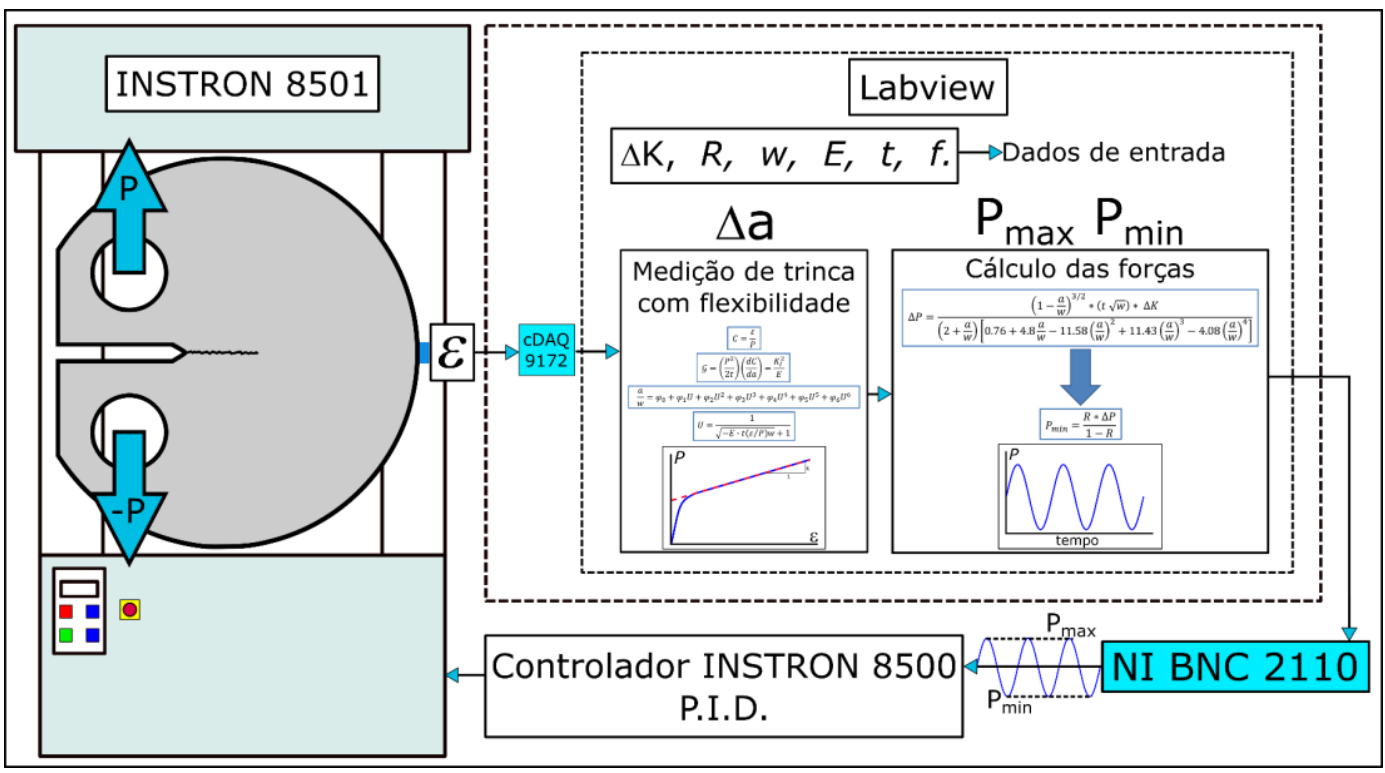

Figura 3.8: Diagrama de funcionamento do sistema de malha fechada, para controle de testes com $\Delta K$ e $K_{\max }$ quase constantes.

Na Figura 3.8 se mostra o diagrama de funcionamento do sistema de malha fechada, para fazer os testes com $\Delta K$ e $K_{\max }$ quase constantes. Primeiro o sistema pega a deformação do extensômetro da face traseira do CP e com método da variação da flexibilidade mede o comprimento da trinca (Seção 3.3.1), depois recalcula a magnitude dos carregamentos necessários para manter $\Delta K$ e $K_{\max }$ constantes (Equação 3.10 e 3.11), e por fim altera o sinal de saída que vai para o controlador da máquina (neste caso usando uma carga senoidal). A Tabela 3-3 lista os equipamentos de aquisição e emissão de sinais usados neste sistema malha fechada. A Tabela 3-4 lista as principais características da máquina servo-hidráulica INSTRON 8501 usada para fazer todos os ensaios de laboratório.

Tabela 3-3: Descrição dos equipamentos, da National Instruments [40].

\begin{tabular}{|c|c|}
\hline Nome & Descrição \\
\hline cDAQ-9172 & $\begin{array}{l}\text { Chassi de oito slots, com aquisição de da- } \\
\text { dos por conexão de USB. }\end{array}$ \\
\hline NI 9215 & $\begin{array}{l}\text { Módulo de entrada analógica com quatro } \\
\text { canais, } 100 \mathrm{kS} / \mathrm{s}, 16 \text { bits, } \pm 10 \mathrm{~V} \text {. }\end{array}$ \\
\hline NI 9237 & $\begin{array}{l}\text { Módulo para extensômetros com ponte } \\
\text { analógica, } 50 \mathrm{kS} / \mathrm{s} / \text { canal, } 4 \text { canais, } 120 \Omega \text {. }\end{array}$ \\
\hline NI BNC 2110 & $\begin{array}{l}\text { Bloco de conectores BNC blindados com } \\
\text { rejeição de ruído, para entrada e saída de } \\
\text { sinais. }\end{array}$ \\
\hline
\end{tabular}


Tabela 3-4: Caraterísticas gerais da máquina servo-hidráulica INSTRON 8501 [49].

\begin{tabular}{|l|l|}
\hline Armação & Duas colunas sobre estrutura de reação. \\
\hline Controlador & 8501Plus, para testes a fadiga, com 4 saídas analogias. \\
\hline Tipo de controle & P.I.D. por deslocamento, força ou deformação. \\
\hline Célula de carga & Capacidade máxima de 100 KN, tipo sanduíche. \\
\hline Acoples mecânicos & Rosca central M30 e padrão circular de seis roscas M10. \\
\hline
\end{tabular}

\section{5.}

\section{Testes com $\Delta K$ e $K_{\max }$ quase constantes, com sobrecarga.}

Na propagação de trincas por fadiga, o estudo dos efeitos de sequência de carga é de vital importância, porque na maioria dos casos, as peças em serviço estão submetidas a carregamentos variáveis [1]. Então para entender melhor este fenômeno, foram feitos testes de propagação de trinca com eventos de sobrecarga.

Para fazer estes testes, primeiramente aplicou-se $\Delta K$ e $K_{\max }$ quase constante na trinca, até que esta propagasse o suficiente para sair da zona de influência do entalhe e ter uma taxa de propagação estável. Depois, foi aplicado um evento de sobrecarga $\left(K_{S C}\right)$, e em seguida se aplicou de novo o mesmo carregamento com $\Delta K$ e $K_{\max }$ quase constantes, para propagar a trinca até sair da zona de retardo e ter aproximadamente a taxa de propagação de antes da sobrecarga. A Figura 3.9 ilustra este procedimento.

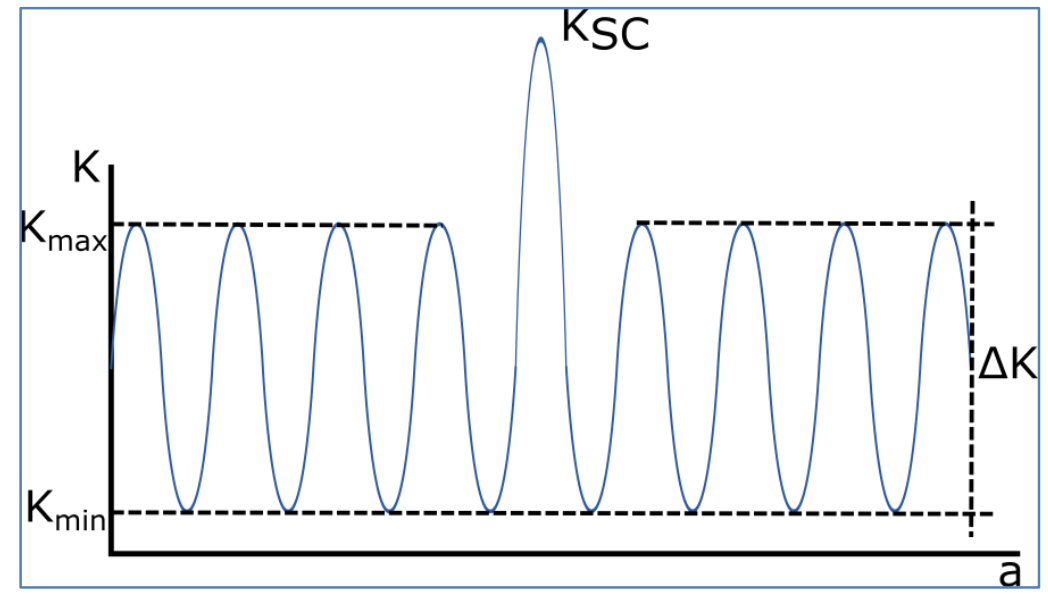

Figura 3.9: Esquema teórico de crescimento da trinca $(a)$, nos testes de propagação com $\Delta K$ e $K_{\max }$ constante, com um evento de sobrecarga $\left(K_{S C}\right)$.

Estes testes foram feitos em CPs em tensão e deformação plana. Os efeitos que pode ter o evento de sobrecarga na taxa de propagação $(d a / d N)$, segundo a maioria dos autores, são explicados na Seção 2.2.1. 


\section{6.}

\section{Sistema de microscópio estéreo DIC}

Um segundo sistema DIC 3D acoplado num microscópio estéreo foi usado em alguns testes para medir os campos de deslocamento e de deformação à frente da ponta da trinca com maior resolução. Esta técnica usa a maioria dos procedimentos explicados anteriormente (Seção 3.2.1), mas precisa de um padrão de pontos aleatório muito mais refinado do que o padrão usado no DIC convencional. Para isso, pó de toner de impressora laser é espalhando por meio de um Aerógrafo sobre uma camada de tinta branca, garantindo que as partículas não se aglomerem. Os tamanhos das partículas variam entre 1 e $15 \mu \mathrm{m}$. O sistema está formado por um microscópio estéreo Olympus SZX16 com duas câmeras CCD de 5.0 megapixels, montado numa base motorizada de 3 eixos para controle de posição. Também usa um software de correção de distorção, que calcula os campos de distorção não paramétricos, para eliminar problemas associados à obtenção de medições $3 \mathrm{D}$ em alta magnificação [50]. Neste estudo, o sistema de microscópio estéreo DIC foi calibrado para analisar uma região de aproximadamente $3 \times 3.5 \mathrm{~mm}$ na superfície do CP. A Figura 3.10a mostra um padrão aleatório obtido com o pó de toner na superfície do CP. A Figura 3.10b mostra a montagem do CP na máquina de testes, junto com o sistema de microscópio estéreo DIC.

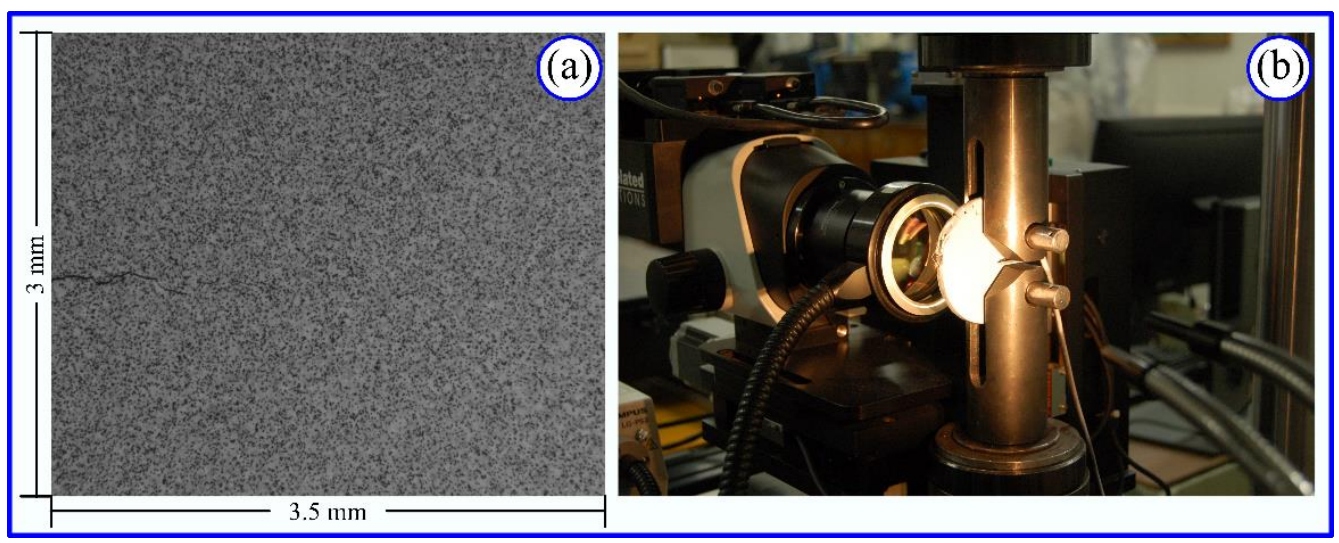

Figura 3.10: (a) Superfície do CP com o padrão aleatório feito com pó de toner e (b) montagem do CP na máquina de testes com o sistema de microscópio estéreo.

Nos testes feitos com o sistema microscópio estéreo DIC também foi medido o campo deslocamento/deformação com o sistema convencional DIC, na superfície oposta do CP, como mostrado na Figura 3.11. Todavia, nesses testes não foram 
instalados extensômetros à frente da ponta da trinca, mas foi colado um extensômetro na fase traseira do CP (Seção 3.2), para medir o comprimento da trinca e a $P_{a b}$.

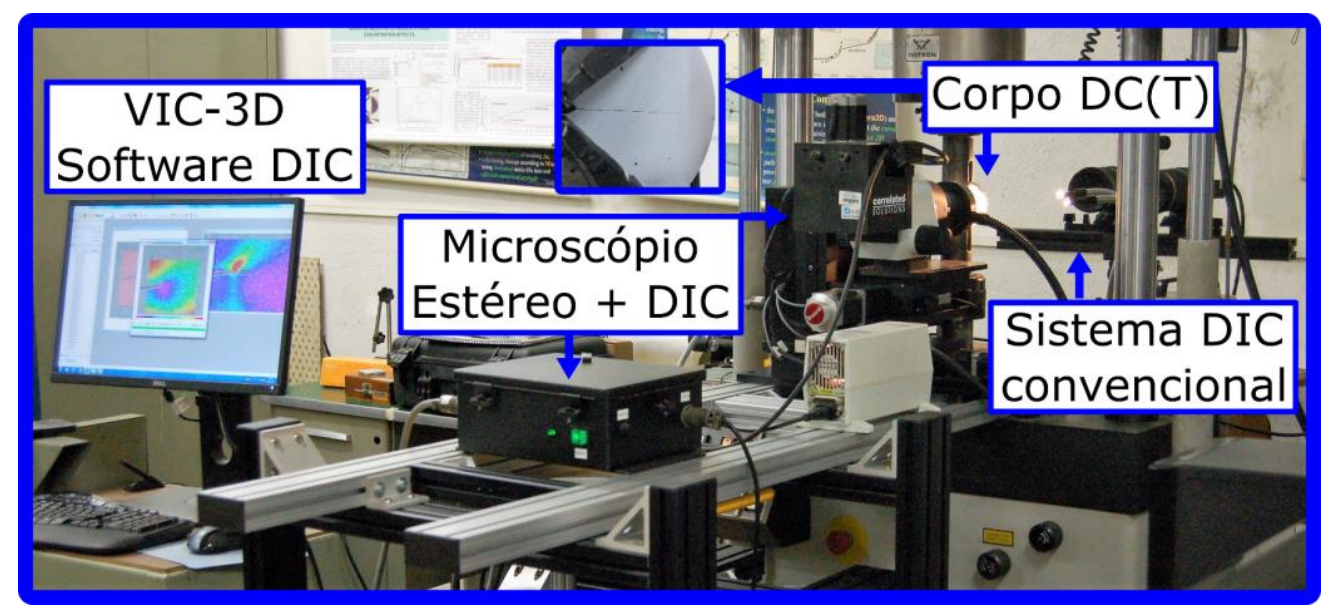

Figura 3.11: Montagem do CP na máquina de testes, para medir a deformação à frente da ponta da trinca, com o sistema de microscópio estéreo e o sistema convencional DIC.

\section{7.}

\section{Processamento de dados}

As medidas de comprimento de trinca e do número de ciclos de carregamento permitem calcular a taxa de propagação de trincas por fadiga com a equação [24]:

$$
\frac{d a}{d N}=\frac{a_{i+1}-a_{i}}{N_{i+1}-N_{i}}
$$

onde, $\left(a_{i+1}-a_{i}\right)$ é o incremento no comprimento da trinca em relação ao número de ciclos $\left(N_{i+1}-N_{i}\right)$, durante o qual o crescimento acontece.

Nas medidas de da/dN no programa de malha fechada é feita uma filtragem seguindo as recomendações da Norma ASTM E647. Isso é necessário porque a medição detecta incrementos de trinca bem pequenos (cerca de $\Delta a<0.01 \mathrm{~mm}$ ), que geram ruído inerentes à técnica de flexibilidade, que um filtro de média resolve.

A carga de abertura de trinca $P_{a b}$ foi medida por vários métodos. Pelo método de Elber, que ajusta uma reta por mínimos quadrados na parte superior do trecho linear da curva $P$ vs. $\delta$ durante o ciclo de descarga do CP e sobrepõe a reta e a curva $P$ vs. $\delta$ num só gráfico, para achar a $P_{a b}$ onde inicia o trecho linear da curva [6]. A Figura 3.12a ilustra uma medida de $P_{a b}$ com o método proposto por Elber, numa curva idealizada. Cabe salientar que a variável $\delta$ pode ser substituída por uma medida de deformação do CP ou de abertura de boca de trinca. 
Outro método que foi empregado é subtrator de linearidade de Paris e Hermann, que usa a inclinação da linha calculada por mínimos quadrados ( $\kappa$ na Figura 3.12a) para plotar uma nova curva $[P-\kappa \delta]$ vs. $\delta$, que mostra $P_{a b}$ no ponto em que a reta horizontal inicia (Figura 3.12b) [23].

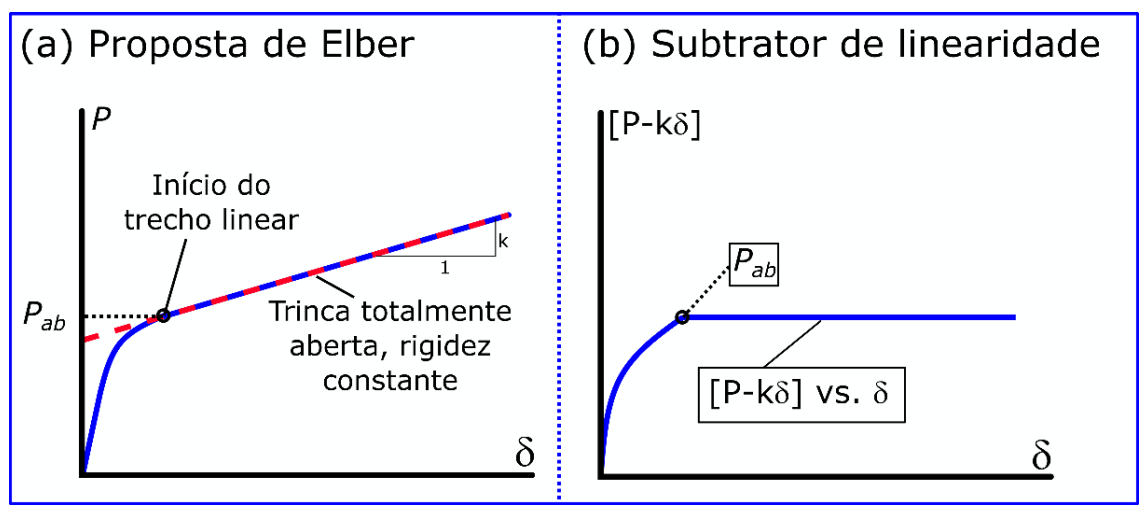

Figura 3.12: Medição da carga de abertura de trinca com o método tradicional, em uma curva idealizada.

Também foi usado o "Opening Force by the Compliance Offset Method" da ASTM [24], calculando:

$$
C O_{i}=\frac{\operatorname{Cop}-C_{i}}{\operatorname{Cop}} \cdot 100 \%
$$

onde Cop é a flexibilidade com a trinca toda aberta, determinada pela inclinação da reta calculada por mínimos quadrados no $25 \%$ da parte superior da curva $\varepsilon$ vs. $P$, durante o ciclo de descarga; $C i$ é a flexibilidade do segmento $i$, onde cada segmento tem um tamanho equivalente a $10 \%$ do intervalo de força durante o carregamento, selecionando cada novo segmento depois de um avanço de $5 \%$ na curva $\varepsilon$ vs. $P$ (Figura 3.13a); e $C O_{i}$ é o "Compliance Offset" para cada segmento $i$.

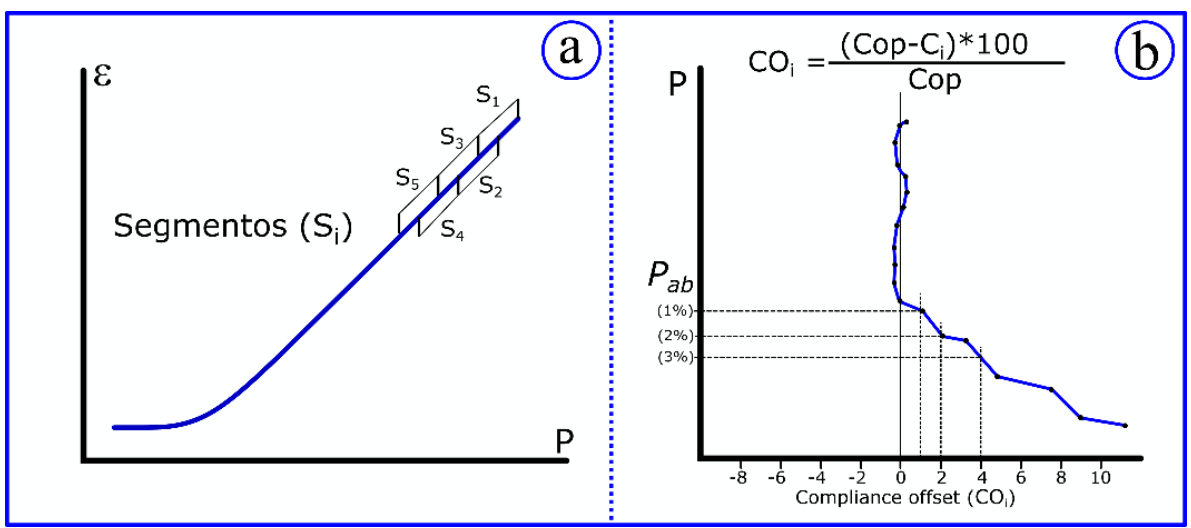

Figura 3.13: (a) Exemplo da distribuição dos segmentos $i$ e (b) medição da $\boldsymbol{P}_{a b}$ com o método da ASTM, usando um critério de deslocamento de $2 \%$. 
Com os valores de $\mathrm{CO}_{i}$ calculados para cada segmento $i$, plota-se um gráfico $P / P_{\max }$ vs. $C O_{i}$ (juntando cada par de pontos via uma linha) para escolher o critério de deslocamento e medir a $P_{a b}$, vide Figura $3.13 \mathrm{~b}$. A norma comenta sobre o uso de critérios de deslocamento de 1,2 e $4 \%$, mas recomenda o critério de $2 \%$.

\section{8.}

\section{Corpos de prova de aço AISI 1020}

Nos primeiros testes foi usada uma barra de aço AISI 1020 para fazer corpos de prova DC(T). A Figura 3.14 mostra as dimensões dos corpos de prova $\mathrm{DC}(\mathrm{T})$, a composição química do aço AISI 1020 e as propriedades mecânicas do material, que foram medidas em testes de tração seguindo a norma ASTM E8 [51].

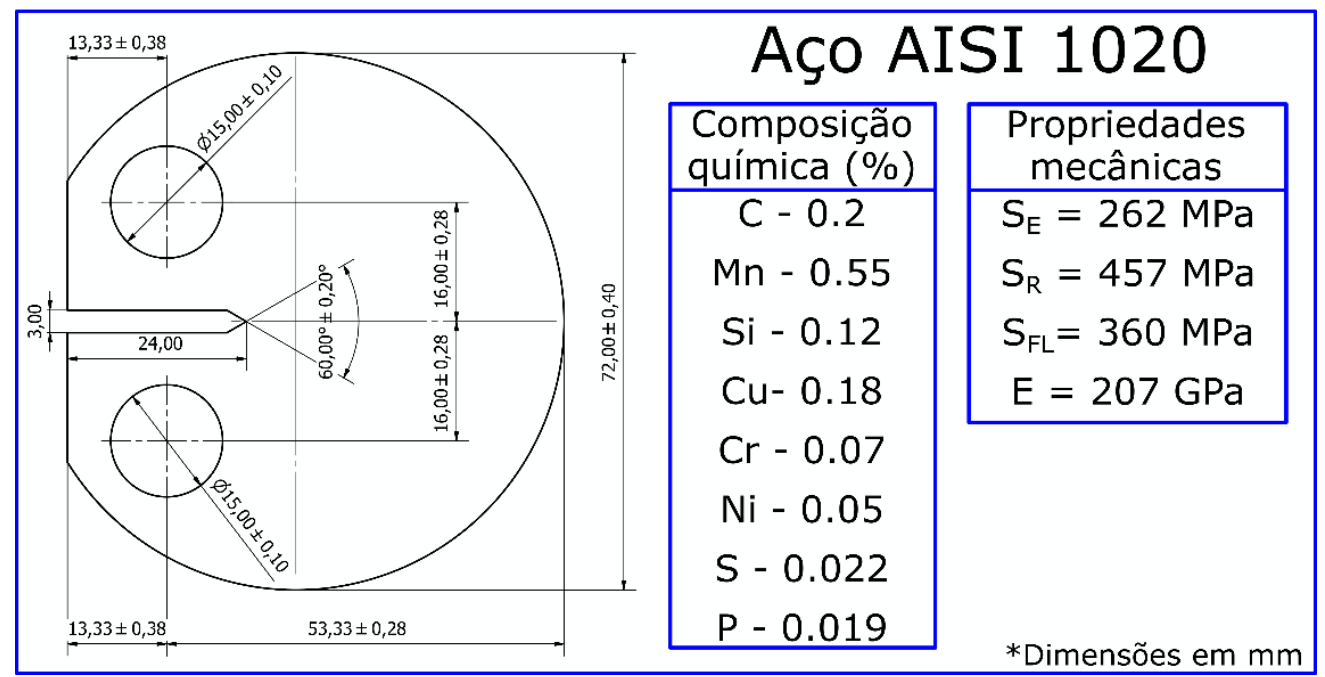

Figura 3.14: Dimensões em milímetros dos corpos de prova DC(T), composição química e propriedades mecânicas do aço AISI 1020.

Para definir as espessuras dos CPs, foram respeitados os critérios de tensão e de deformação plana da Seção 2.4. Então, sob cargas quase fixas $\{\Delta K=20 M P a \sqrt{ }$, $R=0.1\}$, corpos de prova de 2 e de $30 \mathrm{~mm}$ de espessura são apropriados para propagar a trinca sob tensão ou sob deformação plana dominante, respectivamente. As Eq. 3.5 e 2.4 mostram que a trinca no $\mathrm{CP}$ de $2 \mathrm{~mm}$ de espessura de aço AISI 1020 com $S_{E}=262 \mathrm{MPa}$ cresce em tensão plana sob $\{\Delta \mathrm{K}=20 \mathrm{MPa} \sqrt{\mathrm{m}}, \mathrm{R}=0.1\}$ :

$$
K_{\max }=\frac{\Delta K}{1-R}=22.22 \mathrm{MPa} \sqrt{m}
$$




$$
z p_{\text {max }}=\frac{K_{\text {max }}^{2}}{\pi S_{E}^{2}}=\frac{(22.22)^{2}}{\pi(262)^{2}}=2.29 \mathrm{~mm}>t=2 \mathrm{~mm}
$$

Já no CP de 30mm a trinca cresce em deformação plana dominante pelo critério da ASTM, Equação 2.5:

$$
2.5\left(\frac{K_{\max }}{S_{E}}\right)^{2}=2.5\left(\frac{22.22}{262}\right)^{2}=17.99 \mathrm{~mm}<(t=30 \mathrm{~mm})
$$

\section{9.}

\section{Corpos de prova de alumínio 6351-T6}

Para criar uma base de resultados mais robusta, foi feita uma segunda etapa de testes com corpos de prova tipo DC(T), todos usinados da mesma barra de alumínio AA 6351-T6. A ideia foi testar um material que em vez de cúbico de corpo centrado (como o aço AISI 1020), fosse cúbico de face centrada, para verificar se a microestrutura poderia alterar o comportamento da carga de abertura de trinca $P_{a b}$. A Figura 3.15 mostra as dimensões dos corpos de prova DC(T), a composição química do alumínio AA 6351-T6 e as propriedades mecânicas deste material, medidas em testes de tração seguindo a norma ASTM E8.

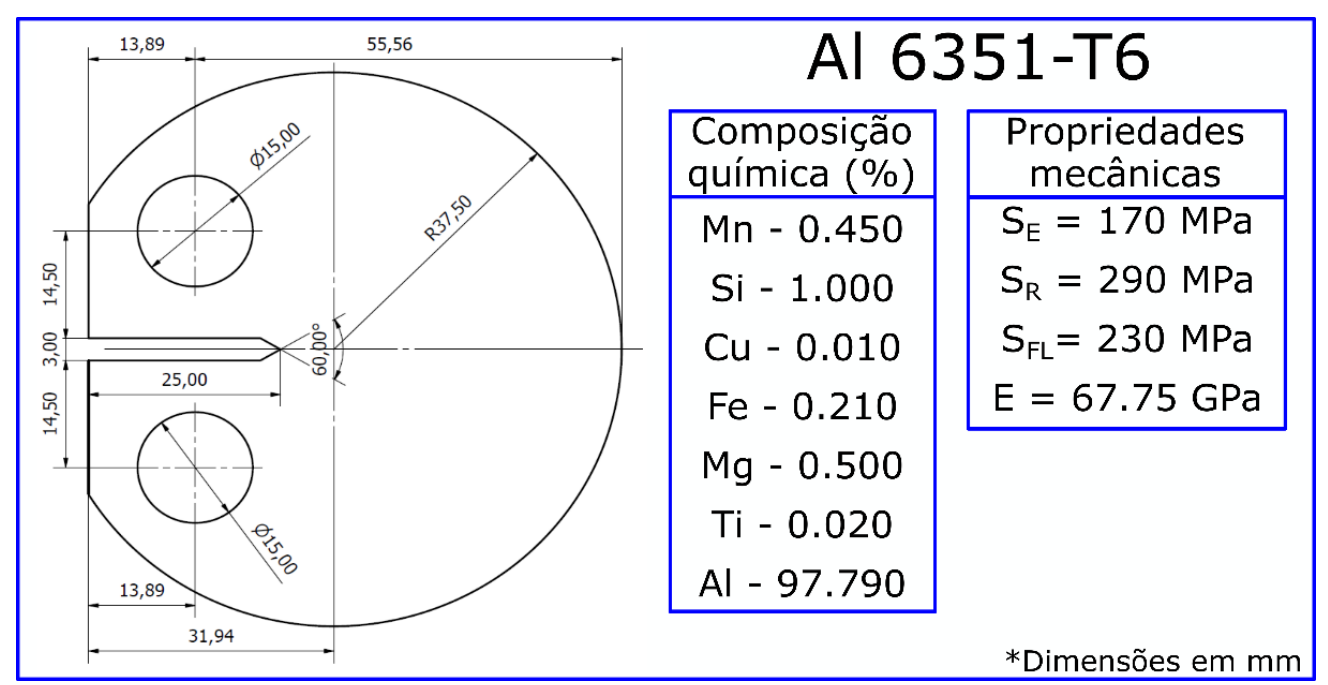

Figura 3.15: Dimensões em milímetros dos corpos de prova DC(T). Composição química e propriedades mecânicas do alumínio AA 6351-T6. 
Para definir as espessuras dos CPs, foram novamente usados os critérios de tensão e deformação plana explicados na Seção 2.4. Então, sob condições de $\Delta K$ e $K_{\max }$ quase constantes, foi estabelecido que corpos de prova de 2 e de $30 \mathrm{~mm}$ de espessura são apropriados para propagar a trinca em tensão e em deformação plana, respectivamente. Por tanto, para comprovar que no CP de $2 \mathrm{~mm}$ a trinca cresce sob tensão plana dominante se $\{\Delta K=15 \mathrm{MPa} \sqrt{ } \mathrm{m}$ e $R=0.1\}$ e $S_{E}=170 \mathrm{MPa}$, são usadas as Equações 3.5 e 2.4:

$$
\begin{gathered}
K_{\max }=\frac{\Delta K}{1-R}=16.66 \mathrm{MPa} \sqrt{\mathrm{m}} \\
z p_{\max }=\frac{K_{\max }^{2}}{\pi S_{E}^{2}}=\frac{(16.66)^{2}}{\pi(170)^{2}}=3.05 \mathrm{~mm}>(t=2 \mathrm{~mm})
\end{gathered}
$$

Já para demostrar que o $\mathrm{CP}$ de $30 \mathrm{~mm}$ propaga trincas sob deformação plana dominante segundo o critério da norma ASTM E399:

$$
2.5\left(\frac{K_{\max }}{S_{E}}\right)^{2}=2.5\left(\frac{16.66}{170}\right)^{2}=24.03 \mathrm{~mm}<t=30 \mathrm{~mm}
$$

\subsection{1.}

\section{Corpos de prova tipo $\mathrm{C}(\mathrm{T})$ de alumínio}

Para verificar se o tipo de CP poderia afetar os resultados medidos, foram usados também corpos de prova tipo C(T) de alumínio AA 6351-T6. A Figura 3.16 mostra as dimensões dos $\mathrm{C}(\mathrm{T}) \mathrm{s}$, a composição química e as propriedades mecânicas do alumínio AA 6351-T6. Cabe salientar que foi usada uma única barra de alumínio para usinar os corpos de prova $\mathrm{DC}(\mathrm{T})$ e $\mathrm{C}(\mathrm{T})$ de alumínio.

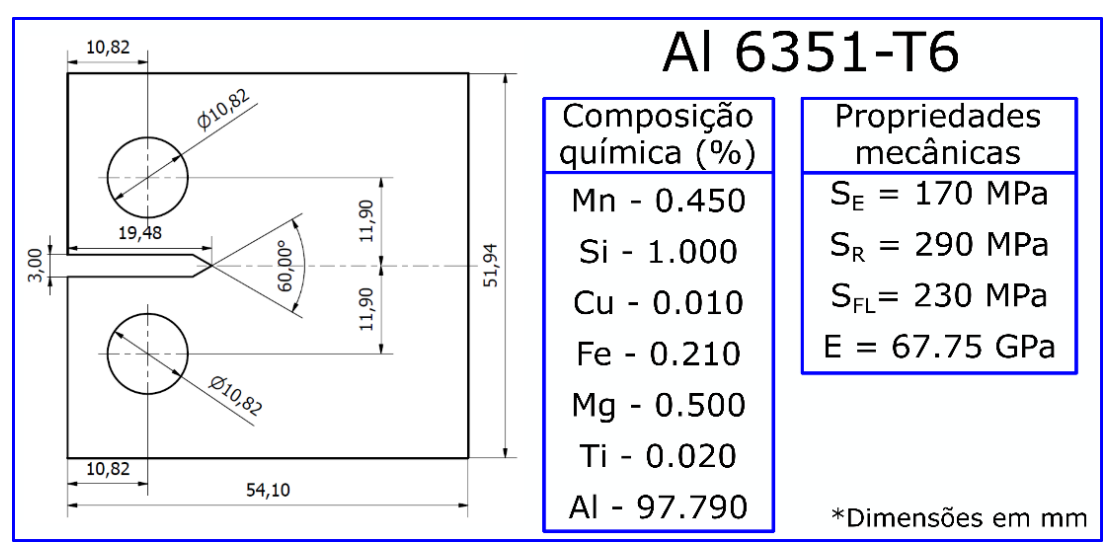

Figura 3.16: Dimensões em milímetros dos corpos de prova $C(T)$. Composição química e propriedades mecânicas do alumínio AA 6351-T6. 
Para testar os corpos de prova tipo $\mathrm{C}(\mathrm{T})$ é necessário introduzir em todos os procedimentos, o fator de intensidade de tensões para este tipo de $\mathrm{CP}(K)$. Então, a seguir se mostra a equação para calcular o $K$ em corpos tipo C(T) (Seção 3.1) [24].

$$
\begin{gathered}
K=\frac{P}{t \sqrt{w}} * \frac{\left(2+\frac{a}{w}\right)\left[0.886+4.64 \frac{a}{w}-13.32\left(\frac{a}{w}\right)^{2}+14.72\left(\frac{a}{w}\right)^{3}-5.6\left(\frac{a}{w}\right)^{4}\right]}{\left(1-\frac{a}{w}\right)^{3 / 2}} \\
\frac{a}{w}=N_{0}+N_{1} U+N_{2} U^{2}+N_{3} U^{3}+N_{4} U^{4}+N_{5} U^{5} \\
U=\frac{1}{\sqrt{-E \cdot t(\varepsilon / P) w}+1}
\end{gathered}
$$

Por outro lado, para calcular o comprimento da trinca com o extensômetro na face traseira em corpos C(T) (Seção 3.3.1), são usadas as Equações 3.15 e 3.16 e as constantes da Tabela 3-5.

Tabela 3-5: Constantes da equação que relaciona a deformação da fase traseira do corpo de prova tipo $\mathbf{C}(\mathbf{T})$, com o comprimento da trinca [24].

\begin{tabular}{|c|c|}
\hline $\boldsymbol{i}$ & Constante $\boldsymbol{\psi}_{\boldsymbol{i}}$ \\
\hline $\mathbf{0}$ & 1.0033 \\
\hline $\mathbf{1}$ & -2.35 \\
\hline $\mathbf{2}$ & 1.3694 \\
\hline $\mathbf{3}$ & -15.294 \\
\hline $\mathbf{4}$ & 63.182 \\
\hline $\mathbf{5}$ & -74.42 \\
\hline
\end{tabular}

\subsection{0.}

\section{Lista de todos os testes realizados}

A Figura 3.17 resume todos os testes que foram realizados neste trabalho com suas principais características. Para cada teste se menciona o tipo de CP ensaiado, o material, os valores de $\Delta K$ e $R$, o tipo de controle usado, as espessuras dos CPs e se especifica se foram testados dos CPs sob condições idênticas de teste. Cabe salientar que em todos os casos as condições de carga foram com $\Delta K$ e $K_{\max }$ quase constantes. 


\section{Testes com $\Delta \mathrm{K}$ e $\mathrm{K}_{\max }$ quase constantes}

\begin{tabular}{|l|}
\hline $\mathrm{DC}(\mathrm{T})$ \\
$\mathrm{R}=0.1$ \\
$\Delta \mathrm{K}=20 \mathrm{MPa} \mathrm{m}^{1 / 2}$ \\
Aço AISI 1020 \\
Controle manual \\
\hline
\end{tabular}

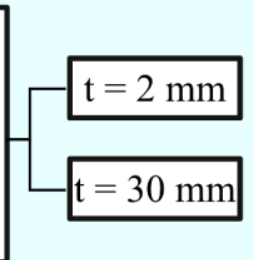

\begin{tabular}{|l|}
\hline $\mathrm{DC}(\mathrm{T})$ \\
$\mathrm{R}=0.1$ \\
$\Delta \mathrm{K}=15 \mathrm{MPa} \mathrm{m}^{1 / 2}$ \\
Aço AISI 1020 \\
Controle manual
\end{tabular}

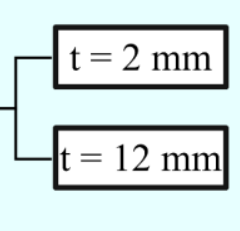

\begin{tabular}{|l|}
\hline $\mathrm{DC}(\mathrm{T}) \quad * 2$ de cada \\
$\mathrm{R}=0.1$ \\
$\Delta \mathrm{K}=15 \mathrm{MPa} \mathrm{m}^{1 / 2}$ \\
$\mathrm{Al}$ 6351-T6 \\
Controle automático
\end{tabular}
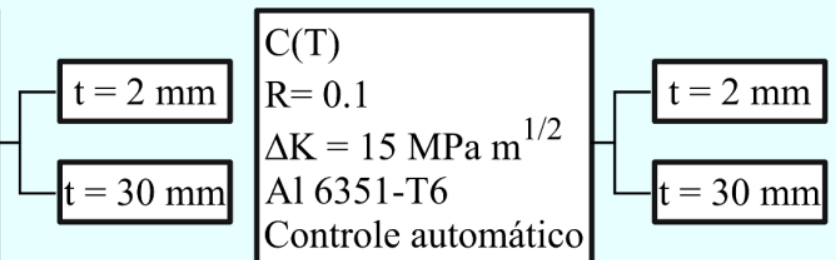

1

$\mathrm{DC}(\mathrm{T}) * 2$ de cada

$\mathrm{R}=0.1$

$\Delta \mathrm{K}=20 \mathrm{MPa} \mathrm{m}^{1 / 2}$

Aço AISI 1020

Controle manual

Testes com Sobrecarga
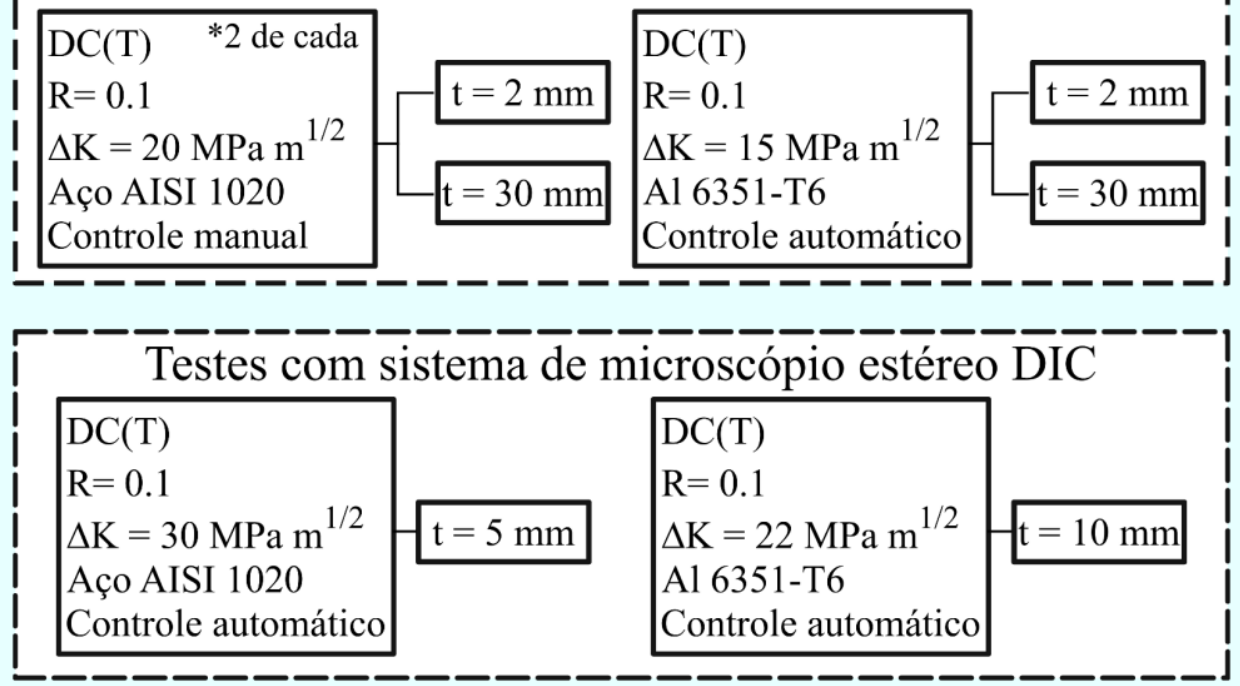

Figura 3.17: Listado de todos os testes realizados, com suas características principais. 


\section{4. \\ Resultados e discussão}

\section{1.}

\section{Primeira etapa de testes}

Os primeiros testes visaram verificar os resultados de estudos anteriores [52], que mostraram uma grande queda na razão $K_{a b} / K_{\max }$ enquanto a trinca crescia sob $\Delta K$ e $K_{\max }$ quase fixos com taxas $d a / d N$ quase constantes, mostrando que variações significativas em $\Delta K_{e f}$ não afetavam a taxa $d a / d N$, contrariando a hipótese de que $\Delta K_{e f}$ é a força motriz na propagação de trincas por fadiga. Por isso, nesta primeira etapa de testes foi usada a mesma barra de aço AISI 1020 para fazer novos corpos de prova $\mathrm{DC}(\mathrm{T})$ (Seção 3.8), e foram mantidas as condições de carregamento para fazer os novos testes sob $\Delta K$ e $K_{\max }$ quase constantes.

As medições redundantes de $P_{a b}$ foram feitas usando três métodos: (i) uma série de extensômetros colados à frente da ponta da trinca, (ii) por um extensômetro colado na face traseira do CP (Seção 3.2), e (iii) por um sistema independente de correlação digital de imagens (DIC), que mede os campos de deslocamento e de deformação na face do CP (Seção 3.2.1). As Figuras 4.1 e 4.2 ilustram esses testes.

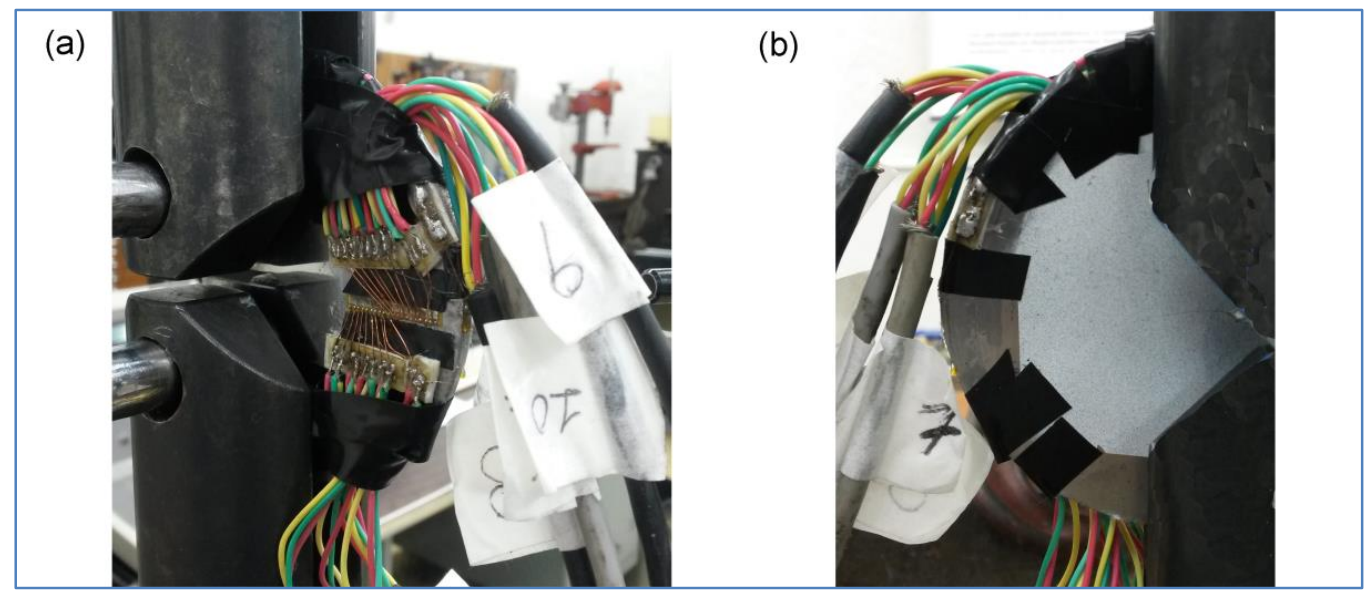

Figura 4.1: (a) Série de 10 extensômetros colados no CP à frente da ponta da trinca; (b) padrão de pontos aleatórios com contraste alto na face do CP para as medidas de DIC.

Para identificar a carga de abertura de trinca $P_{a b}$ a partir do campo de deslocamento/deformação medido por DIC, foram usadas duas técnicas: (i) a deformação de campo próximo na direção de aplicação da força $1 \mathrm{~mm}$ à frente da ponta da trinca (no ligamento residual) vide Figura 4.3a; e (ii) uma medida de abertura de trinca 
(COD) em dois pontos do campo próximo de deslocamento das faces da trinca $2 \mathrm{~mm}$ atrás da sua ponta, vide Figura 4.3b. Ou seja, a Figura 4.3 mostra um exemplo do campo de deformação (a) e do campo de deslocamento (b), na direção de aplicação da força (eixo y vertical), obtidos por DIC [53].

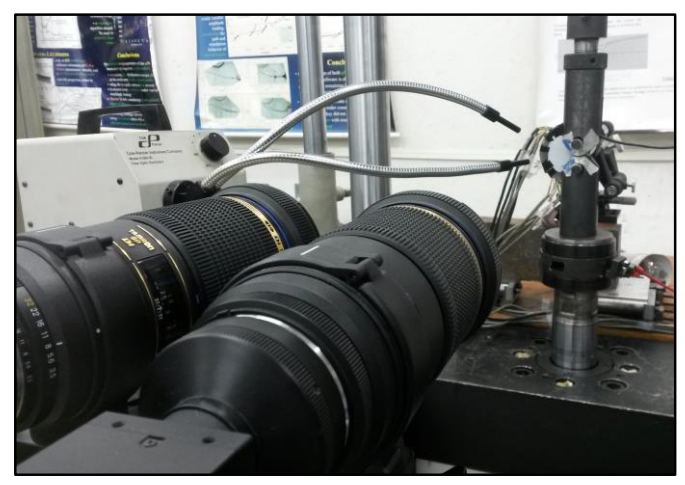

Figura 4.2: Montagem completa do ensaio de propagação de trinca, medindo a deformação do CP com DIC e com extensômetros.

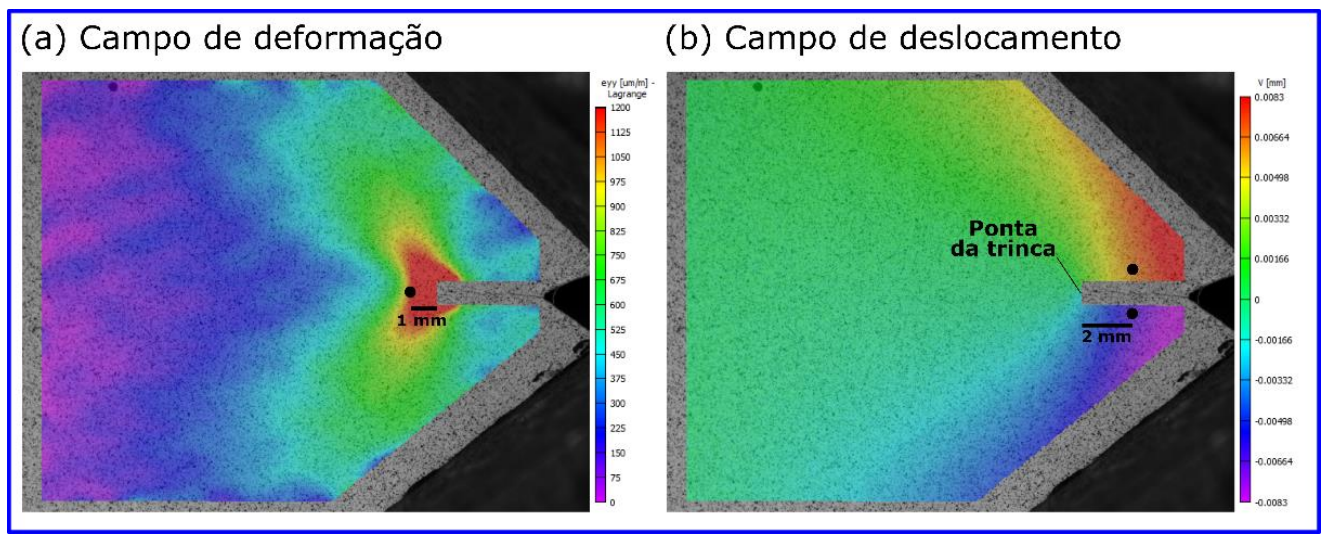

Figura 4.3: (a) campo de deformação e (b) campo de deslocamento, resultado da análise DIC na face do CP de aço AISI 1020.

As medidas de $P_{a b}$, tanto as feitas em campos de deslocamento e de deformação próximos à ponta da trinca, quanto as feitas no campo de deformação distante dela, foram sempre similares, isto é, sempre apresentaram pouca dispersão entre elas. Portanto, essas medidas confirmam que não é necessário medir $P_{a b}$ sempre próximo à ponta da trinca. As Figuras 4.4 e 4.5 mostram dois exemplos de medidas de $P_{a b}$, uma sob tensão plana e outra sob deformação plana, respectivamente.

É necessário enfatizar que essas medidas redundantes de $P_{a b}$ foram feitas usando quatro técnicas independentes: (i) a deformação do extensômetro perto da ponta da trinca (SG perto), (ii) a deformação do extensômetro na face traseira do CP (SG face traseira), (iii) a deformação obtida por DIC $1 \mathrm{~mm}$ à frente da ponta da trinca, e (iv) a abertura da trinca medida por DIC $2 \mathrm{~mm}$ atrás da ponta da trinca. 


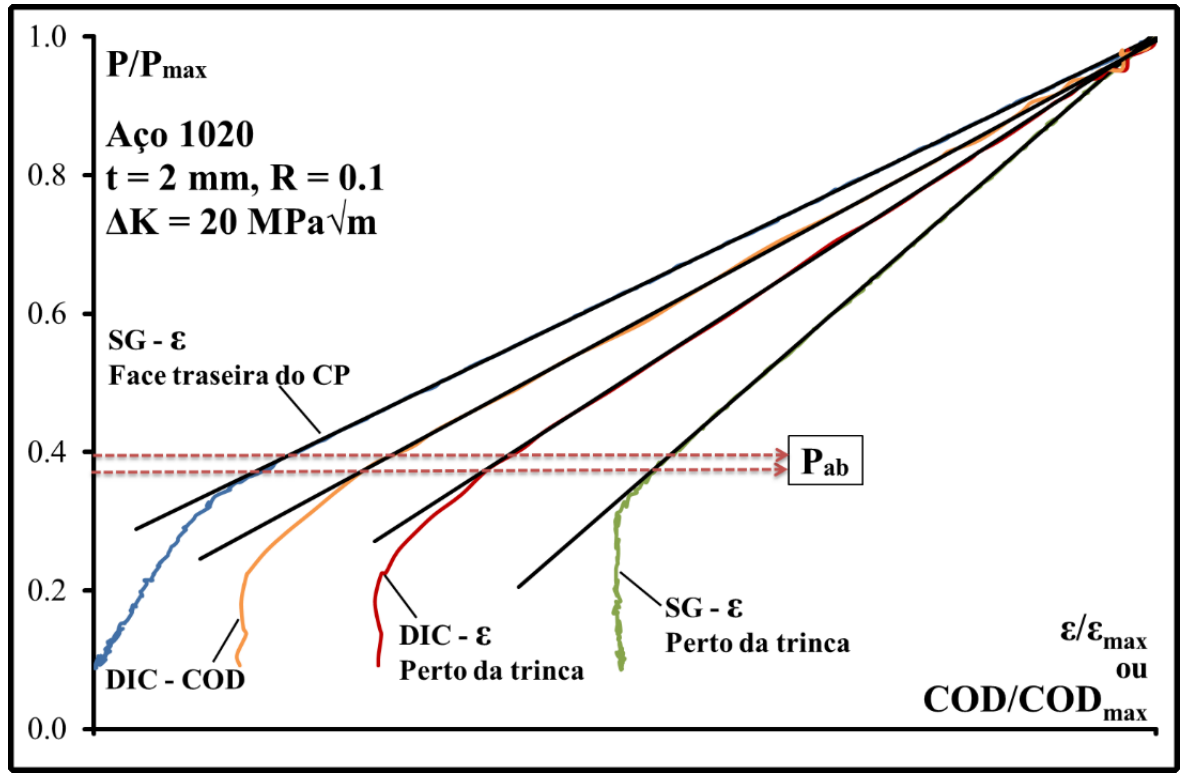

Figura 4.4: Medição de $\boldsymbol{P}_{a b}$ feita no campo próximo e no campo distante da ponta da trinca, no CP em tensão plana.

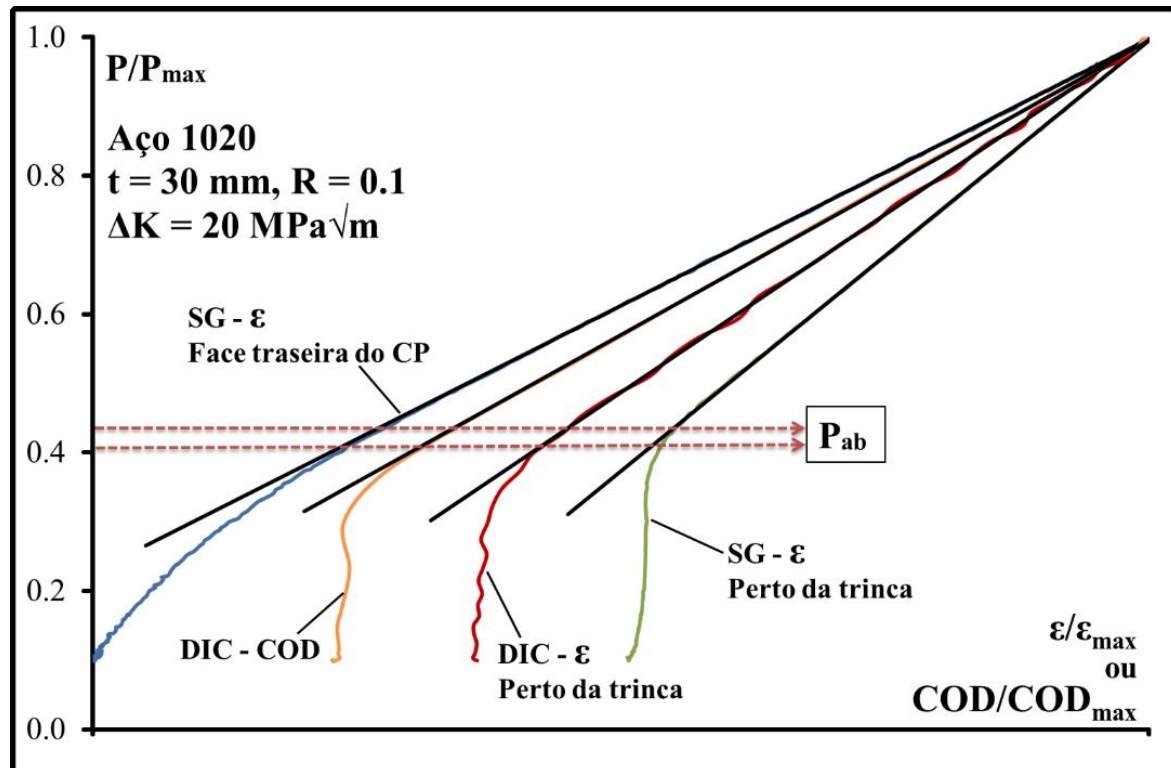

Figura 4.5: Medição de $\boldsymbol{P}_{a b}$ feita no campo próximo e no campo distante da ponta da trinca, no CP em deformação plana.

\subsection{1.}

\section{Resultados dos testes com $\Delta K$ e $K_{\max }$ quase constantes. Aço}

As Figuras 4.6 e 4.7 mostram os resultados da taxa de propagação medida nos testes feitos no trabalho anterior [52] e nos novos testes feitos durante esta pesquisa. Essas figuras apresentam dados medidos em DC(T)s de aço AISI 1020 com 2 e $30 \mathrm{~mm}$ de espessura, respectivamente. 


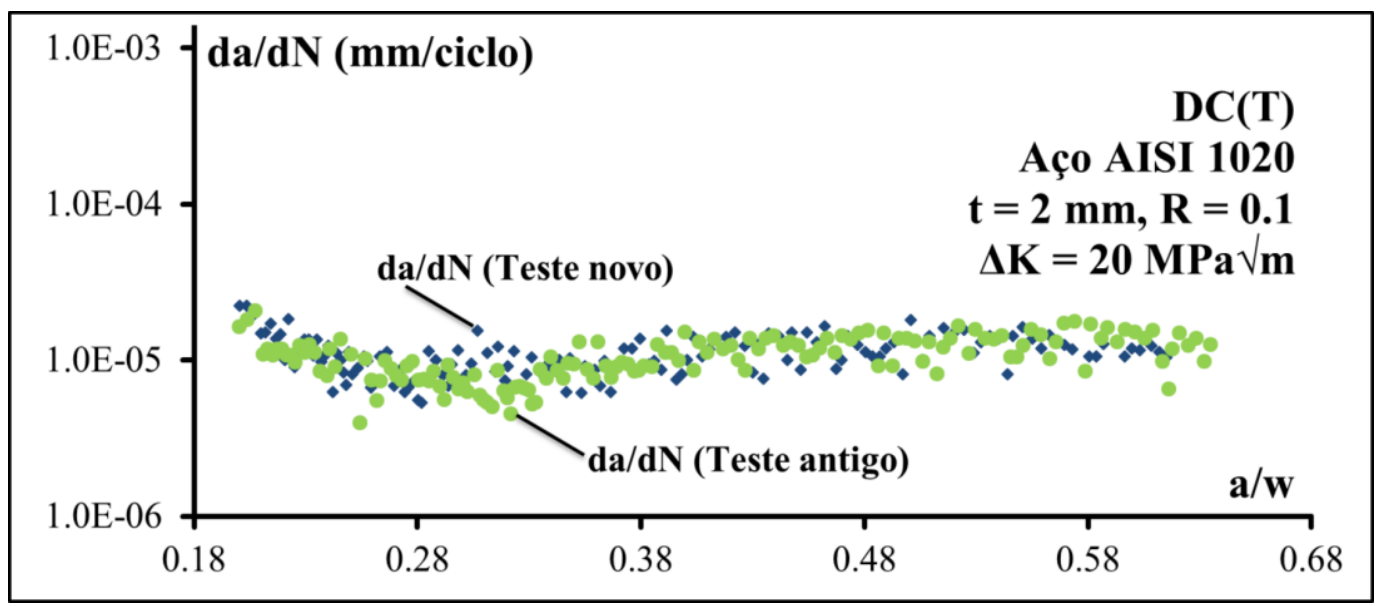

Figura 4.6: Taxas de propagação de trinca por fadiga sob $\{\Delta K, R\}$ quase constantes medidas nos testes novos e antigos em DC(T)s de aço 1020 sob tensão plana $(t=2 \mathrm{~mm})$.

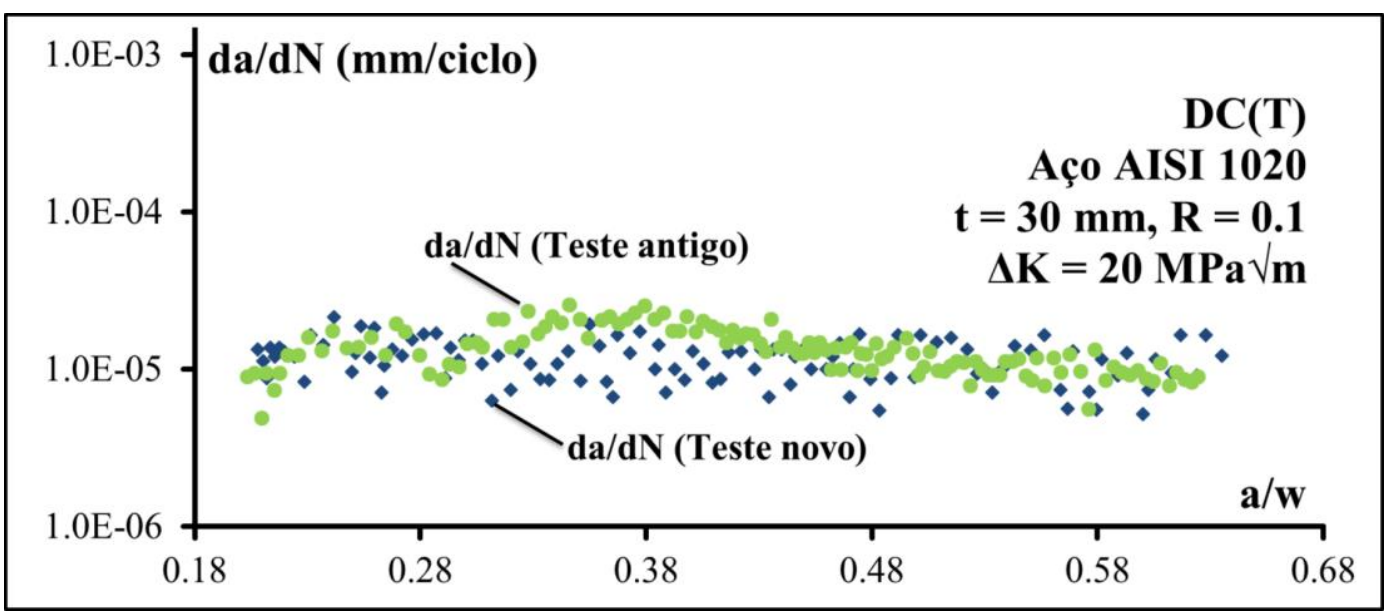

Figura 4.7: Taxas de propagação de trinca por fadiga sob $\{\Delta K, R\}$ quase constantes medidas nos testes novos e antigos em DC(T)s de aço 1020 sob deformação plana $(t=30 \mathrm{~mm})$.

Tanto nos ensaios feitos em tensão plana (Figura 4.6), quanto nos ensaios em deformação plana (Figura 4.7), as taxas de propagação de trinca por fadiga medidas sob carga $\{\Delta K=20 \mathrm{MPa} \sqrt{\mathrm{m}}, R=0.1\}$ quase constante foram similares e assim permaneceram durante todos os testes à medida que as trincas cresciam. Esses dados experimentais cuidadosamente medidos suportam a ideia de que o par $\left\{\Delta K, K_{\max }\right\}$ pode de fato ser encarado como a força motriz daquelas trincas de fadiga.

As Figuras 4.8 e 4.9, além de plotar mais uma vez as taxas de propagação $d a / d N$ relatadas acima, mostram as grandes variações das razões $K_{a b} / K_{\max }$ medidas enquanto as trincas cresciam por fadiga nos corpos de 2 e $30 \mathrm{~mm}$, respetivamente. É preciso enfatizar que essas medidas de $K_{a b}$ foram feitas por até quatro técnicas redundantes e independentes, as quais sempre geraram valores similares, como estudado no item anterior. Esse fato corrobora a qualidade dessas medições. 


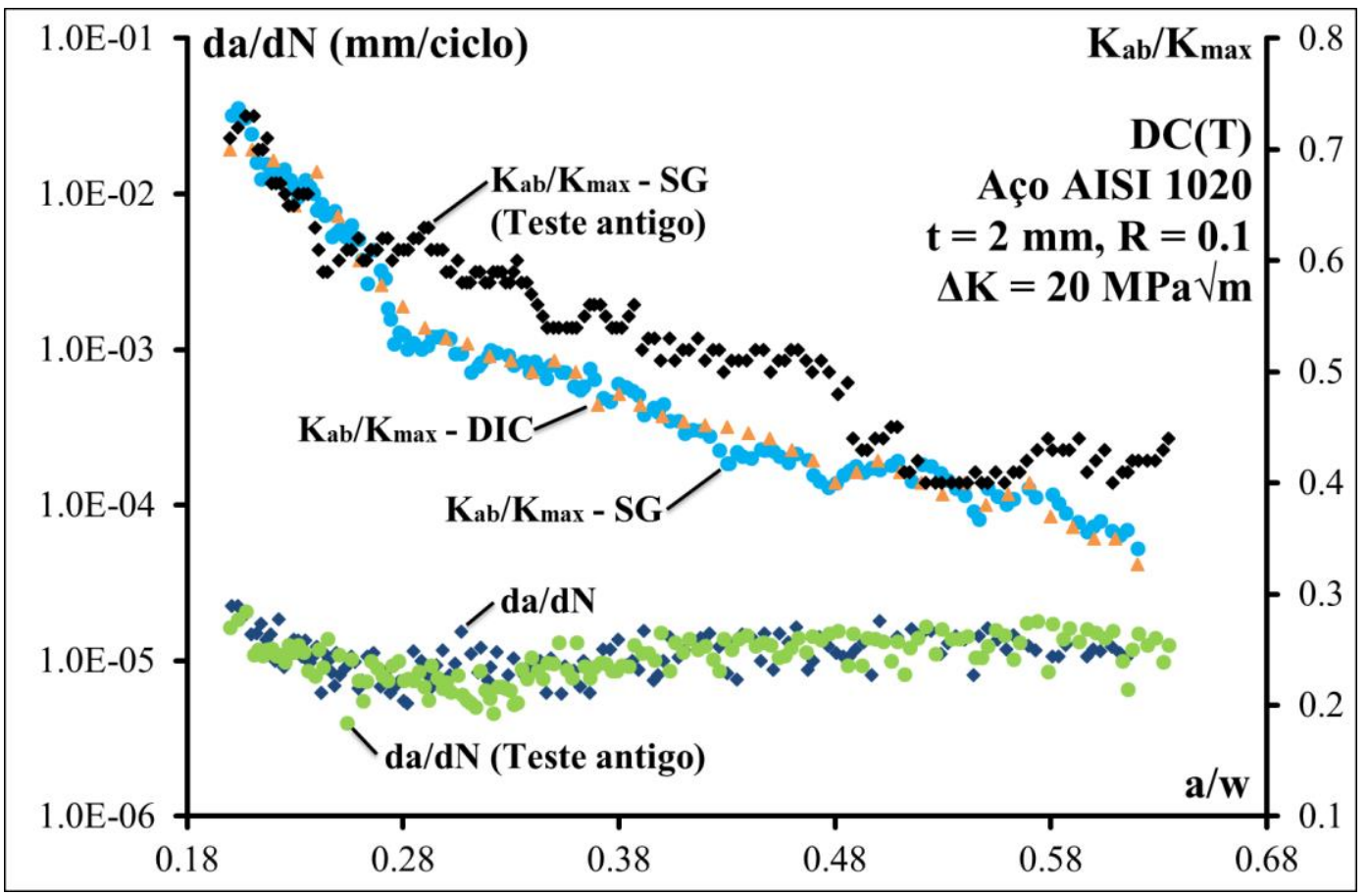

Figura 4.8: Taxas de propagação da/dN e razões $K_{a b} / K_{\max }$ medidas simultaneamente por técnicas redundantes à medida que a trinca cresce por fadiga. CPs em tensão plana.

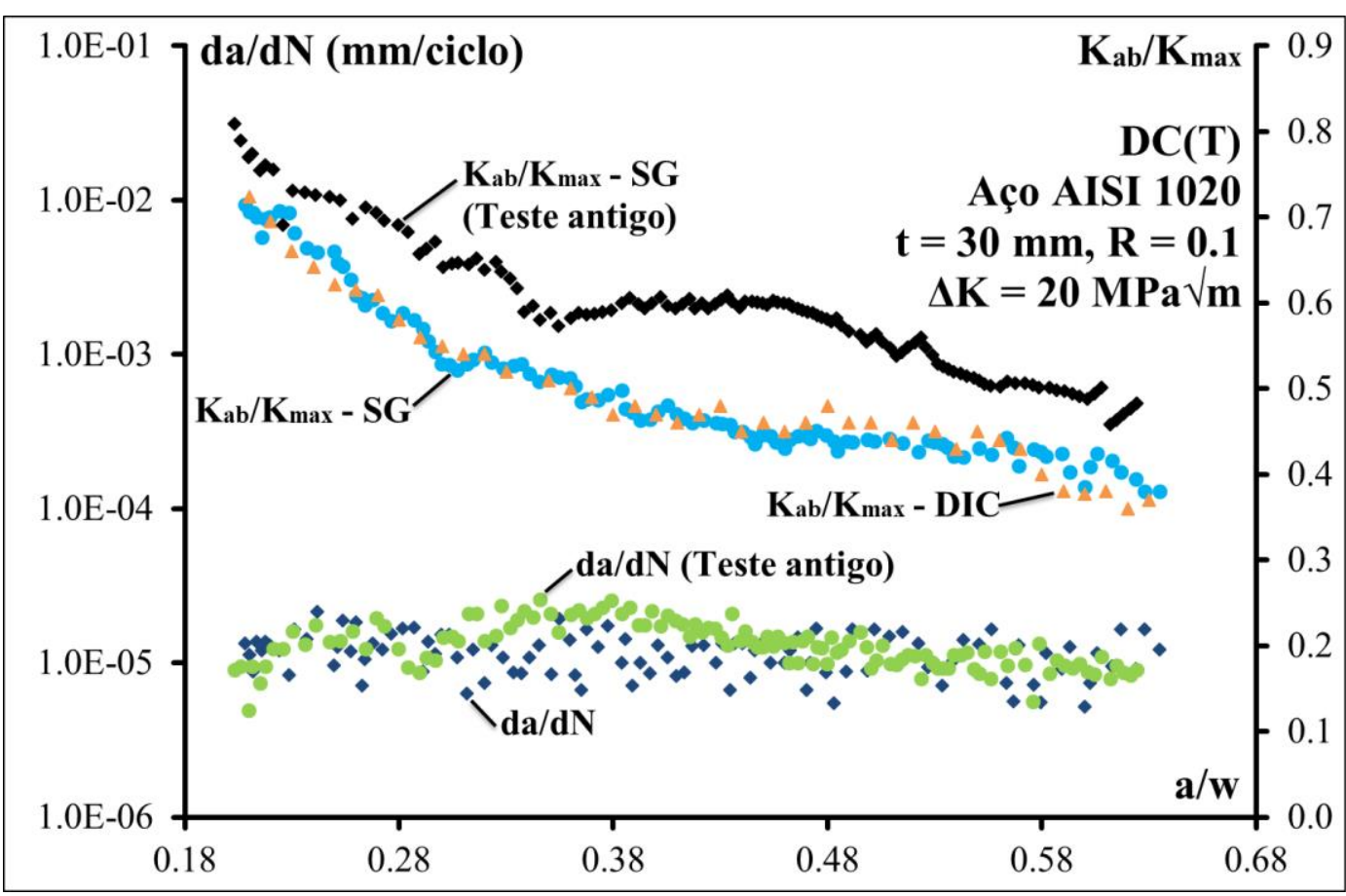

Figura 4.9: Taxas de propagação da/dN e razões $K_{a b} / K_{\max }$ medidas simultaneamente por técnicas redundantes à medida que a trinca cresce por fadiga. CPs em deformação plana.

As Figuras 4.8 e 4.9 mostram que a razão $K_{a b} / K_{\max }$ diminui sensivelmente em todos os testes à medida que a trinca cresce. Então, como $\Delta K_{e f}=K_{\max }-K_{a b}$, esta diminuição também deveria alterar as taxas de propagação medidas, caso elas fossem, como proposto por Elber, de fato controladas pela gama efetiva $\Delta K_{e f}$ e não 
pelo par $\left\{\Delta K, K_{\max }\right\}$. Todavia, como as taxas $d a / d N$ se mantiveram quase constantes em todos os testes, pode-se inequivocamente concluir que (pelo menos nesses testes) $\Delta K_{e f} \boldsymbol{n} \tilde{a} \boldsymbol{o} e ́$ a força motriz da propagação de trincas por fadiga.

Como questionamentos das ideias de Elber sempre geram controvérsias (muitas vezes exaltadas), testes adicionais foram feitos sob condições similares, exceto pelo valor do $\Delta K$ aplicado. Dois corpos de prova $\mathrm{DC}(\mathrm{T})$, um com $2 \mathrm{~mm}$ e outro com $12 \mathrm{~mm}$ de espessura foram então usados em novos ensaios de propagação de trincas por fadiga sob $\{\Delta K=15 \mathrm{MPa} \sqrt{ } m, R=0.1\}$ quase constantes. Com isso, o tamanho da maior zona plástica em tensão plana pela estimativa de Irwin muda para $K_{\max }=$ $\Delta K /(1-R)=16.66 M P a \sqrt{ } m \Rightarrow z p=(1 / \pi)\left(K_{\max } / S_{E}\right)^{2}=(1 / \pi)(16.66 / 262)^{2}=1.3 \mathrm{~mm}$, enquanto segundo o critério de deformação plana usado na norma E399 da ASTM $2.5\left(K_{\max } / S_{E}\right)^{2}=2.5(16.66 / 262)^{2}=10.11 \mathrm{~mm}<t=12 \mathrm{~mm}$.

Então, é razoável assumir que sob $\{\Delta K=15 M P a \sqrt{ } m, R=0.1\}$ as trincas de fadiga crescem sob um estado de deformação plana dominante no CP de $12 \mathrm{~mm}$ de espessura. Já no CP de $2 \mathrm{~mm}$ de espessura as trincas poderiam propagar em modo misto, ainda que quase sob tensão plana dominante, porque $t=2 \mathrm{~mm}>\mathrm{zp}=1.3 \mathrm{~mm}$, mas essa espessura não chega a ser muito maior do que o tamanho da $z p$. Os resultados desses testes são mostrados nas Figuras 4.10 e 4.11.

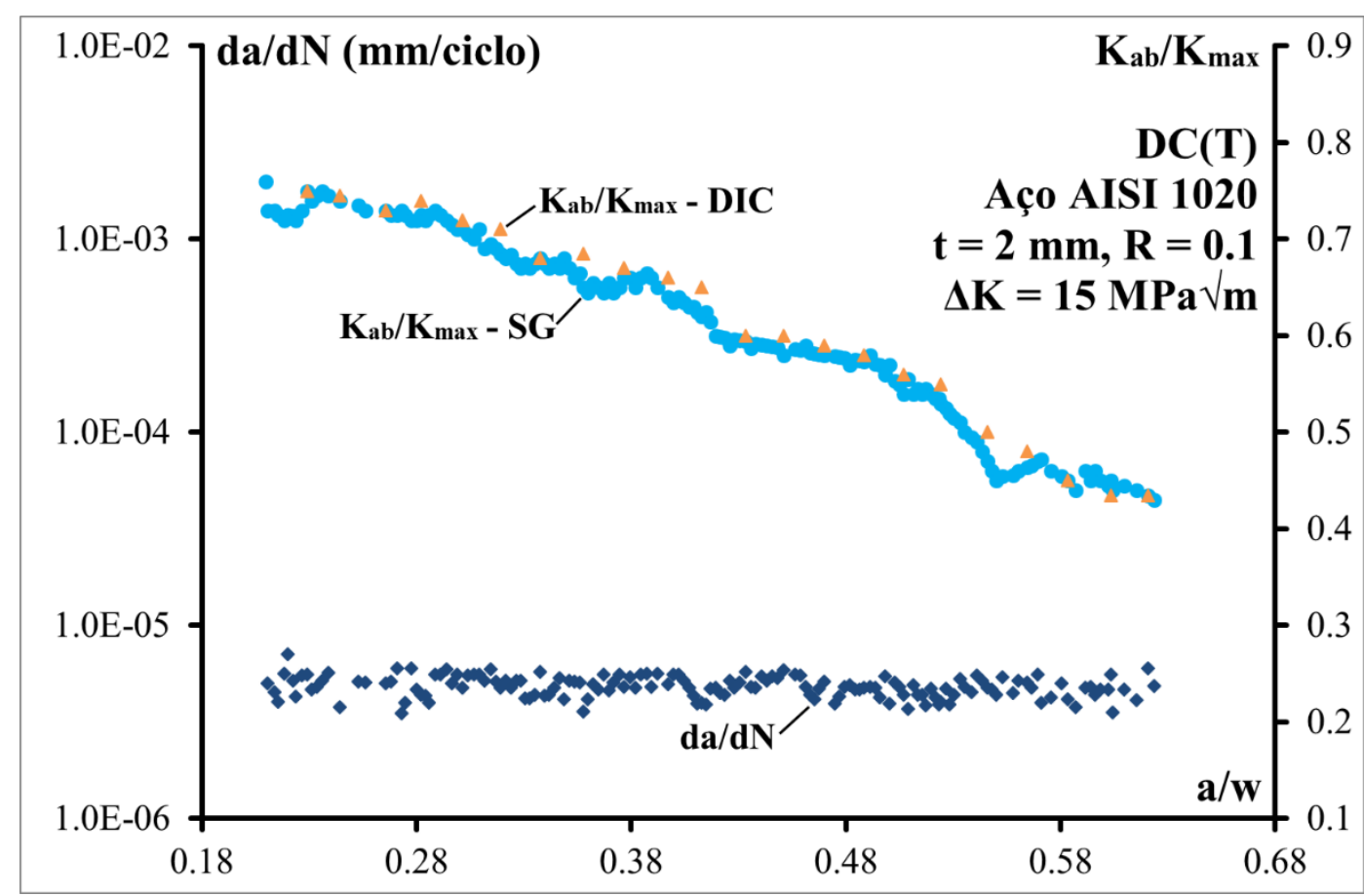

Figura 4.10: Taxas de propagação da/dN e razões $K_{a b} / K_{\max }$ medidas simultaneamente por técnicas redundantes à medida que a trinca cresce por fadiga sob $\triangle K=15 \mathrm{MPa} \sqrt{\mathrm{m}}_{\mathrm{m}}$ no $\mathrm{CP}$ de $2 \mathrm{~mm}$ de espessura. 


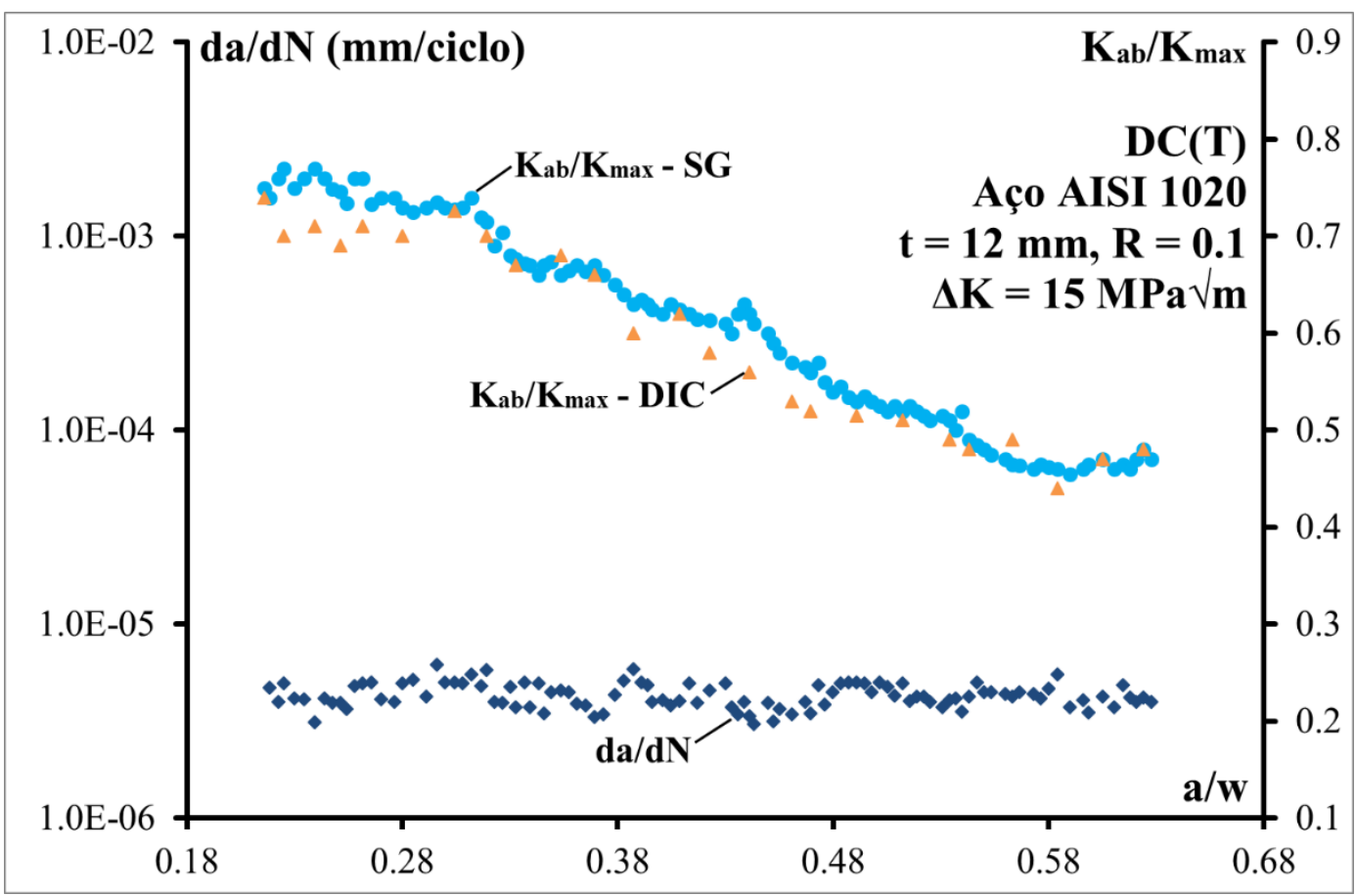

Figura 4.11: Taxas de propagação da/dN e razões $K_{a b} / K_{\max }$ medidas simultaneamente por técnicas redundantes à medida que a trinca cresce por fadiga sob $\Delta K=15 \mathrm{MPa} \sqrt{\mathrm{m}}$, sob condições de deformação plana dominante no CP de $12 \mathrm{~mm}$ de espessura.

Esses resultados adicionais suportam mais uma vez a ideia de que um par $\left\{\Delta K, K_{\max }\right\}$ quase constante gera taxas de propagação de trincas por fadiga $d a / d N$ quase fixas, mesmo se tendo medido (por técnicas redundantes e independentes) uma queda não desprezível na razão $K_{a b} / K_{\max }$ ao longo do crescimento da trinca. Portanto, também nesses testes pode-se afirmar que $\Delta K_{\text {ef }} \boldsymbol{n} \tilde{\boldsymbol{a} o} \boldsymbol{e} \dot{\boldsymbol{e}}$ a força motriz da propagação de trincas por fadiga.

\section{2.}

\section{Segunda etapa de testes}

Para criar uma base de resultados mais robusta, foi feita mais uma etapa de testes, mantendo a maioria dos procedimentos e condições experimentais, com algumas exceções. Primeiro, nos testes mostrados até agora, as cargas na máquina servohidráulica eram mudadas manualmente cada vez que o tamanho da trinca aumentava aproximadamente $\Delta a \cong 0.1 \mathrm{~mm}$. Porém nesta nova etapa, todos os testes foram feitos com um programa de malha fechada, que automaticamente controlava as cargas para manter condições de $\left\{\Delta K, K_{\max }\right\}$ quase constantes, medindo a trinca com o extensômetro na face traseira do CP, como descrito na Seção 3.4.1. 
Os corpos de prova também foram do tipo $\mathrm{DC}(\mathrm{T})$, todos usinados da mesma barra de material, só que neste caso foi usada uma barra de alumínio AA 6351-T6. As propriedades do alumínio e as dimensões dos corpos de prova, incluindo a escolha das espessuras para manter condições de tensão plana e deformação plana, estão na Seção 3.9.

Para medir $P_{a b}$ foram usados os mesmos sistemas de campo próximo e campo distante dos testes anteriores. Portanto, medições redundantes de $P_{a b}$ foram feitas usando uma série de extensômetros colados à frente da ponta da trinca (SG), por um extensômetro colado na face traseira do CP (Seção 3.2), e por um sistema independente de correlação digital de imagens (DIC), que mede os campos de deslocamento e de deformação na face do CP (Seção 3.2.1). A Figura 4.12 mostra um campo de deformação (a) e o campo de deslocamento que o gera (b), medidos na direção de aplicação da força (eixo y vertical) via DIC. A Figura 4.12 também indica os pontos que foram usados para medir $P_{a b}$ com estes campos; um ponto de deformação $1 \mathrm{~mm}$ à frente da ponta da trinca e dois pontos de deslocamento $2 \mathrm{~mm}$ atrás da ponta da trinca (usados para medir COD).

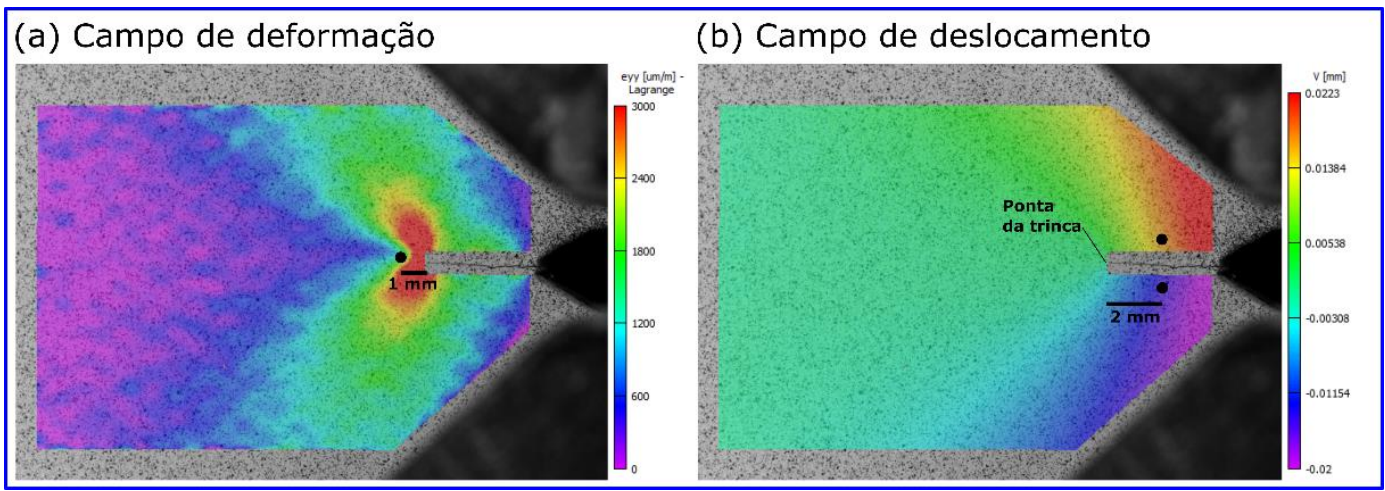

Figura 4.12: (a) campo de deformação e (b) campo de deslocamento, resultantes da análise DIC na face do CP de alumínio AA 6351-T6.

\subsection{1.}

\section{Testes sob $\Delta K$ e $K_{\max }$ quase constantes na liga de Al 6351-T6}

As Figuras 4.13 e 4.14 mostram as taxas de propagação $d a / d N$ medidas nos testes sob $\Delta K$ e $K_{\max }$ quase constantes nos CPs de alumínio de 2 e $30 \mathrm{~mm}$ de espessura, respectivamente. Foram testados dois corpos de prova de cada espessura. As taxas medidas mostram que o programa de ciclo fechado de fato consegue um controle dos testes mais fino, uma vez que a dispersão ou o ruído das taxas medidas 
diminuiu sensivelmente quando comparadas com as taxas medidas sob controle manual. A repetitividade dos testes foi de fato bastante boa, pois as diferenças nas taxas medidas sob tensão e deformação plana são desprezíveis.

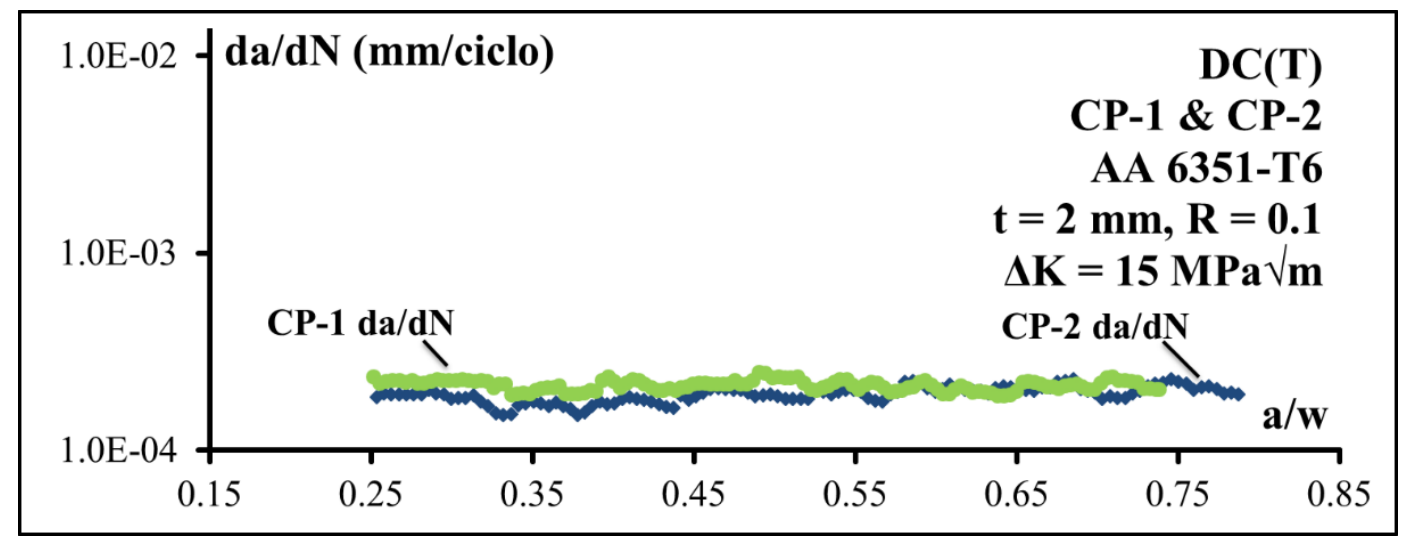

Figura 4.13: Taxas de propagação medidas nos CPs de alumínio com $2 \mathrm{~mm}$ de espessura.

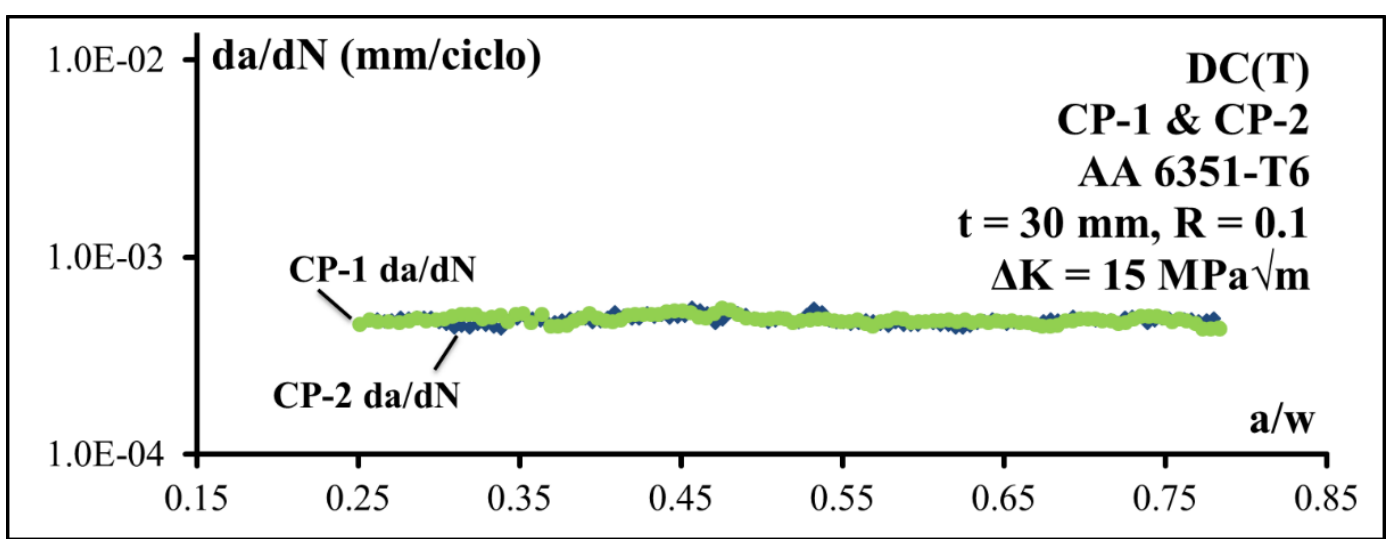

Figura 4.14: Taxas de propagação medidas nos CPs de alumínio com 30mm de espessura.

Apesar de uma maior dispersão dos dados, nos testes dos CPs de aço AISI 1020 (Seção 4.1) não se observou uma diferença significativa entre as taxas medidas em tensão e em deformação plana, que foi em média $1.0 \times 10^{-5} \mathrm{~mm} /$ ciclo para $\Delta \mathrm{K}$ $=20 \mathrm{MPa} \sqrt{\mathrm{m}}$ e $4.5 \times 10^{-6} \mathrm{~mm} /$ ciclo para $\triangle K=15 \mathrm{MPa} \sqrt{\mathrm{m}}$. Já nos resultados dos testes em CPs de alumínio, observou-se uma diferença maior entre a média das taxas medidas nos CPs de $2 \mathrm{~mm}\left(1,9 \times 10^{-4} \mathrm{~mm} /\right.$ ciclo $)$ e nos CPs de $30 \mathrm{~mm}\left(4,8 \times 10^{-4} \mathrm{~mm} /\right.$ ciclo $)$, evidenciada pela menor dispersão dos dados medidos sob controle automatizado de $\Delta K$ e $K_{\max }$.

As Figuras 4.15 e 4.16 mostram a razão $K_{a b} / K_{\max }$ e as taxas $d a / d N$ medidas simultaneamente nos CPs de alumínio à medida que a trinca cresce por fadiga sob estados de tensão e de deformação plana dominantes, respectivamente. Como no caso do aço 1020, os testes dos CPs de alumínio também mostram uma queda pronunciada da razão $K_{a b} / K_{\max }$ à medida que a trinca cresce, tanto em tensão como em 
deformação plana. Este comportamento, é claro, não pode ser explicado pela clássica hipótese elberiana "as taxas da/dN são controladas por $\Delta K_{e f}$ ", porque a taxa $d a / d N$ permaneceu essencialmente constante durante todos os testes (feitos sob $\Delta K$ e $K_{\max }$ quase constante, com ajuste automatizado da carga).

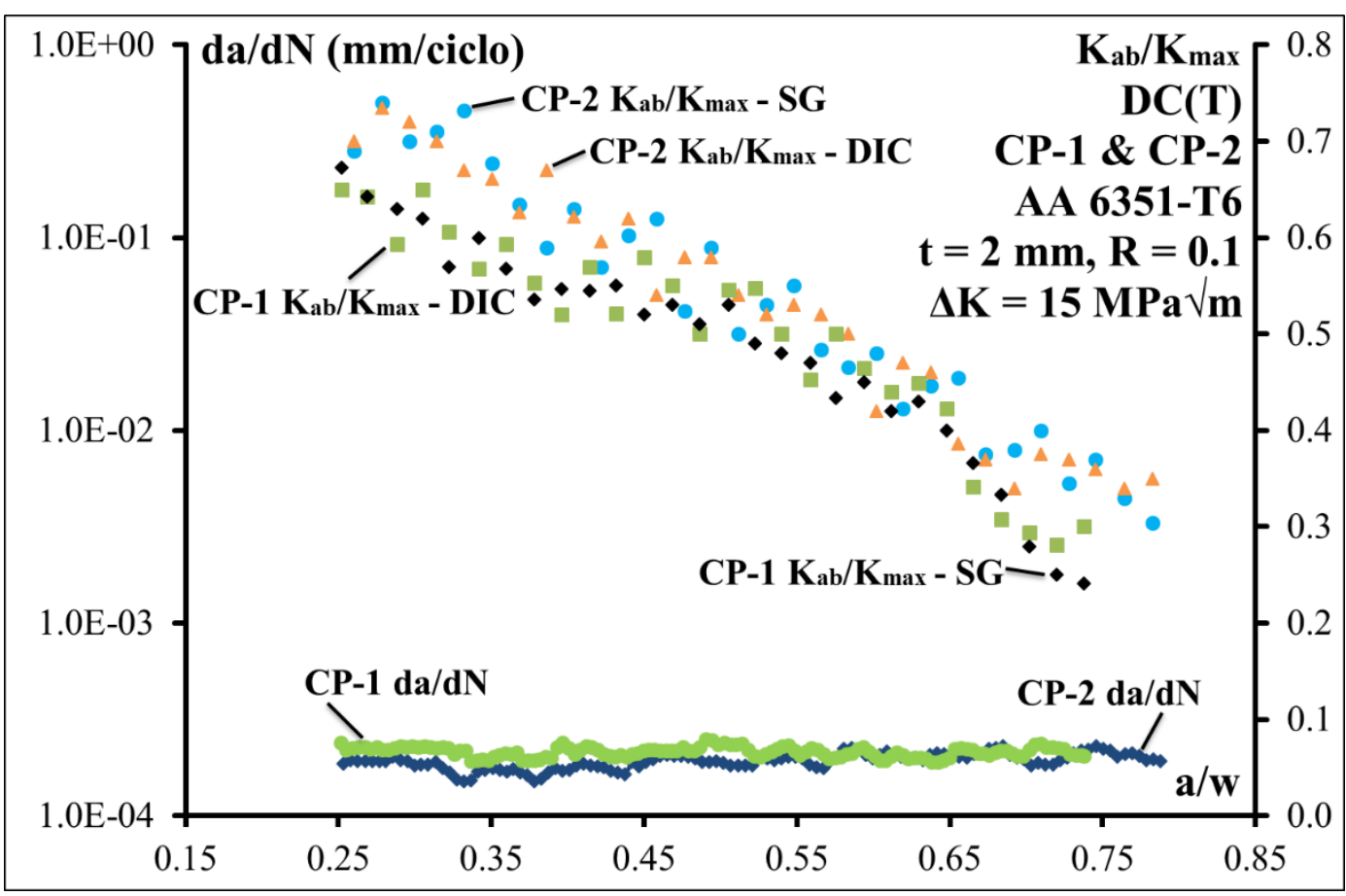

Figura 4.15: Taxas de propagação $d a / d N$ e razões $K_{a b} / K_{\max }$ medidas nos testes em DC(T)s de alumínio sob tensão plana.

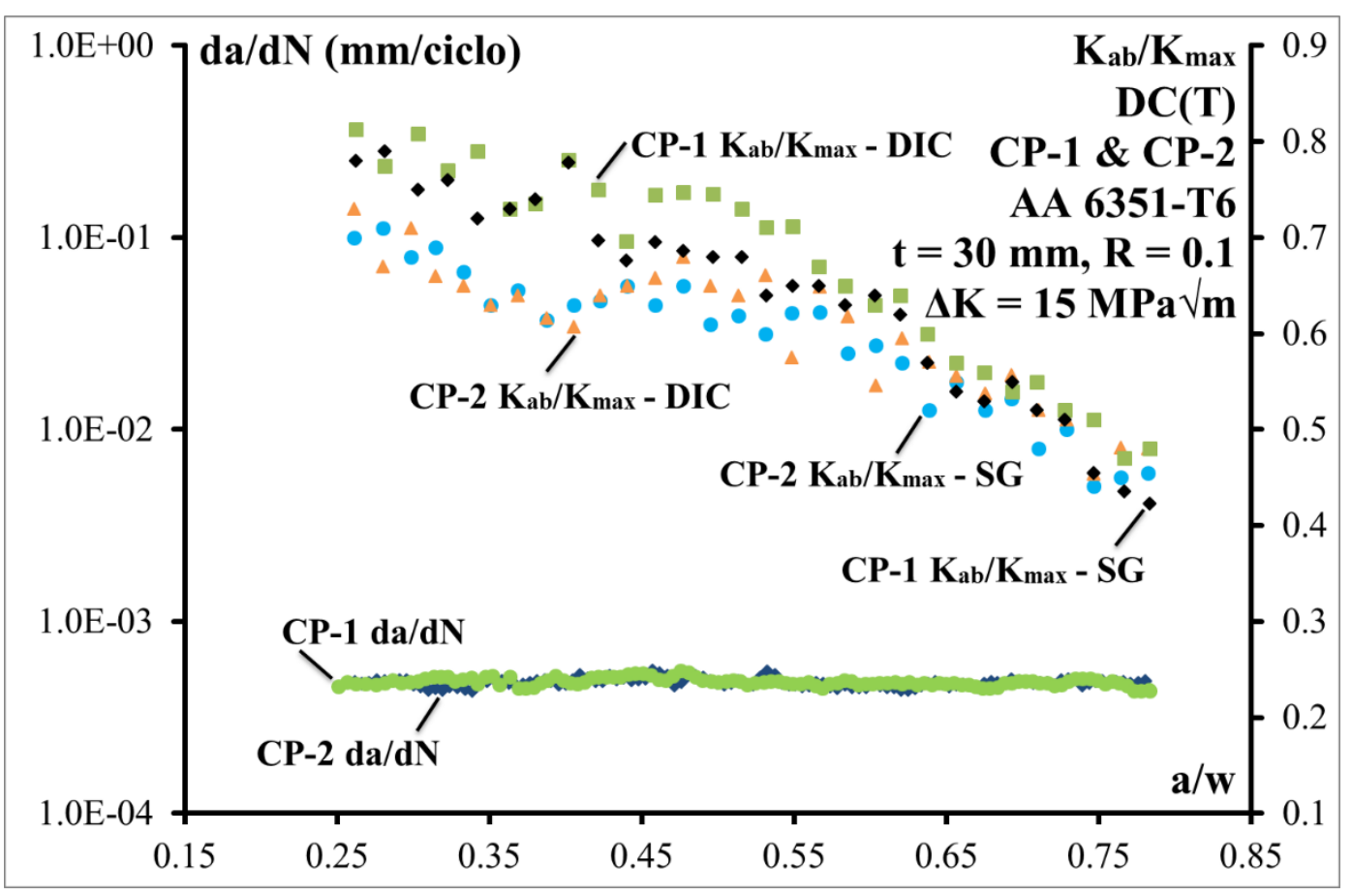

Figura 4.16: Taxas de propagação $d a / d N$ e razões $K_{a b} / K_{\max }$ medidas nos testes em DC(T)s de alumínio sob deformação plana. 
Para verificar se o tipo de CP poderia afetar os resultados medidos, novos testes foram feitos sob as mesmas condições dos testes anteriores, só que desta vez usando corpos de prova tipo C(T) de alumínio AA 6351-T6. Na Seção 3.9.1 se mostram as dimensões dos $\mathrm{C}(\mathrm{T}) \mathrm{s}$, a composição química e as propriedades mecânicas do alumínio AA 6351-T6. Cabe salientar que foi usada uma única barra de alumínio para usinar os corpos de prova $\mathrm{DC}(\mathrm{T})$ e $\mathrm{C}(\mathrm{T})$ de alumínio.

Para medir $P_{a b}$ nos C(T)s foram usados os mesmos métodos dos testes feitos em corpos DC(T): (i) a deformação do extensômetro perto da ponta da trinca (SG perto); (ii) a deformação do extensômetro na face traseira do CP (SG face traseira); (iii) a deformação medida por DIC $1 \mathrm{~mm}$ à frente da ponta da trinca; e (iv) a abertura das faces da trinca medida por DIC $2 \mathrm{~mm}$ atrás da sua ponta. As Figuras 4.17 e 4.18 mostram a razão $K_{a b} / K_{\max }$ e a taxa $d a / d N$ medidas nos $\mathrm{C}(\mathrm{T})$ s de alumínio sob tensão e deformação plana, respectivamente.

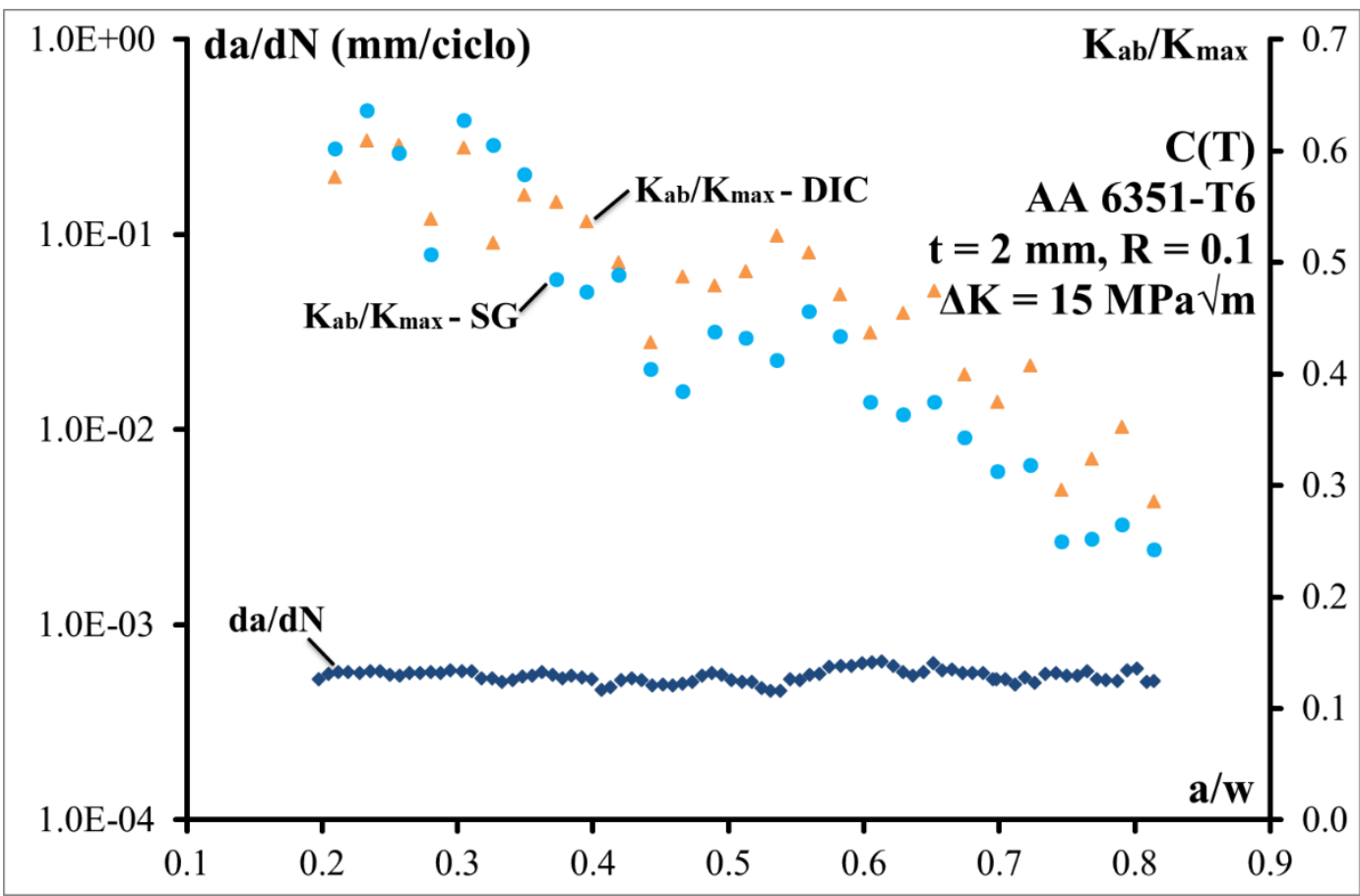

Figura 4.17: Taxas de propagação $d a / d N$ e razões $K_{a b} / K_{\max }$ medidas nos testes em C(T)s de alumínio sob tensão plana.

As taxas de propagação $(d a / d N)$ medidas nesses $\mathrm{C}(\mathrm{T})$ s são quase constantes, tanto em tensão como em deformação plana, apesar da queda significativa na razão $K_{a b} / K_{\max }$ à medida que a trinca cresce. Logo, esta queda não é causada pela geometria do $\mathrm{CP}$, pois nos $\mathrm{DC}(\mathrm{T}) \mathrm{s}$ foram obtidos resultados similares. 
Para enfatizar ainda mais que estes resultados não podem ser explicados pela hipótese do fechamento induzido por plasticidade, as Figuras 4.19 e 4.20 plotam a relação $d a / d N$ vs. $\Delta K_{e f}$ medidas nos testes em DC(T)s de alumínio sob tensão e sob deformação plana dominante, respectivamente. A mesma relação $d a / d N$ vs. $\Delta K_{e f}$ é mostrada nas Figuras 4.21 e 4.22 para os corpos tipo C(T), medidas em testes de propagação de trinca por fadiga sob condições de tensão e de deformação plana dominante, respectivamente.

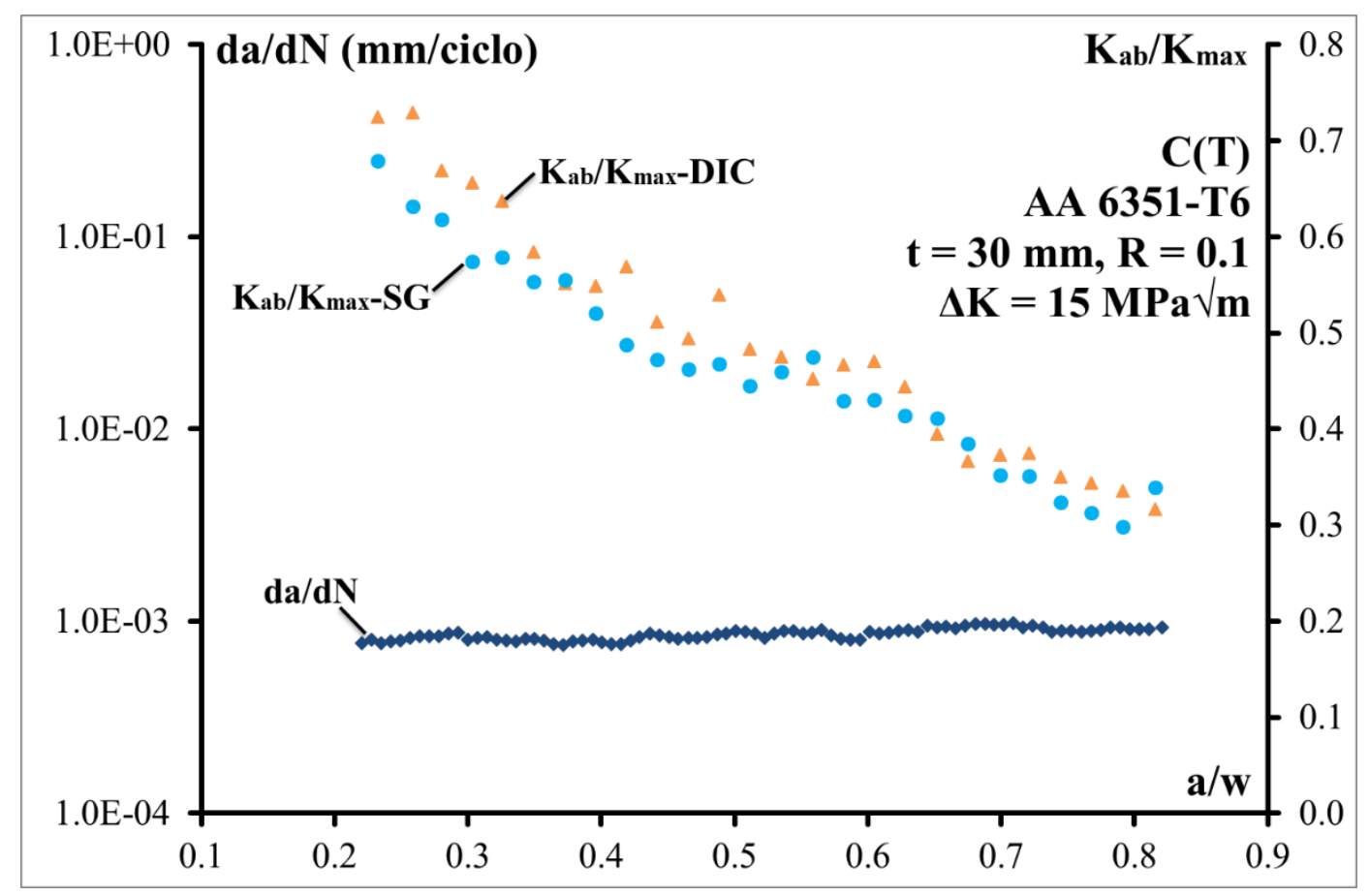

Figura 4.18: Taxas de propagação $d a / d N$ e razões $K_{a b} / K_{\max }$ medidas nos testes em C(T)s de alumínio sob deformação plana.

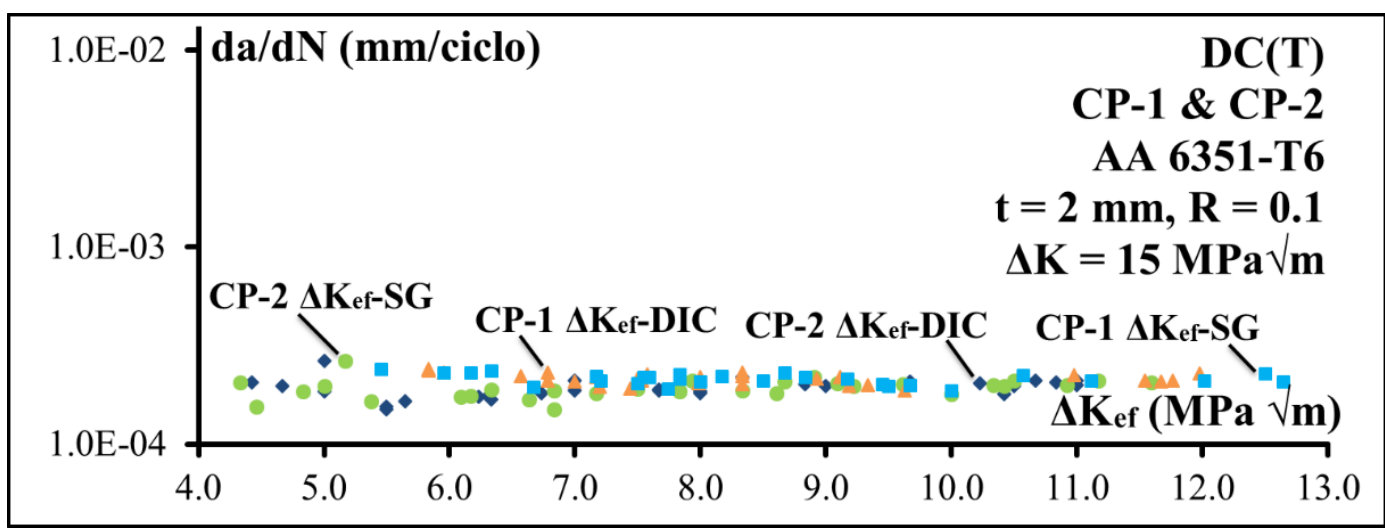

Figura 4.19: Taxas $d a / d N$ vs. $\Delta K_{e f}$ medidas em DC(T)s de Al sob tensão plana. 


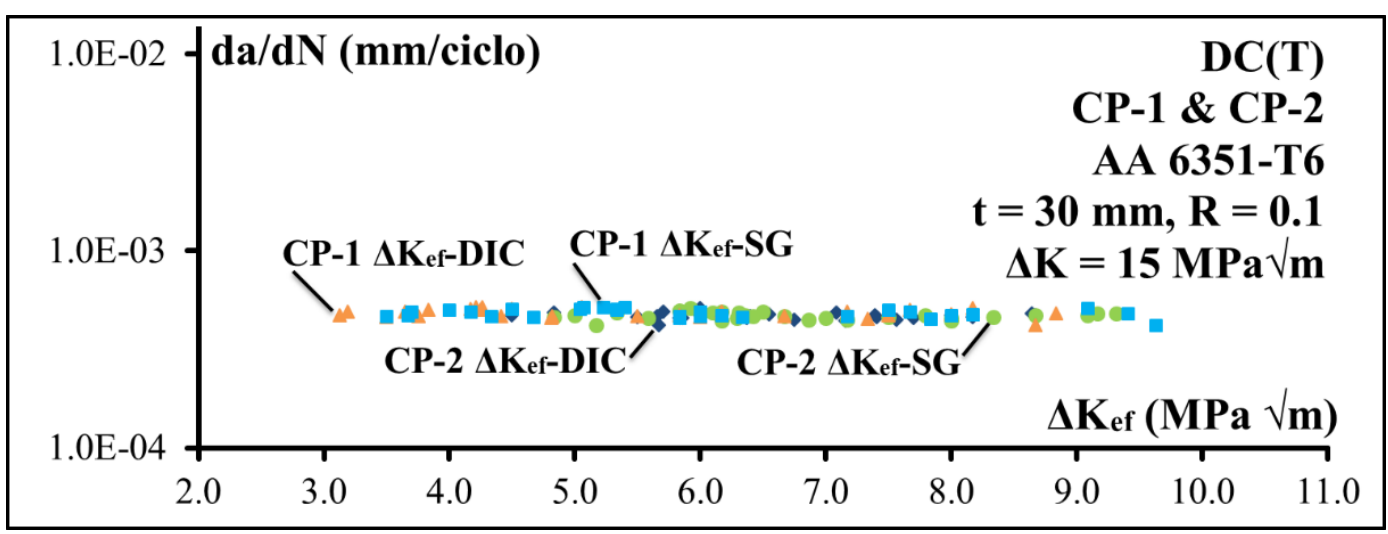

Figura 4.20: Taxas $d a / d N$ vs. $\Delta K_{e f}$ medidas em DC(T)s de Al sob deformação plana.

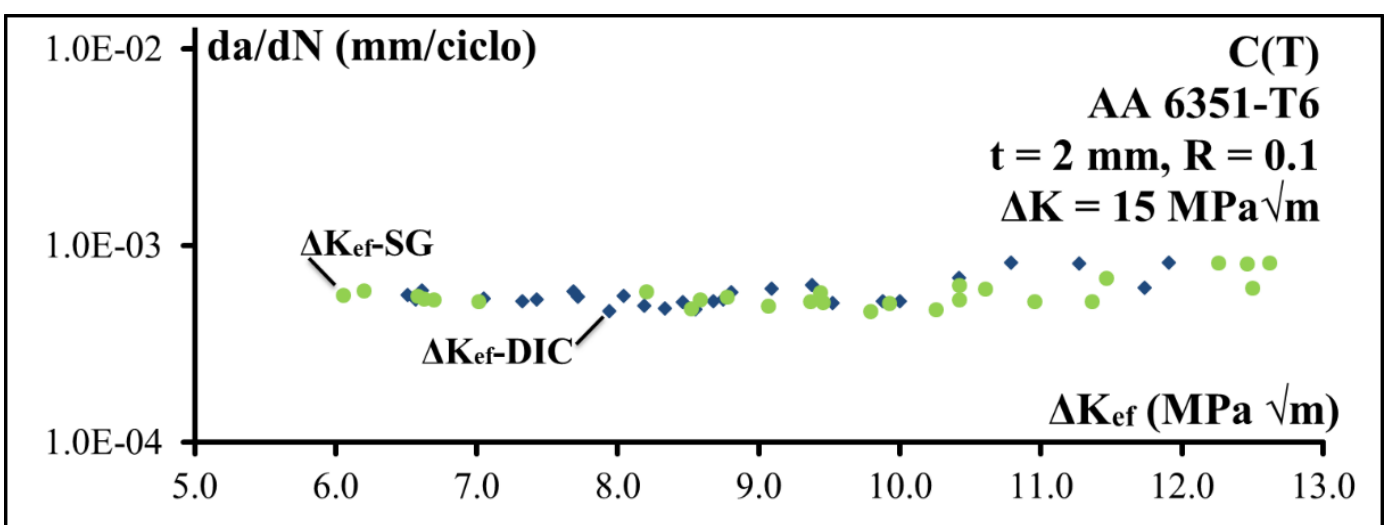

Figura 4.21: Taxas $d a / d N$ vs. $\Delta K_{e f}$ medidas em C(T)s de Al sob tensão plana.

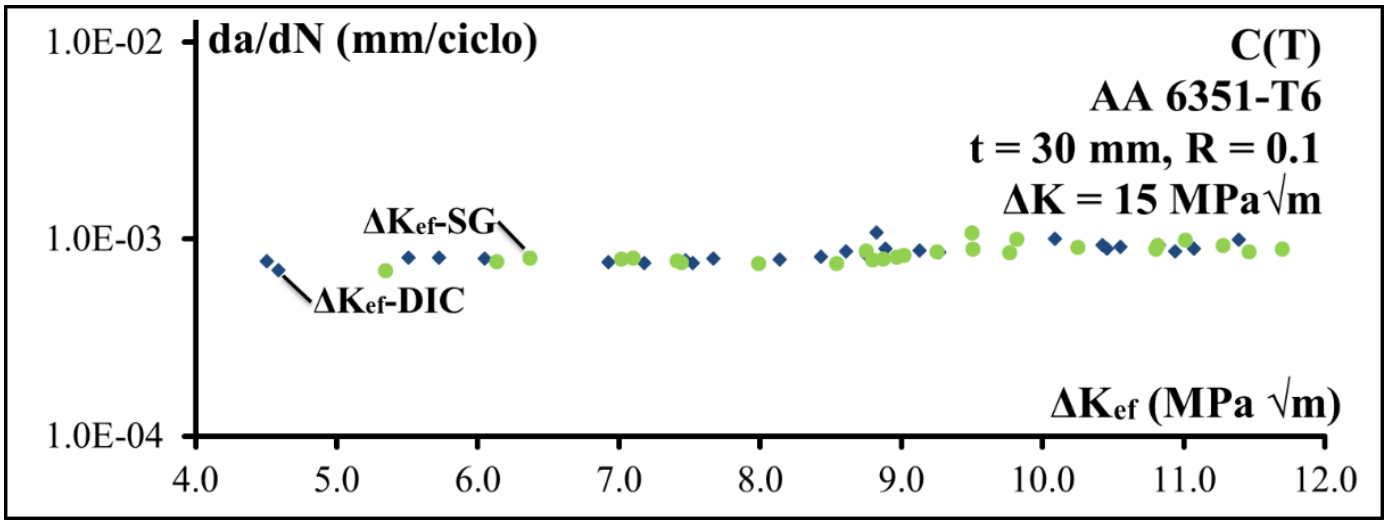

Figura 4.22: Taxas $d a / d N$ vs. $\Delta K_{e f}$ medidas em $\mathrm{C}(\mathrm{T}) \mathrm{s}$ de Al sob deformação plana.

Portanto, nos testes com corpos de prova de Al 6351-T6, pode-se mais uma vez afirmar que $\Delta K_{e f} \boldsymbol{n} \tilde{a} \boldsymbol{o} e ́$ a força motriz da propagação de trincas por fadiga. 


\section{3.}

\section{Testes com sobrecarga em CPs de aço}

Testes de sobrecarga foram feitos em DC(T)s de aço 1020 de 2 e de $30 \mathrm{~mm}$ de espessura mantendo $\{\Delta K=20 M P a \sqrt{ } m, R=0.1\}$ quase constantes antes e após as sobrecargas através de controle manual. $P_{a b}$ foi medida por extensômetros próximos e distantes da trinca, e por campos de deslocamento e de deformação medidos com DIC, como descrito anteriormente (Seção 4.1). As trincas cresceram sob carga quase constante até atingirem aproximadamente $5 \mathrm{~mm}$ de comprimento, e nesse instante, foi aplicada uma única sobrecarga de $100 \%$ de $K_{\max }\left(K_{S C}=44.44 M P a \sqrt{ } m\right)$. A seguir, foram reaplicadas as cargas quase constantes para continuar propagando a trinca. As taxas de propagação $d a / d N$ e a razão $K_{a b} / K_{\max }$ medidas antes e depois da sobrecarga em dois CPs de $2 m m$ de espessura (CP-1 e CP-2) são mostradas nas Figuras 4.23 e 4.24, que também mostram o tamanho da zona plástica da sobrecarga segundo a estimativa de Irwin em tensão plana, $z p_{S C}=(1 / \pi) \cdot\left(K_{S C} / S_{E}\right)^{2}$.

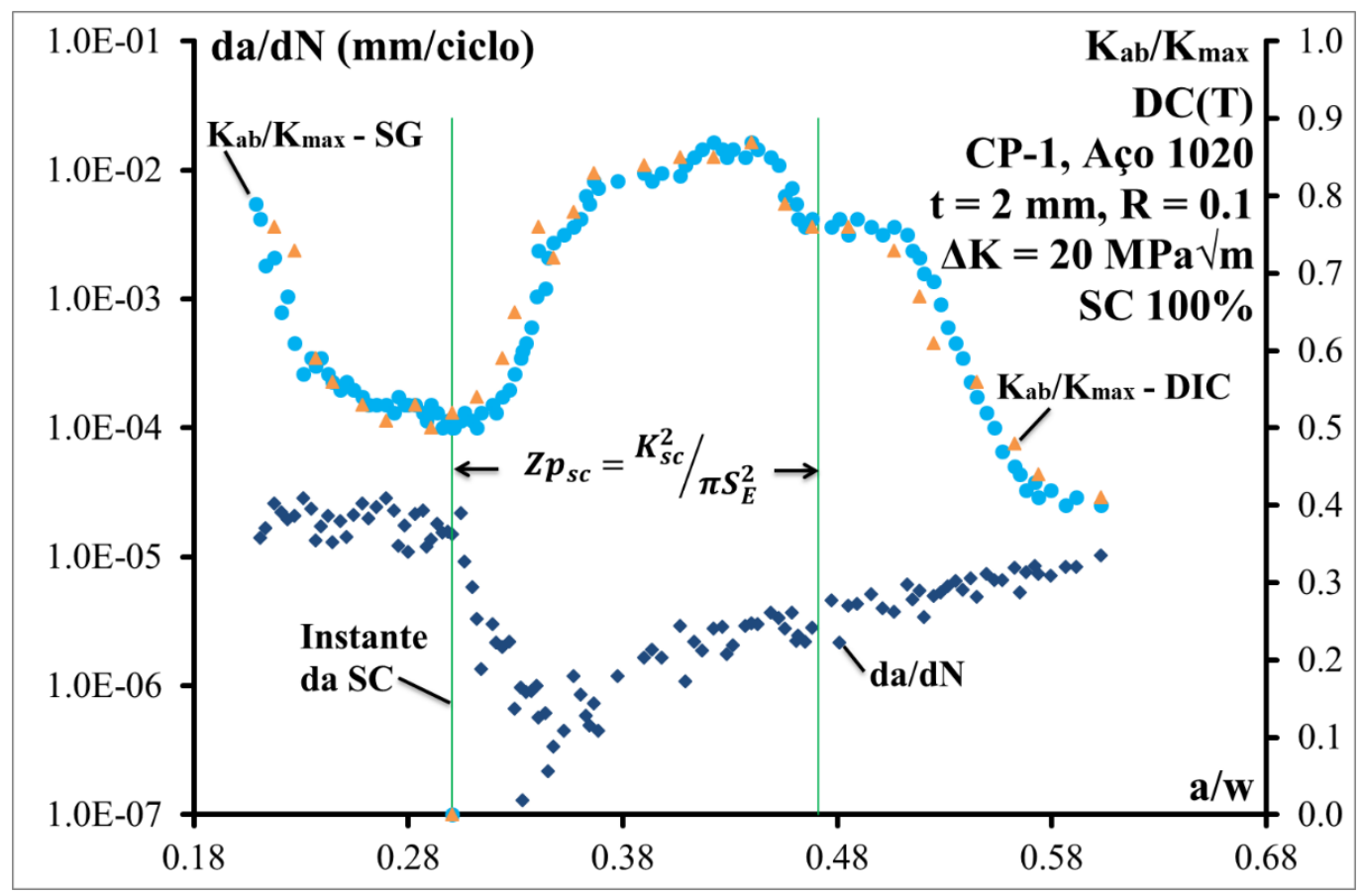

Figura 4.23: Taxas de propagação $d a / d N$ e razão $K_{a b} / K_{\max }$ medidas durante o teste de sobrecarga no corpo de prova 1 (CP-1) de aço AISI 1020 em tensão plana. 


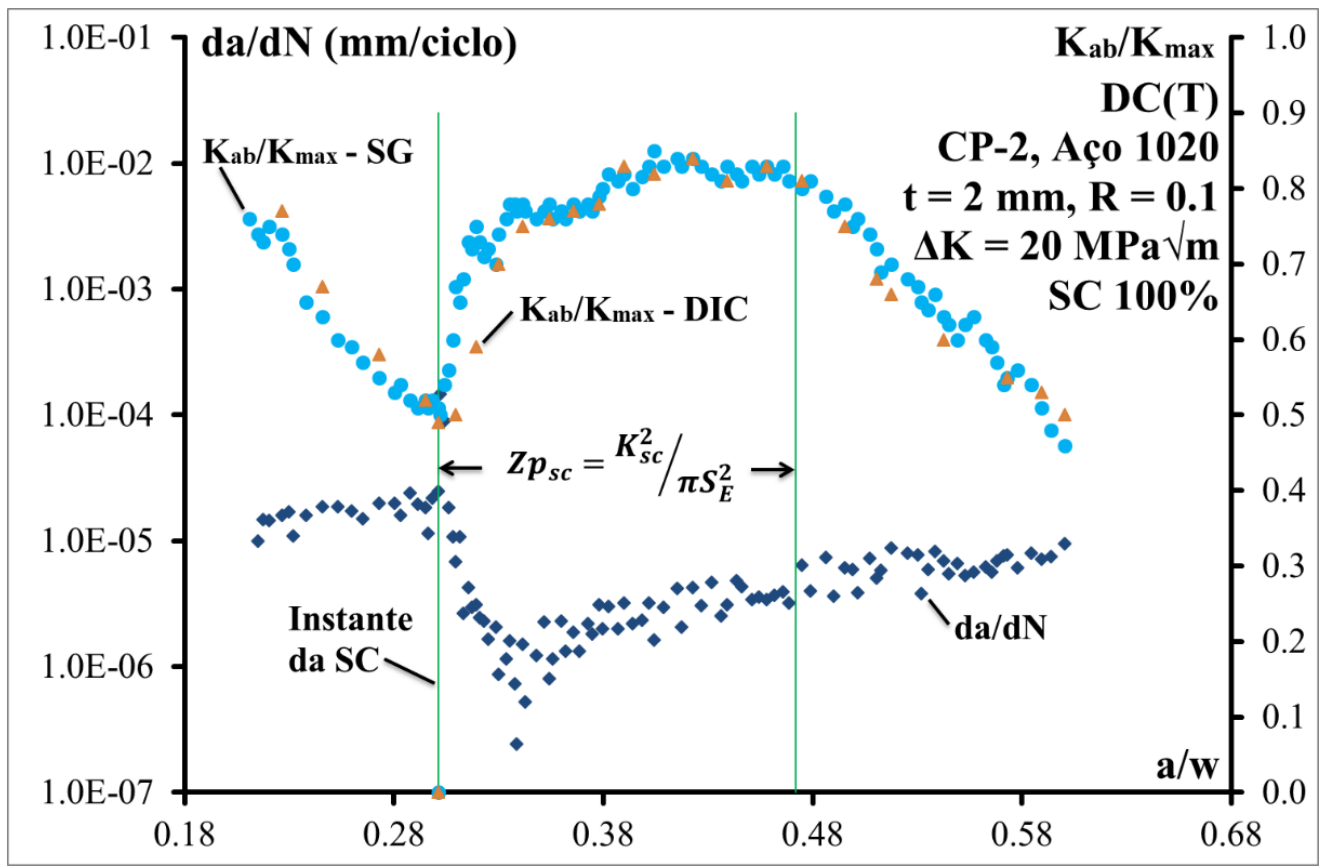

Figura 4.24: Taxas de propagação $d a / d N$ e razão $K_{a b} / K_{\max }$ medidas durante o teste de sobrecarga no corpo de prova 2 (CP-2) de aço AISI 1020 em tensão plana .

As Figuras 4.25 e 4.26 mostram as taxas $d a / d N$ e as razões $K_{a b} / K_{\max }$ medidas nos testes de sobrecarga nos CPs de $30 \mathrm{~mm}$ (CP-1 e CP-2), e a estimativa de Irwin para zona plástica em deformação plana $z p_{S C}=(1 / 3 \pi) \cdot\left(K_{S C} / S_{E}\right)^{2}$. Nestes CPs foi possível aplicar duas sobrecargas devidamente espaçadas, já que a taxa $d a / d N$ estabilizou mais rapidamente quando comparada com a taxa dos testes em tensão plana.

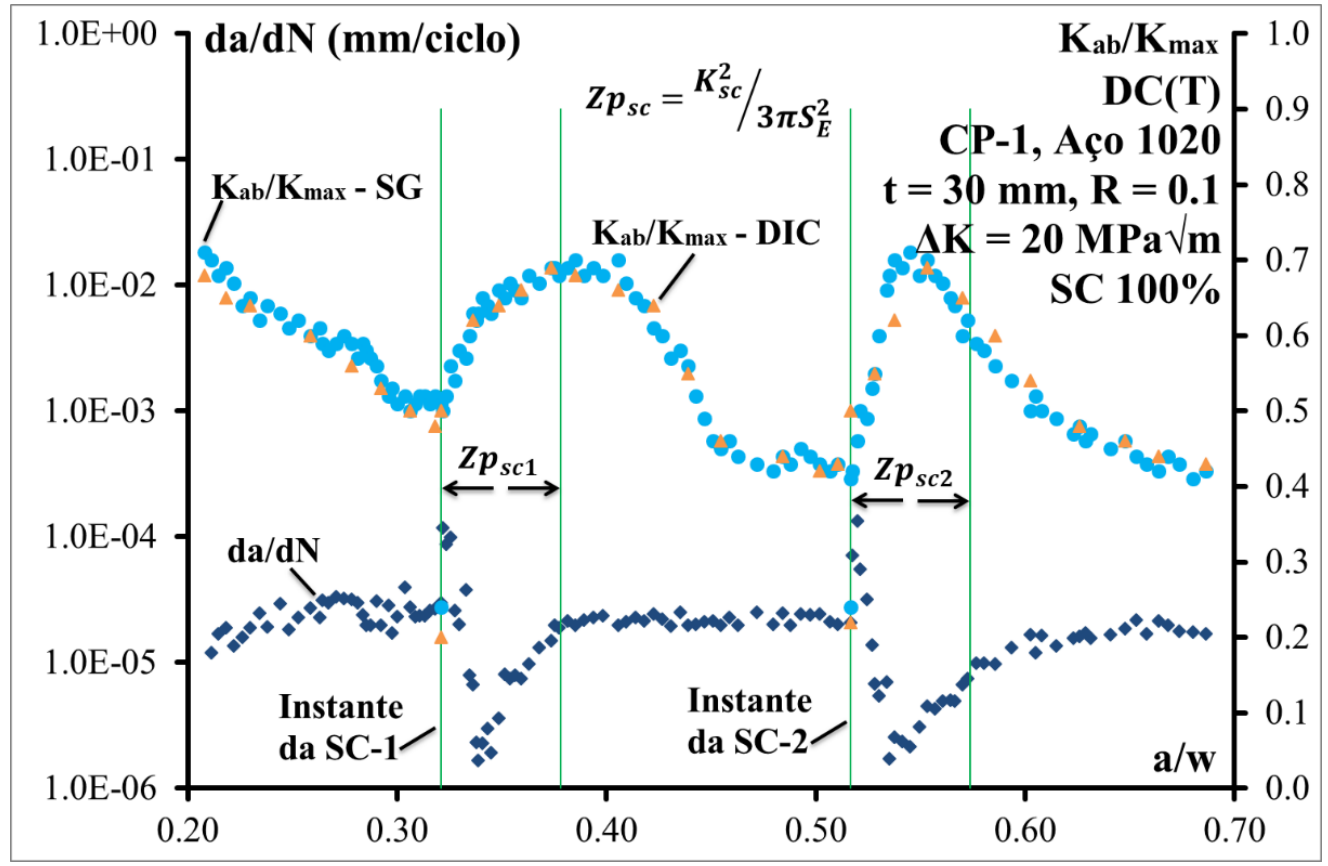

Figura 4.25: Taxas de propagação $d a / d N$ e razão $K_{a b} / K_{\max }$ medidas durante o teste de sobrecarga no corpo de prova 1 (CP-1) de aço AISI 1020 em deformação plana. 


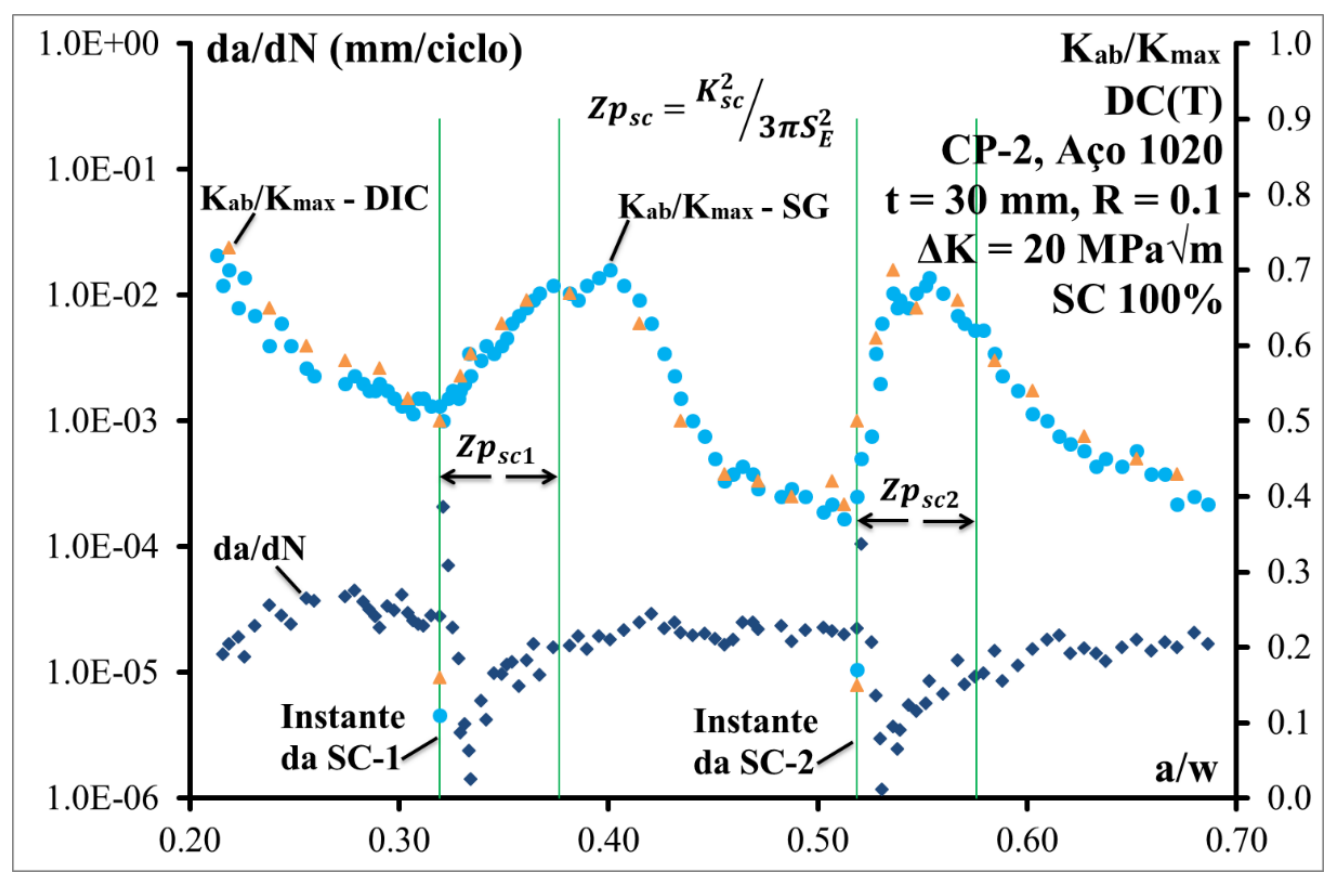

Figura 4.26: Taxas de propagação $d a / d N$ e razão $K_{a b} / K_{\max }$ medidas durante o teste de sobrecarga no corpo de prova 2 (CP-2) de aço AISI 1020 em deformação plana.

As figuras acima mostram que as sobrecargas induzem retardos significativos nas taxas de propagação subsequentes, mas em todos os casos as taxas $d a / d N$ e a razão $K_{a b} / K_{\max }$ estão desfasadas. De fato, as taxas $d a / d N$ mínimas durante os retardos causados pelas sobrecargas não correspondem aos valores máximos da razão $K_{a b} / K_{\max }$, pois eles ocorrem em comprimentos de trinca diferentes. Além disso, depois que o valor máximo da razão $K_{a b} / K_{\max }$ é atingindo, ele se mantém quase constante, enquanto o valor da taxa começa a se recuperar à medida que a trinca se afasta do ponto onde $d a / d N$ é mínima. Fleck achou resultados parecidos, que ele atribuiu a um "fechamento descontínuo", pois eles não podem ser explicados pelo fechamento elberiano [38]. Além disso, nos testes de tensão plana com sobrecarga das Figuras 4.23 e 4.24, os efeitos do retardo continuam afetando a trinca após ela ter ultrapassado o tamanho da $z p_{S C}$, o que também não pode ser explicado pelas teorias tradicionais de efeitos de sequência. Este comportamento também é característico do "fechamento descontínuo" proposto por Fleck. 


\section{4.}

\section{Testes com sobrecarga em CPs de Alumínio}

Testes de sobrecarga similares também foram feitos em DC(T)s de alumínio AA 6351-T6 (Seção 3.9), mas controlando as cargas com o programa de malha fechada para manter $\{\Delta K=15 \mathrm{MPa} \sqrt{ } m, R=0.1\}$ quase constantes (Seção 3.4.1). Espessuras de 2 e de $30 \mathrm{~mm}$ foram usadas para manter condições de tensão e deformação plana, respectivamente (Seção 4.2). Nos CPs de alumínio as trincas foram propagadas até cerca de $6 \mathrm{~mm}$ de comprimento, para nesse instante aplicar uma sobrecarga de $100 \%$ de $K_{\max }, K_{S C}=33.33 M P a \sqrt{ }$. A seguir, foram novamente aplicadas as condições de carga iniciais quase constantes para continuar propagando a trinca. As taxas $d a / d N$ e a razão $K_{a b} / K_{\max }$ medidas ao longo desses testes de sobrecarga em tensão e deformação plana são mostradas nas Figuras 4.27 e 4.28, respectivamente. As figuras também mostram os tamanhos das zonas plásticas das sobrecargas a partir do seu ponto de aplicação, calculados pela estimativa de Irwin para tensão plana, $z p_{S C}=(1 / \pi) \cdot\left(K_{S C} / S_{E}\right)^{2}$, e para deformação plana, $z p_{S C}=(1 / 3 \pi) \cdot\left(K_{S C} / S_{E}\right)^{2}$.

Note como o programa de controle de ciclo fechado diminui consideravelmente o ruído nas taxas de propagação medidas. Novamente se observa que o valor mínimo das taxas $d a / d N$ e os valores máximos da razão $K_{a b} / K_{\max }$ estão desfasados, como nos testes do aço AISI 1020, e que os efeitos de sobrecarga não são totalmente eliminados quando a trinca atinge um comprimento maior que o da $z p_{S C}$.

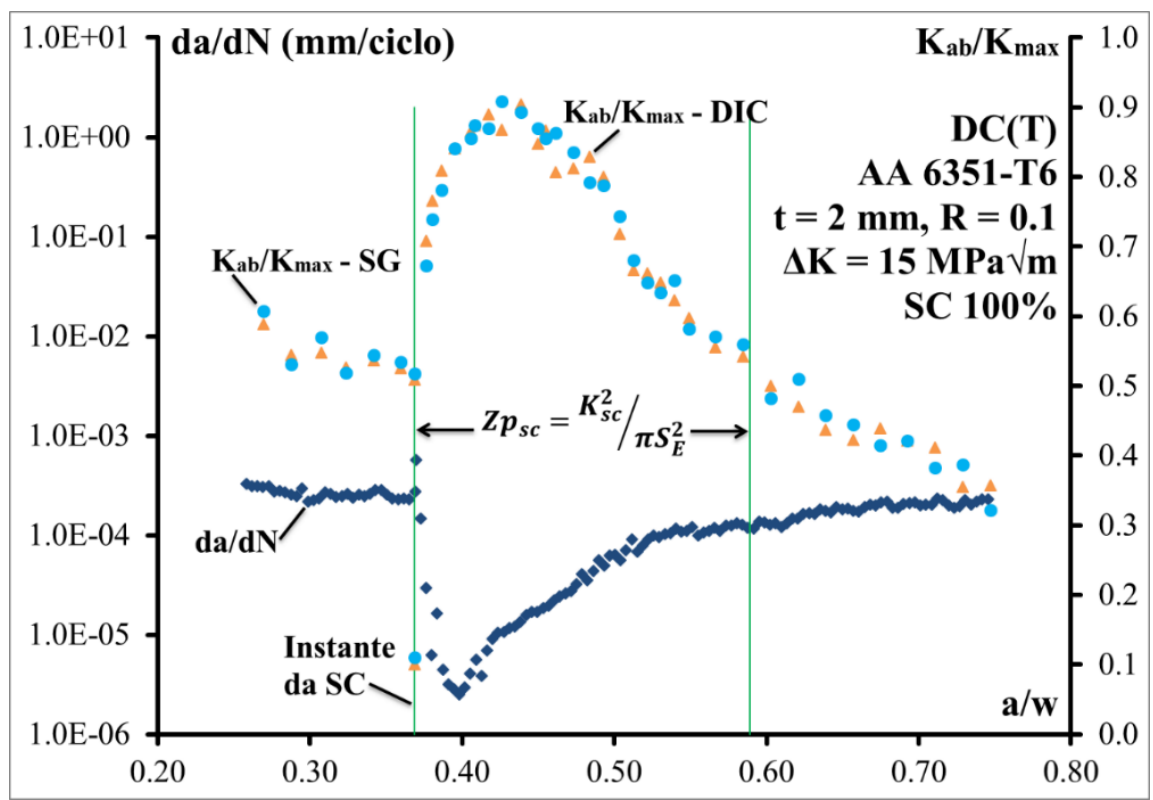

Figura 4.27: Taxa de propagação $(d a / d N)$, junto com o comportamento da razão $K_{a b} / K_{\max }$, para o teste de sobrecarga no CP de alumínio AA 6351-T6, em tensão plana. 


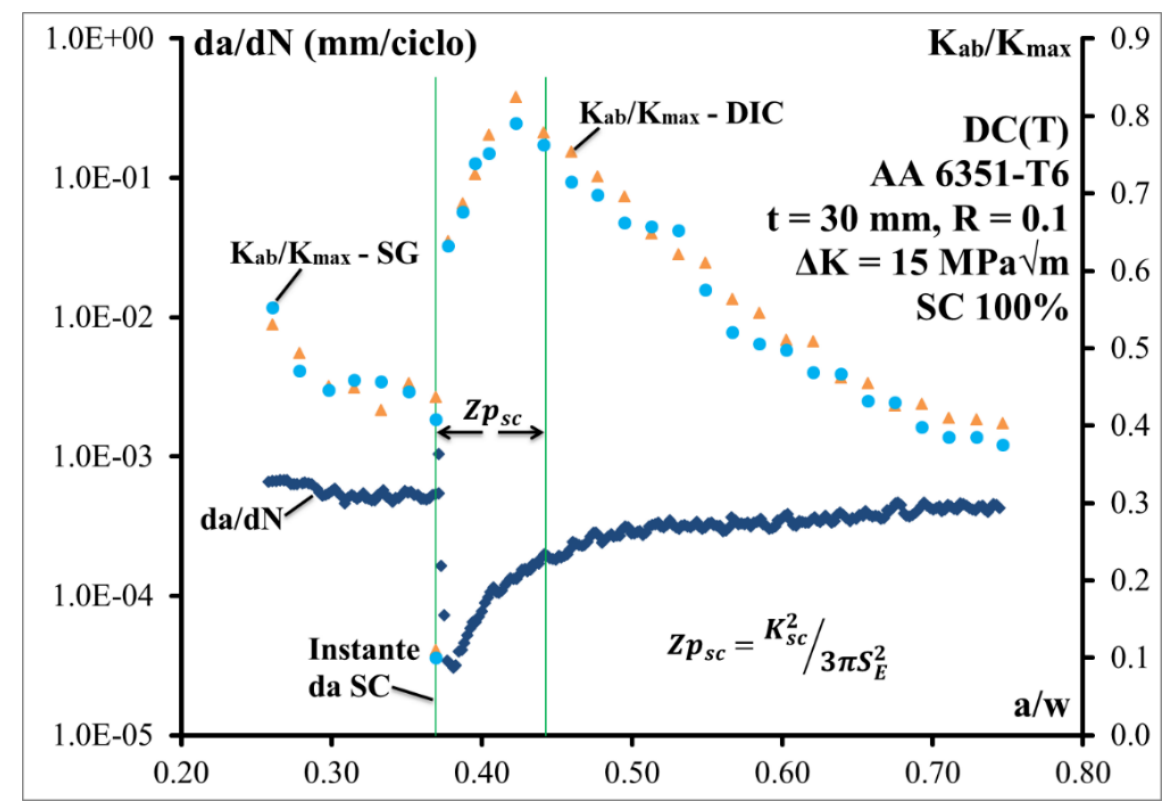

Figura 4.28: Taxa de propagação $(d a / d N)$, junto com o comportamento da razão $K_{a b} / K_{\max }$, para o teste de sobrecarga no CP de alumínio AA 6351-T6, em deformação plana.

Nestes testes, como em todos os testes anteriores, $P_{a b}$ também foi medida de forma redundante com extensômetros em campo próximo e distante (SG), e com os campos de deslocamento/deformação obtidos com DIC, seguindo os procedimentos descritos na Seção 4.1 .

\section{5.}

\section{Testes com o sistema de microscópio estéreo DIC}

Segundo os modelos de dano crítico, as trincas crescem por fadiga porque o material à sua frente é submetido a ciclos de deformação elastoplástica que geram dano. Logo, é necessário modelar as deformações à frente da ponta da trinca para calcular o dano acumulado e prever a eventual propagação da trinca por fadiga (Seção 2.3). Como a região que envolve as maiores deformações à frente da ponta da trinca é a zona plástica reversa $\left(z p_{r}\right)$, foram feitos testes com o objetivo de medir as deformações dentro dela, com um sistema de microscópio estéreo DIC (Seção 3.6).

Esses testes não são simples, pois precisam de uma magnificação que permita medir deformações com um gradiente muito severo dentro da $z p_{r}$, cujo tamanho é estimado por $z p_{r} \cong(1 / \pi)\left(\Delta K / 2 S_{E}\right)^{2}$. Com o sistema de microscópio estéreo se conseguiu analisar uma região de $3 \times 3.5 \mathrm{~mm}$, na qual cada pixel tinha aproximadamente 1.6 $\mathrm{m}$ de tamanho. Os parâmetros da análise DIC foram, uma Janela de $41 \times 41$ pixels, um Passo de 11 pixels e uma Janela de deformação de 19×19 (Seção 3.6). 
Estes parâmetros permitem que a cada 11 pixels (passo) seja feita uma medição numa região de $41 \times 41$ pixels. Depois são pegas regiões de 19x19 pontos de deformação (a janela de deformação) para suavizar estas medidas e eliminar possíveis erros causados pela diferenciação numérica. Assim, neste caso a filtragem de deformação abarca regiões de 199x199 pixels, ou de cerca de 0.32x0.32mm. Estes parâmetros foram selecionados seguindo o guia de boas práticas DIC [43-45].

Então, foram feitas medições de deformação à frente da ponta da trinca, com o sistema de microscópio estéreo DIC, em corpos tipo DC(T). Simultaneamente foi medido o campo de deslocamento/deformação na face oposta do CP com o sistema DIC convencional, e a deformação com um extensômetro colado na face traseira do CP.

\subsection{1.}

\section{Teste no CP de aço com o sistema microscópio estéreo + DIC}

As primeiras medidas foram feitas num DC(T) de aço AISI 1020 (Figura 3.14). Neste caso as cargas foram escolhidas para obter uma boa resolução das deformações dentro da zona plástica reversa. Sob $\{\Delta K=30 M P a \sqrt{ } m, R=0.1\}$ quase constantes, a estimativa de Irwin do tamanho da zona plástica reversa é: $z p_{r} \cong$ $(1 / \pi)\left(\Delta K / 2 S_{E}\right)^{2}=(1 / \pi)(30 / 2(262))^{2}=1.04 \mathrm{~mm}$. Como foi feita uma medição a cada $17.6 \mu m$ (passo), existem aproximadamente 50 pontos de medição dentro da $z p_{r}$ estimada. Neste caso a espessura do CP foi $t=5 \mathrm{~mm}$ e a zona plástica foi $z p=$ $(1 / \pi)\left(K_{\max } / S_{E}\right)^{2}=5.15 \mathrm{~mm}$, propagando a trinca num estado de tensão plana dominante.

O teste de propagação neste $\mathrm{DC}(\mathrm{T})$ foi controlado com o programa de malha fechada. A trinca cresceu numa taxa quase constante de cerca de $1 \times 10^{-4} \mathrm{~mm} / \mathrm{ciclo}$, até estar longe da região de influência dos efeitos do entalhe. Neste ponto foi feita uma medida de $P_{a b}$ com o extensômetro na face traseira do CP, e com os campos do sistema DIC convencional, usando os procedimentos descritos anteriormente.

A Figura 4.29 mostra curvas usadas para medir $P_{a b}$ pelo método tradicional de Elber e a Figura 4.30 as medidas feitas com subtrator de linearidade. Cabe salientar que as medidas de $P_{a b}$ também foram corroboradas pelo método da ASTM (Seção 3.7). Como se mostra nas figuras o valor da carga de abertura em relação à carga máxima foi aproximadamente: $P_{a b} / P_{\max }=0.56 \pm 0.02$. 
Neste instante foi medida a deformação à frente da ponta da trinca com o sistema de microscópio estéreo DIC. Foram medidos dois ciclos de carregamento, tirando 100 fotos por ciclo. A Figura 4.31 mostra o campo de deformações medido na carga máxima, na direção do eixo de aplicação da carga $\left(\varepsilon_{y}\right)$, ou seja, na direção perpendicular ao plano da trinca.

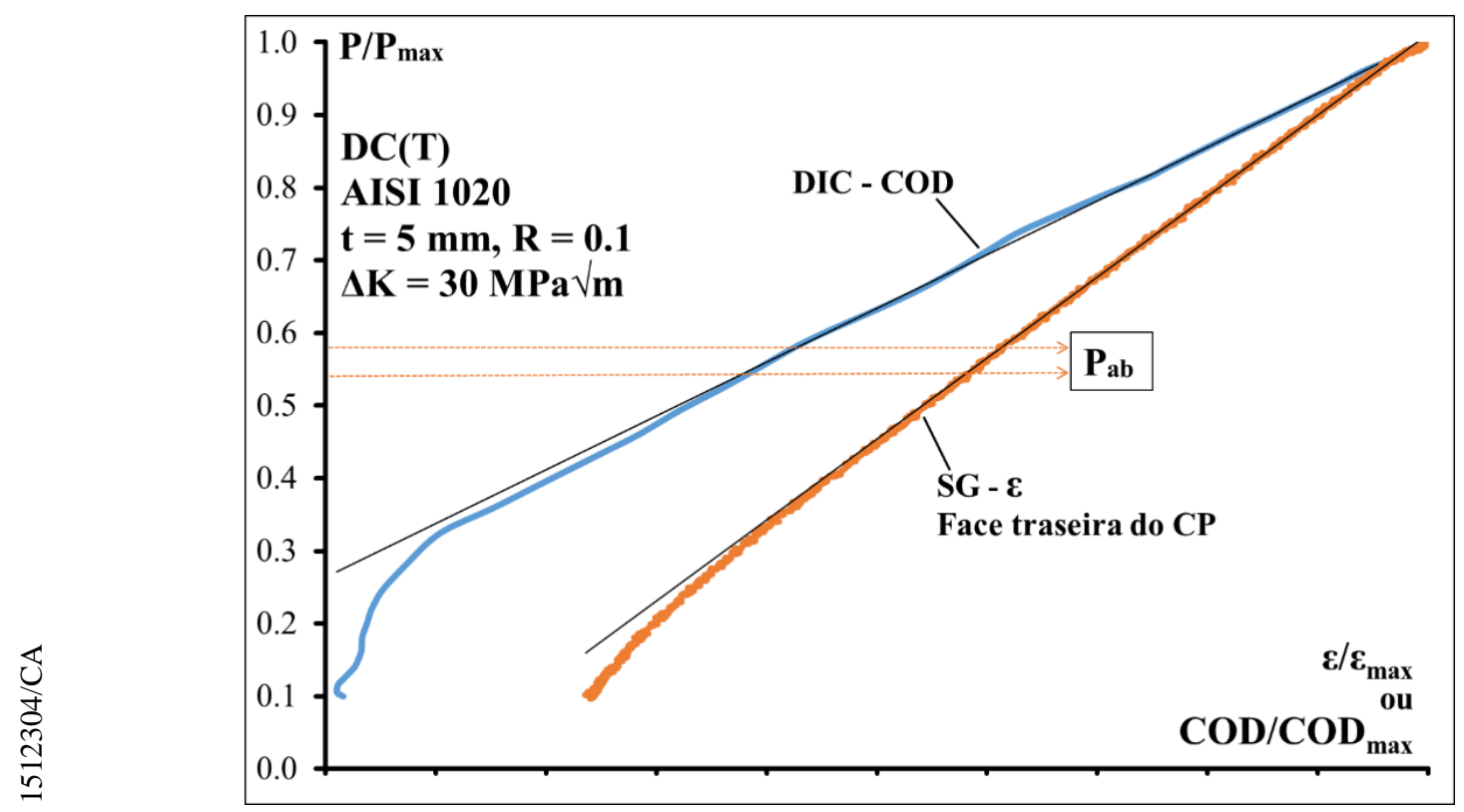

Figura 4.29: Medição de $\boldsymbol{P}_{a b}$ no CP de aço pelo método de Elber, no teste com o sistema microscópio estéreo + DIC.

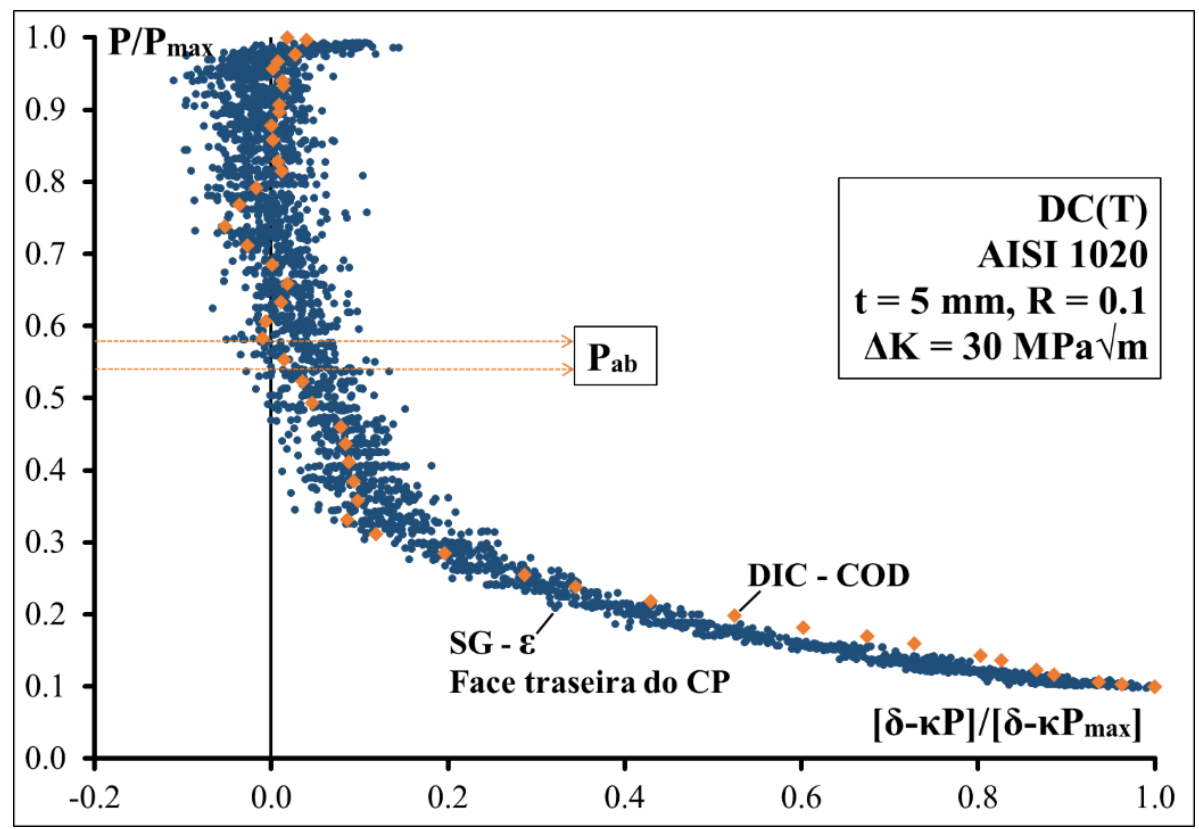

Figura 4.30: Medição de $P_{a b}$ no CP de aço com o subtrator de linearidade, no teste com o sistema microscópio estéreo + DIC. 


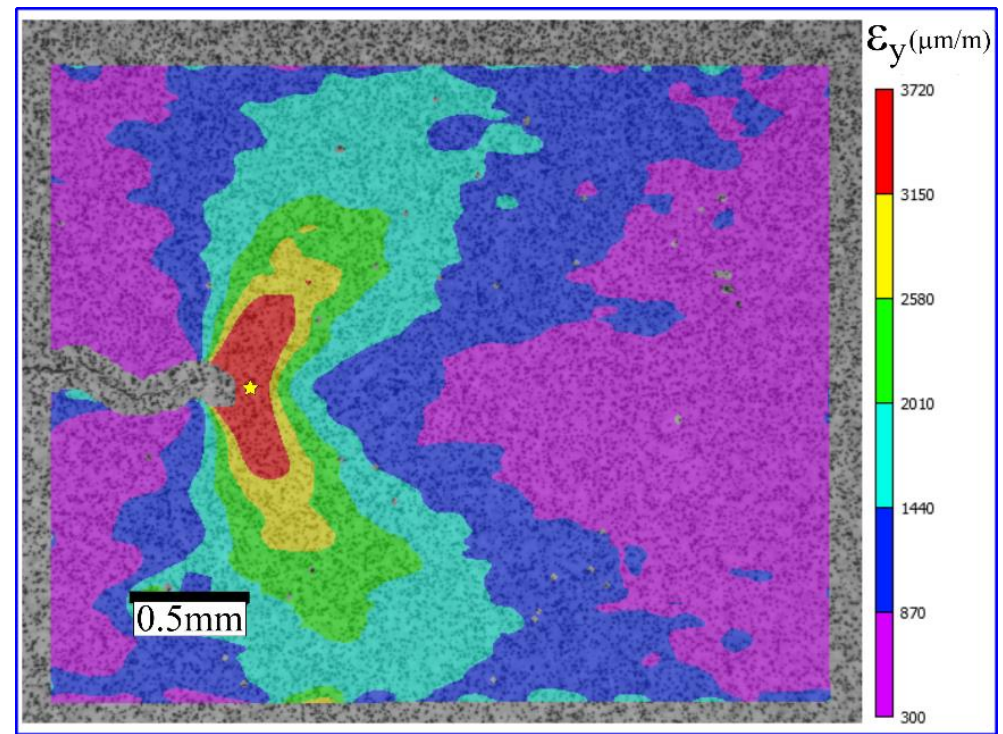

Figura 4.31: Campo de deformações na carga máxima, medido com o sistema microscópio estéreo + DIC.

Com a deformação medida dentro da $z p_{r}$ a uma distância de $0.1 \mathrm{~mm}$ da ponta da trinca, como se indica com uma estrela na Figura 4.31, foi plotado um gráfico de dois ciclos de carregamento na Figura 4.32. Com os cálculos feitos acima pode-se assumir que os ciclos de deformação apresentados na Figura 4.32 são de um ponto dentro da $z p_{r}$. É preciso considerar também que como $P_{a b} \cong 0.56 \cdot P_{\max }$, claramente existe deformação à frente da ponta da trinca antes dela estar totalmente aberta, tanto na carga como na descarga. Este fato mais uma vez contraria claramente a hipótese elberiana de que não há atividade à frente da trinca enquanto $P<P_{a b}$.

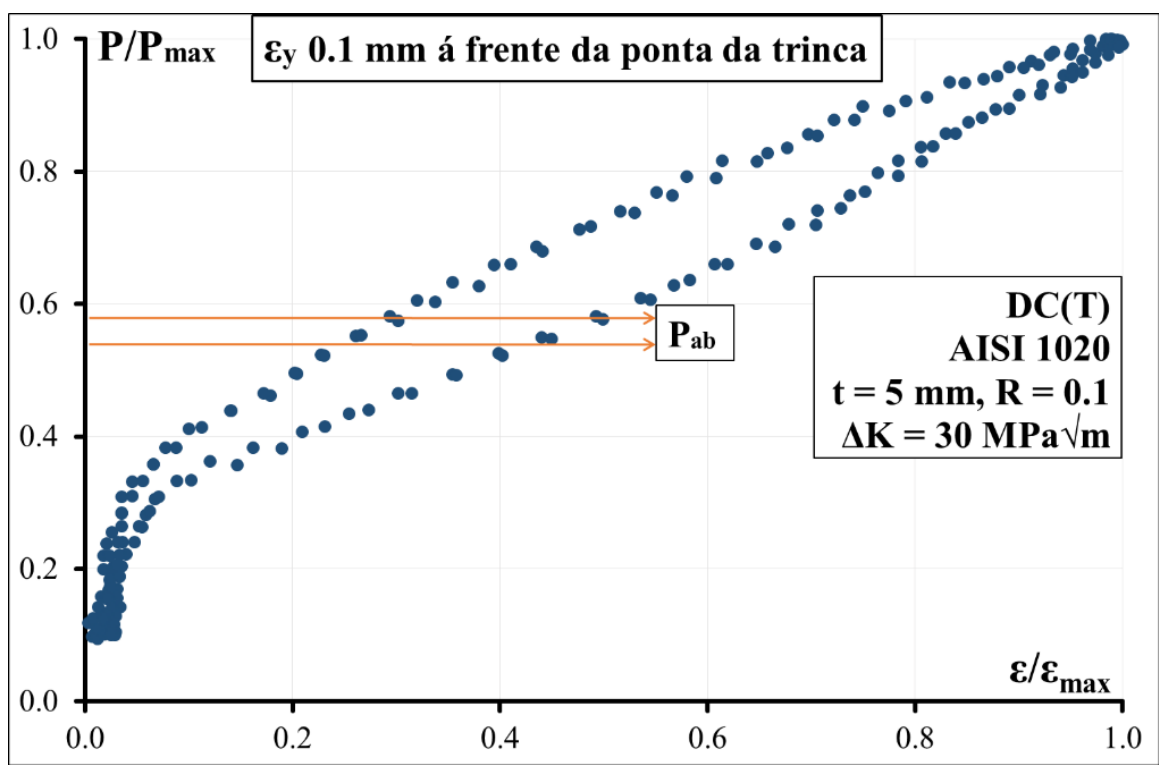

Figura 4.32: Laços de deformação $0.1 \mathrm{~mm}$ à frente da ponta da trinca no $\mathrm{CP}$ de aço. 


\subsection{2.}

\section{Teste no CP de Al com o sistema microscópio estéreo + DIC}

Para corroborar os resultados obtidos acima, foi feito um segundo teste num corpo de prova DC(T) de alumínio 6351-T6 (Seção 3.9). De novo as cargas de propagação foram calculadas para obter uma boa resolução das deformações dentro da $z p_{r}$. Assim, sob cargas quase constantes $\{\Delta \mathrm{K}=22.22 \mathrm{MPa} \sqrt{\mathrm{m}}, \mathrm{R}=0.1\}$, o tamanho da zona plástica reversa ou cíclica estimado por Irwin é $z p_{r} \cong(1 / \pi)\left(\Delta K / 2 S_{E}\right)^{2}=$ $(1 / \pi)(22.22 / 2(170))^{2}=1.36 \mathrm{~mm}$. Portanto como foi feita uma medição a cada $17.6 \mu \mathrm{m}$ (passo), existem aproximadamente 70 pontos de medição dentro da $z p_{r}$ estimada. A espessura do CP é $t=10 \mathrm{~mm}$ e a zona plástica é $z p=(1 / \pi)\left(K_{\max } / S_{E}\right)^{2}=6.71 \mathrm{~mm}$, propagando a trinca num estado misto com tensão plana dominante. Note que a resolução da deformação medida pelo sistema microscópio estéreo + DIC dentro desta $z p_{r}$ é melhor, porque ela é maior do que a $z p_{r}$ do aço relatada acima.

Os procedimentos deste teste foram iguais aos do teste anterior. A trinca cresceu sob uma taxa quase constante de aproximadamente $1.5 \times 10^{-3} \mathrm{~mm} / \mathrm{ciclo}$, até estar longe da região de influência dos efeitos do entalhe. As curvas para medir $P_{a b}$ pelo método de Elber e pelo subtrator de linearidade estão nas Figuras 4.33 e 4.34. A carga de abertura medida foi $P_{a b} / P_{\max }=0.54 \pm 0.02$.

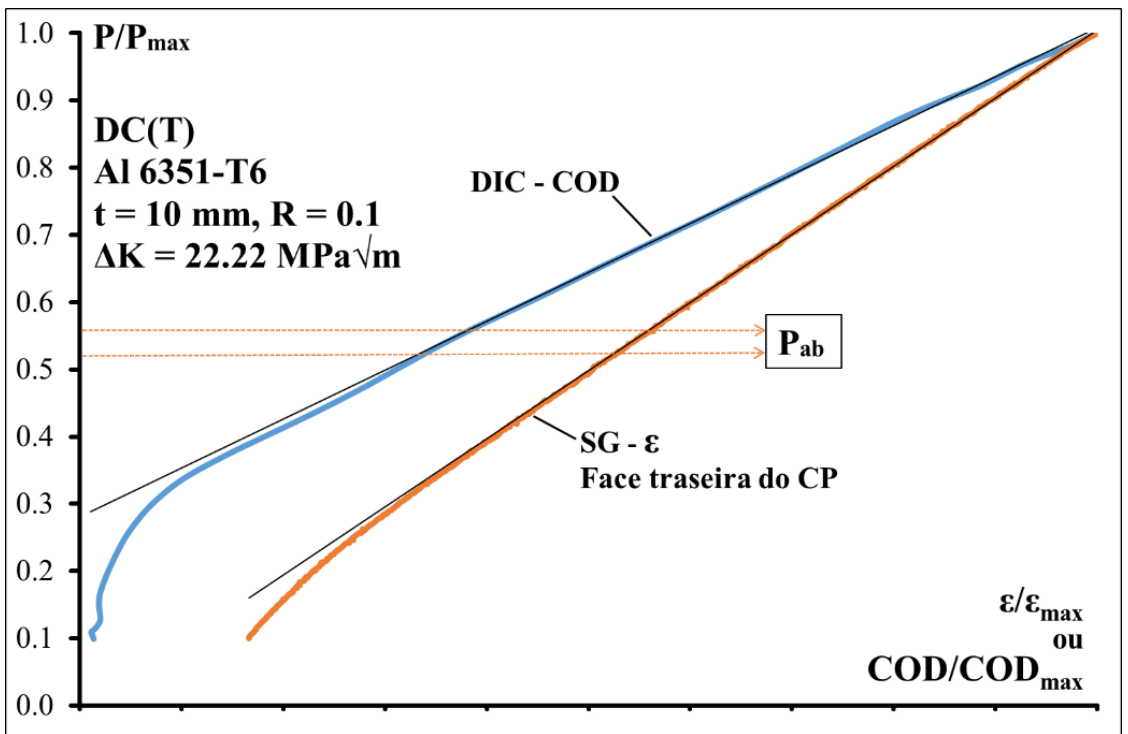

Figura 4.33: Medição da $P_{a b}$ no CP de alumínio pelo método de Elber, no teste com os sistema microscópio estéreo + DIC. 


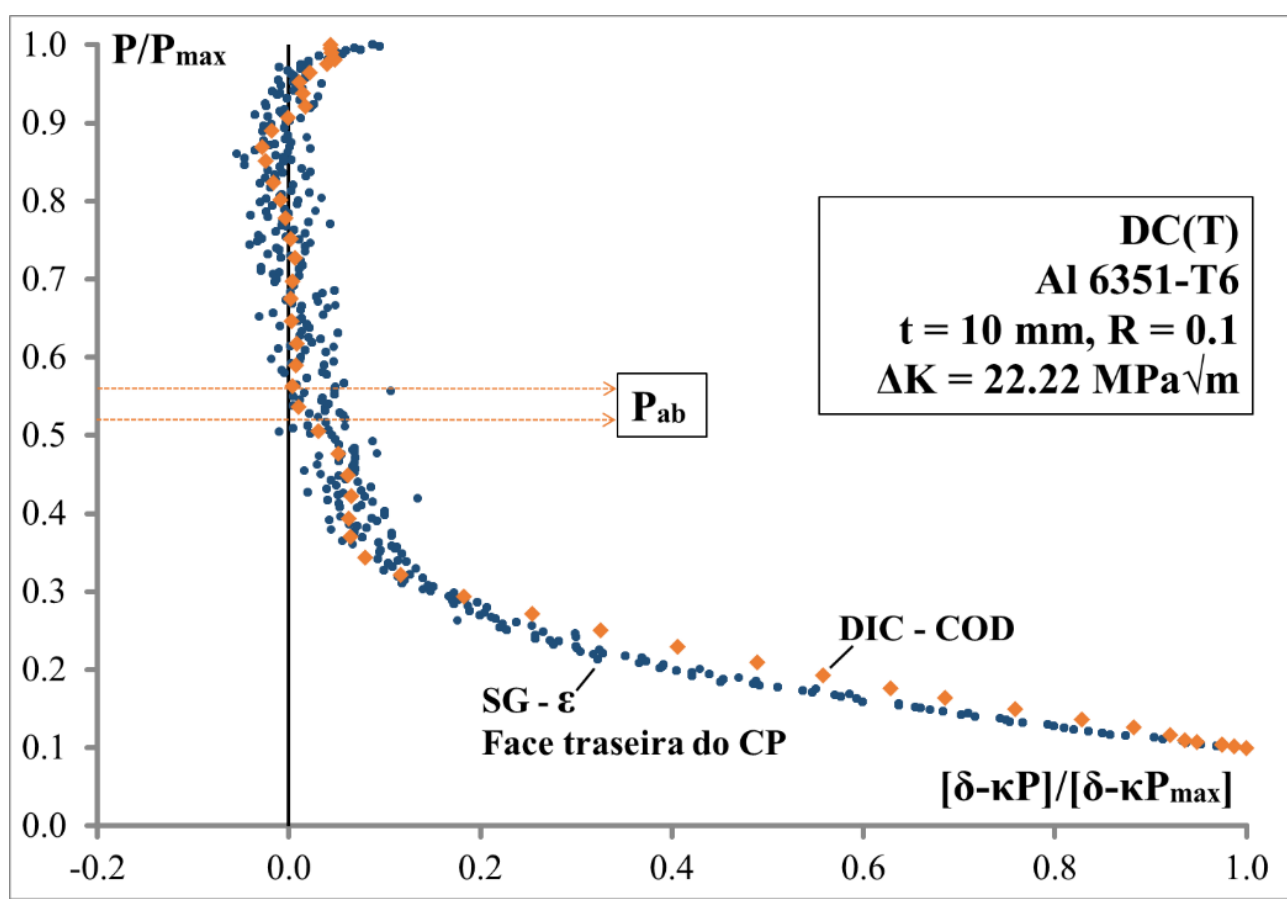

Figura 4.34: Medição da $\boldsymbol{P}_{a b}$ no CP de alumínio com o subtrator de linearidade, no teste com o sistema microscópio estéreo + DIC.

Dois ciclos de carregamento foram analisados com o sistema microscópio estéreo + DIC, tirando 100 fotos por ciclo numa frequência de $0.01 \mathrm{~Hz}$, mantendo as mesmas condições de carregamento. A Figura 4.35 mostra os laços de histerese elastoplástica medidos dentro da $z p_{r} 0.1 \mathrm{~mm}$ à frente da ponta da trinca.

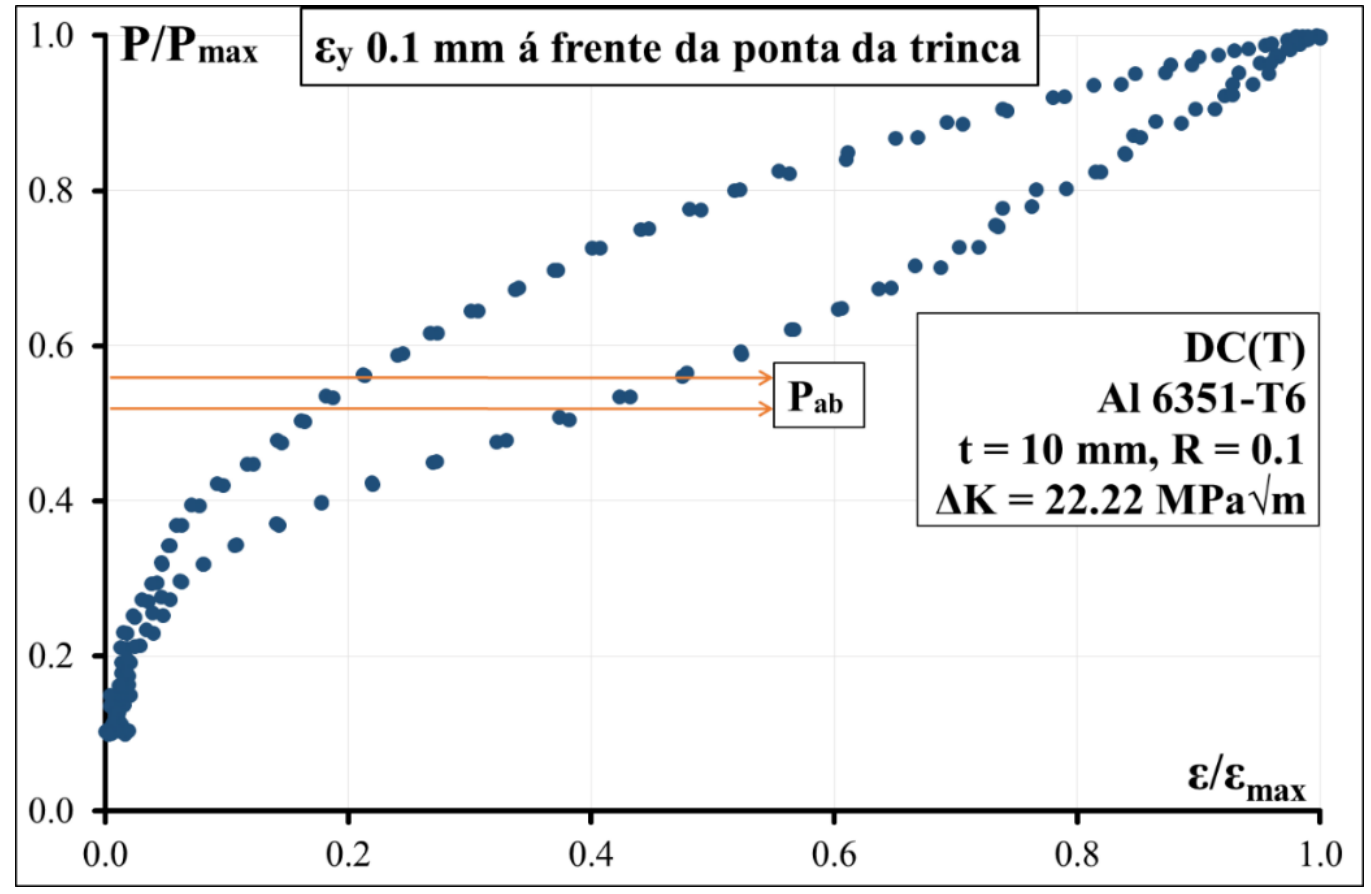

Figura 4.35: Laços de deformação $0.1 \mathrm{~mm}$ à frente da ponta da trinca no $\mathrm{CP}$ de alumínio. 
Como no caso do $\mathrm{CP}$ de aço, nos laços da Figura 4.35 é evidente que existe deformação sob cargas $P<P_{a b}$ no ponto onde as deformações foram medidas. Também se observa como a plastificação gerada na carga é quase totalmente revertida na descarga, já que em $P_{\min }$ a deformação residual é aproximadamente zero, antes e depois do ciclo de carregamento. $O$ fato de existir deformação abaixo da $P_{a b}$, numa região tão próxima da ponta da trinca, claramente contradiz a teoria de Elber.

\section{6.}

\section{Discussão}

Embora alguns autores afirmem que há diferenças entre as medidas de $P_{a b}$ feitas no campo próximo e no campo distante da ponta da trinca $[54,55]$, as $P_{a b}$ medidas redundantemente neste trabalho tanto próximo quanto longe da ponta da trinca foram quase coincidentes e apresentaram pouca dispersão (Figura 4.4 e 4.6). Vale mencionar que nas curvas de flexibilidade de campo próximo e distante, para tamanhos de trinca pequenos $(a / w<0.3)$, existem diferenças sutis de sensibilidade, que não chegam a ser relevantes.

Os testes que foram feitos sob as mesmas condições mostram uma repetitividade muito boa, já que a média da taxa de propagação foi aproximadamente a mesma nos CPs testados.

Além disso, aplicando $\Delta K$ e $K_{\max }$ quase constantes durante todos os testes, foi possível obter uma taxa $d a / d N$ quase constante, corroborando a ideia inicial de Paris que afirma que trincas submetidas ao mesmo $\Delta K$ nominal, geram incrementos iguais por ciclo independentemente do tamanho da trinca. Este comportamento também respalda teorias como o enfoque unificado do dano à fadiga, que afirma que são duas as forças motrizes das trincas de fadiga, $\Delta K$ e $K_{\max }$ (Seção 2.1).

É importante mencionar que foi um grande avanço a criação do programa de controle de malha fechada (Seção 3.4.1), não só pela maior facilidade na realização dos testes, mas também porque melhorou o controle, eliminando muito ruído dos resultados de taxa de propagação, quando comparados com os resultados obtidos com controle manual.

Tendo em conta que tanto nos testes em aço, como nos testes em alumínio, a razão $K_{a b} / K_{\max }$ teve uma queda significativa (pelo menos $30 \%$ ), enquanto a trinca 
crescia com uma taxa quase constante, é evidente que a hipótese de Elber não consegue explicar os resultados obtidos nestes testes.

$\mathrm{O}$ uso de diferentes tipos de CP não deveria ser um problema, porque em princípio, as taxas de propagação podem ser medidas em qualquer tipo de CP com um fator de intensidade de tensão conhecido, já que esses dados são usados em qualquer componente estrutural. De qualquer forma, os dados obtidos a partir de corpos tipo $\mathrm{C}(\mathrm{T})$ mostram mais uma vez o comportamento de queda na razão $K_{a b} / K_{\max }$. De fato, $K_{a b} / K_{\max }$ diminuiu sensivelmente à medida que o comprimento da trinca aumentou, enquanto o $d a / d N$ permaneceu quase constante durante os testes, tanto em tensão plana quanto em deformação plana.

Nos casos em que o mesmo teste foi feito mas de uma vez (e.g. Figura 4.15 e Figura 4.16), mostra-se como o comportamento medido $K_{a b}$ não é idêntico entre os CPs testados. Isso indica que nos testes feitos neste trabalho, $K_{a b}$ não é uma propriedade do conjunto geometria/carga. Em vez disso, $K_{a b}$ varia um pouco entre espécimes nominalmente idênticos submetidos a condições de carga iguais. Esta variação de $K_{a b}$ é outra razão para questionar o uso de modelos que assumem que $\Delta K_{e f}$ é a força motriz da propagação de trincas por fadiga.

Vale ressaltar que há uma pequena diferença entre o $d a / d N$ obtido nos corpos DC(T) e C(T). Há também uma diferença ainda menor entre as taxas medidas em amostras finas e grossas. Um comportamento semelhante foi relatado por Forth et al. em testes de propagação realizados sob condições de força constante, em corpos $\mathrm{C}(\mathrm{T}), \mathrm{M}(\mathrm{T})$, e $\mathrm{ESE}(\mathrm{T})$, com a mesma largura $(w)$ e espessura $(t)[56,57]$. Eles concluíram que as diferenças observadas nas taxas de propagação foram provavelmente causadas por efeitos ambientais e rugosidade nas faces da trinca, o que poderia explicar a variação relatada nesses resultados.

Nos testes de sobrecarga em tensão e deformação plana, em CPs de alumínio e aço, o valor mínimo de $d a / d N$ está consideravelmente desfasado em relação ao valor máximo da razão $K_{a b} / K_{\max }$ (mín. $\Delta K_{e f}$ ). Isso impede relacionar quantitativa e qualitativamente o $\Delta K_{\text {ef }}$ com a taxa $d a / d N$, pelo que estes resultados contradizem a hipótese de Elber. Fleck atribuiu problemas como estes ao chamado "fechamento descontínuo", afirmando que pela aplicação da sobrecarga se gera uma "corcova" de material deformado, a qual se torna principal ponto de contato entre as faces da trinca, ao longo da propagação [36]. Esta "corcova" atuaria como uma mola, permitindo geração de dano à frente da ponta da trinca, para cargas abaixo de $K_{a b}$. 
Todavia, não há evidências neste trabalho que suportem ou contradigam esta hipótese.

Nas curvas das Figuras 4.32 e 4.35 observa-se claramente que tanto nos CPs de aço quanto nos de alumínio há deformação significativa dentro da $z p_{r} 0.1 \mathrm{~mm}$ à frente da ponta da trinca em cargas $P<P_{a b}$. Este fato contesta de forma inequívoca a hipótese de Elber que considera que a região à frente da trinca está protegida de qualquer dano abaixo de $P_{a b}$, ou seja, que a trinca só sofre dano após totalmente aberta. É notável que a forma destas curvas dentro da $z p_{r}$ é muito semelhante aos laços de histerese de ensaios $\varepsilon N$ em $R$ negativo, validando a abordagem do problema de propagação de trincas feita pelas teorias de dano crítico (Seção 2.3). Então com uma correta caracterização experimental das deformações à frente da ponta da trinca, seria possível alimentar modelos deste tipo, para modelar a propagação de trincas por fadiga. 


\section{5. \\ Conclusões}

- Mantendo condições de carga com $\Delta K$ e $K_{\max }$ quase constantes, tanto com controle manual como automático, a trinca propagou com uma taxa quase constante em todos os cenários testados neste trabalho, em tensão e deformação plana, corroborando a ideia inicial de Paris que afirma que independentemente do tamanho da trinca, se estiver submetida ao mesmo $\Delta K$ e $K_{\max }$ nominal, avançará em incrementos iguais por ciclo.

- Nos CPs de aço (cúbico de corpo centrado) e de alumínio (cúbico de face centrada), a razão $K_{a b} / K_{\max }$ diminuiu enquanto a trinca avançou com uma taxa de propagação quase constante, mostrando que os testes feitos neste trabalho não foram controlados pelo $\Delta K_{e f}$, já que este teve uma variação não desprezível a longo dos testes (aprox. 30\%), enquanto $d a / d N$ permaneceu quase constante.

- O comportamento da razão $K_{a b} / K_{\max }$ foi independente da geometria, já que esta diminuiu enquanto a trinca avançou com um $d a / d N$ quase constante, nos testes em corpos de prova $\mathrm{DC}(\mathrm{T})$ e $\mathrm{C}(\mathrm{T})$, em tensão plana e deformação plana.

- Em todos os testes de sobrecarga, o valor de $\Delta K_{\text {ef }}$ mínimo está desfasado em relação ao $d a / d N$ mínimo, criando uma grande contradição entre a hipótese de Elber e os dados experimentais, já que não é possível fazer uma relação entre o retardo máximo e a $P_{a b}$ máxima.

- As deformações em uma distância de 0.1 milímetros à frente da ponta da trinca, obtidas com o sistema de microscópio estéreo DIC, mostram que nos testes feitos neste trabalho em alumínio e aço, a região à frente da ponta da trinca não esteve protegida de dano para cargas abaixo da $P_{a b}$. Isso contesta a hipótese de Elber, que diz que a trinca só sofre dano depois de estar totalmente aberta. 


\section{1.}

\section{Trabalhos Futuros}

- Fazer testes com $\Delta K$ e $K_{\max }$ quase constante em corpos de prova tipo M(T), para comparar com os resultados do modelo "Strip-Yield", que está sendo estudado pela equipe do laboratório [11]. Se propõe o uso de esta geometria, porque a formulação desse modelo foi desenvolvida para corpos $\mathrm{M}(\mathrm{T})$ [12].

- Realizar testes em vácuo com $\Delta K$ e $K_{\max }$ quase constantes, em diferentes razões $R$, para testar os efeitos do ambiente na propagação de trincas por fadiga.

- Continuar com as medições com o sistema de microscópio estéreo DIC para caracterizar as deformações à frente da ponta da trinca, e assim poder alimentar modelos de dano crítico que modelem a propagação de trincas por fadiga.

- Analisar o comportamento à frente da ponta da trinca com o sistema de microscópio estéreo DIC, em testes com eventos de sobrecarga.

\section{2.}

\section{Publicações}

A continuação se mostram algumas das publicações que foram feitas utilizando os resultados deste trabalho.

- González, J. A. O.; Castro, J. T. P.; Gonzáles, G. L. G.; Meggiolaro, M. A.; Freire, J. L. F. Verification of the $\Delta K_{\text {eff }}$ hypothesis along the fatigue crack path in thin and thick Al specimens. Frattura ed Integrita Strutturale. v. 49. p. 26-35. 2019.

- Gonzáles, G. L. G.; González, J. A. O.; Castro, J. T. P.; Freire, J. L. F. Using DIC techniques to measure strain ranges inside the cyclic plastic zone ahead of a fatigue crack tip. Frattura ed Integrita Strutturale. v. 49. p. 74-81. 2019.

- Gonzáles, G. L. G.; González, J. A. O.; Paiva, V. E. L.; Freire, J. L. F. CrackTip Plastic Zone Size and Shape via DIC. Conference Proceedings of the Society for Experimental Mechanics Series. 1ed.: Springer International Publishing. v. 6. p. 5-10. 2018. 
- González, J. A. O.; Castro, J. T. P.; Gonzáles, G. L. G.; Meggiolaro, M. A.; Freire, J. L. F. On DIC measurements of $\Delta K_{\text {eff }}$ to verify if it is the FCG driving force. Frattura ed Integrita Strutturale. vol. 11. no 41. p. 227-235. 2017.

- Gonzáles, G. L. G.; González, J. A. O.; Castro, J. T. P.; Freire, J. L. F. A Jintegral approach using digital image correlation for evaluating stress intensity factors in fatigue cracks with closure effects. Theoretical and Applied Fracture Mechanics, vol. 90. p. 14-21. 2017.

- Gonzáles, G. L. G.; González, J. A. O.; Castro, J. T. P.; Freire, J. L. F. Detecting Fatigue Crack Closure and Crack Growth Delays After an Overload Using DIC Measurements. Conference Proceedings of the Society for Experimental Mechanics Series. 1ed.: Springer International Publishing. v. 7. p. 57-65. 2017.

- Gonzáles, G. L. G.; González, J. A. O.; Castro, J. T. P.; Freire, J. L. F. DIC Analysis for Crack Closure Investigations During Fatigue Crack Growth Following Overloads. Conference Proceedings of the Society for Experimental Mechanics Series. 1ed.: Springer International Publishing. p. 151-156. 2017.

- Gonzáles, G.L.G.; González, J.A.O.; Castro, J.T.P.; Freire, J.L.F. Medição do Fechamento de trincas de fadiga utilizando a correlação de imagens digitais. In: $14^{\mathrm{a}}$ Conferência sobre Tecnologia de Equipamentos Rio de Janeiro. COTEQ. 2017.

- Gonzáles, G. L. G.; Diaz, J. G.; González, J. A. O.; Castro, J. T. P.; Freire, J. L. F. Determining SIFs Using DIC Considering Crack Closure and Blunting. Conference Proceedings of the Society for Experimental Mechanics Series. 1ed.: Springer International Publishing. v. 4. p. 25-36. 2016.

- González, J.A.O.; Castro, J.T.P.; Gonzáles, G.L.G. Verification of the driving force for fatigue crack growth: $\Delta K$ or $\Delta K_{\text {eff? }}$ ? In: $71^{\circ}$ Congresso Anual da ABM, 2017, Rio de Janeiro. Anais do Congresso Anual da ABM. São Paulo: Editora Blucher. p. 512. 2016. 


\section{6. Referências Bibliográficas}

[1] Castro, J.T.P.; Meggiolaro, M.A. Fatigue Design Techniques: Vol. III Crack Propagation, $2^{\circ}$. Rio de Janeiro, 2016.

[2] Paris, P.C.; Gomez, M.P.; Anderson, W.E.P. A Rational Analytic Theory of Fatigue, The Trend in Engineering, vol. 13. p. 9-14, 1961.

[3] Paris, P.; Erdogan, F. A Critical Analysis of Crack Propagation Laws. $J$. Basic Eng. vol. 85, n ${ }^{\circ}$ 4. p. 528. jan. 1963.

[4] Vasudevan, A.; Sadananda, K. Unified Approach to Fatigue Damage Evaluation - U.S. Naval Research Laboratory. [Online]. Available at: http://www.nrl.navy.mil/research/nrl-review/2003/featuredresearch/sadananda/.

[5] Elber W. Fatigue Crack Closure Under Cyclic Tension. Eng. Fract. Mech. vol. 2. p. 37-45. 1970.

[6] Elber, W. The significance of fatigue crack closure. Damage Toler. Aircr. Struct. vol. 2. p. 230-242. 1971.

[7] Newman, J, C, J. A crack opening stress equation for fatigue crack growth. Int. J. Fract. vol. 24. p. 131-135. 1984.

[8] NASA. NASGRO 4.0 Demo, Fracture Mechanics and Fatigue Crack Growth Analysis Software, 2002. [Online]. Available at: http://www.swri.org/4org/d18/mateng/matint/nasgro/Demo/default.htm.

[9] Skorupa, M.; Machniewicz, T.; Schijve, J.; Skorupa, A. Application of the strip-yield model from the NASGRO software to predict fatigue crack growth in aluminium alloys under constant and variable amplitude loading. Eng. Fract. Mech. vol. 74, nº 3. p. 291-313. fev. 2007.

[10] Ferreira, S.E.; Castro, J.T.P. de; Meggiolaro, M.A. Fatigue crack growth predictions based on damage accumulation ahead of the crack tip calculated by strip-yield procedures. Int. J. Fatigue. vol. 115, n January. p. 89-106. 2018.

[11] Ferreira, S.E.; Castro, J.T.P. de; Meggiolaro, M.A. Using the strip-yield mechanics to model fatigue crack growth by damage accumulation ahead of the crack tip. Int. J. Fatigue. vol. 103. p. 557-575. 2017.

[12] Ferreira, S.E. Modelagem da Propagação da Trinca de Fadiga Através do Dano Acumulado na Zona Plástica, PUC-Rio, Tese de Doutorado, 2018 .

[13] Castro, J.T.P.; Meggiolaro, M.A. Fadiga - Técnicas e Práticas de Dimensionamento Estrutural sob Cargas Reais de Serviço. Scotts Valley: CreateSpace, 2009.

[14] Vasudevan, A, K.; Sadananda, K.; Holtz, R.L. Analysis of vacuum fatigue crack growth results and its implications. Int. J. Fatigue. vol. 27. p. 15191529. 2005. 
[15] Skorupa, M. Load Interaction Effects During Fatigue Crack Growth Under Variable Amplitude Loading - a Literature Review . Part I : Empirical Trends. Fatigue Fract. Eng. Mater. Struct. p. 987-1006. 1998.

[16] Skorupa, M. Load interaction effects during fatigue crack growth under variable amplitude loading - a literature review. Part II: qualitative interpretation. Fatigue Fract. Eng. Mater. Struct. vol. 22, no 10. p. 905926. 1999.

[17] Noroozi, A.H.; Glinka, G.; Lambert, S. A two parameter driving force for fatigue crack growth analysis. Int. J. Fatigue. vol. 27. p. 1277-1296. 2005.

[18] Barsom, J.M.; Rolfe, S.T. Fracture and Fatigue Control in Structures : Applications of Fracture Mechanics Third Edition. 2012.

[19] Norton, R. Diseño de Maquinas, $3^{\circ}$ ed. Prentice Hall, 2005.

[20] Tada, H.; Paris, P.; Irwin, G. The Stress Analysis of Cracks Handbook, $3^{\circ}$ ed. 2000.

[21] ASTM. ASTM E399-12e2 Linear-Elastic Plane-Strain Fracture Toughness K Ic of of Metallic Materials. Astm. vol. 399. p. 1-33. 2013.

[22] Kemp, P.J. Fatigue Crack Closure - a Review, London, 1990.

[23] Paris, P.C.; Hermann, L. Twenty years of reflections on questions involving fatigue crack growth, part II: some observations of fatigue crack closure. Fatigue Threshold. vol. 1. p. 11-33. 1982.

[24] ASTM-E647-15e1. Standard Test Method for Measurement of Fatigue Crack Growth Rates. Am. Soc. Test. Mater. p. 1-49. 2015.

[25] KUJAWSKI, D. $\Delta$ Keff parameter under re-examination, International Journal of Fatigue, vol. 25, nº 9-11. p. 793-800, 2003.

[26] Song, J.H.; Kang, J.Y.; Koo, J.S. Proposal of modified (normalized) ASTM offset method for determination of fatigue crack opening load. Int. J. Fatigue. vol. 27. p. 293-303. 2005.

[27] Kujawski, D.; Stoychev, S. A New Method for Opening Load Determination from Compliance Measurements. Fatigue Fract. Mech. 34th Vol. vol. 2, n ${ }^{\mathrm{o}}$ 6. p. 525-525-12. 2008.

[28] Chen, D.L.; Weiss, B.; Stickler, R. The effective fatigue threshold: significance of the loading cycle below the crack opening load. vol. 16. p. 485-491. 1994.

[29] Paris, P.C.; Tada, H.; Donald, J, K. Service load fatigue damage - a historical perspective. Int. J. Fatigue. vol. 21. p. 35-46. 1999.

[30] Schijve, J. Fatigue of Structures and Materials, $2^{\circ}$ ed. Delft: Springer, 2009.

[31] Ruckert, C.O.F.T.; Tarpani, J.R.; Milan, M.T.; Filho, W.W.B.; Spinelli, D. Evaluating the Berkovitz Method to Predict Fatigue Loads in Mechanical Failure Investigations. J. Mater. Eng. Perform. vol. 15, $\mathrm{n}^{\mathrm{o}}$ December. p. 661-667. 2006.

[32] Skorupa, M.; Machniewicz, T.; Schijve, J.; Skorupa, a. Application of the strip-yield model from the NASGRO software to predict fatigue crack growth in aluminium alloys under constant and variable amplitude 
loading. Eng. Fract. Mech. vol. 74. p. 291-313. 2007.

[33] Dinda, S.; Kujawski, D. Correlation and prediction of fatigue crack growth for different R-ratios using Kmax and ??K+ parameters. Eng. Fract. Mech. vol. 71. p. 1779-1790. 2004.

[34] Donald, K.; Paris, P.C. An evaluation of $\Delta$ Keff estimation procedures on 6061-T6 and 2024-T3 aluminum alloys, International Journal of Fatigue, vol. 21, no Supplement 1. p. S47-S57, 1999.

[35] Newman, J.C. An Evaluation of the Plasticity-Induced Crack-Closure Concept and Measurement Methods. $n^{0}$ August. 1998.

[36] Fleck, N. Influence of Stress State on Crack Growth Retardation. Basic Quest. Fatigue Vol. I. vol. I. p. 157-157-27. 2009.

[37] Yamada, Y.; Newman, J.C. Crack closure under high load-ratio conditions for Inconel-718 near threshold behavior. Eng. Fract. Mech. vol. 76, no 2. p. 209-220. 2009.

[38] Corbani, S.; Martha, L.F.; Castro, J.T.P.; Carter, B.; Ingraffea, A. Crack Front Shapes and Stress Intensity Factors in Plates under a Pure Bending Loading that Induces Partial Closure of the Crack Faces. Procedia Mater. Sci. vol. 3. p. 1279-1284. 2014.

[39] LINX. Aquisição de Dados. [Online]. Available at: www.lynxtec.com.br.

[40] National Instruments Brasil. [Online]. Available at: http://brasil.ni.com.

[41] Schreier, H.; Orteu, J.-J.; Sutton, M.A. Image Correlation for Shape, Motion and Deformation Measurements. Boston, MA: Springer US, 2009.

[42] Gonzáles, G.L.G. Aplicação da Técnica SIFT para Determinação de Campos de Deformações de Materiais usando Visão Computacional, Dissertação de Mestrado, 2010.

[43] Correlated Colutions. Digital Image Correlation. [Online]. Available at: www.correlatedsolutions.com.

[44] Rodrigues, L.D. Aplicação da técnica DIC a espécimes com diferentes formas , materiais e gradientes de deformação, PUC-Rio, Tese de Doutorado, 2014.

[45] Gonzáles, G.L.G.; Meggiolaro, M.A. Strain field measurements around notches using SIFT features and meshless methods. Appl. Opt. vol. 54, $\mathrm{n}^{\mathrm{o}}$ 14. p. $4520-4528.2015$.

[46] Castro, J.T.P. Some Critical Remarks on the Use of Potential Drop and Compliance Systems to Measure Crack Growth in Fatigue Experiments. REV-BR-MEC. vol. 4. 1985.

[47] Gilbert, C.; McNaney, J.; Dauskardt, R.; Ritchie, R. Back-Face Strain Compliance and Electrical-Potential Crack Length Calibrations for the Disk-Shaped Compact-Tension DC(T) Specimen. J. Test. Eval. vol. 22. p. 117. 1994.

[48] NI LabVIEW. National Instruments. [Online]. Available at: http://www.ni.com/labview/pt/.

[49] Instron : Máquinas de teste de materiais [Online]. Available at: http://www.instron.com.br/wa/home/default_br.aspx. 
[50] Correlated Solutions. VIC-3D Microscopy. [Online]. Available at: https://www.correlatedsolutions.com/vic-3d-old/microscopy.

[51] Astm. E8/E8M standard test methods for tension testing of metallic materials 1. Anпи. B. ASTM Stand. 4. p. 1-27. 2010.

[52] González, J.A.O. Avaliação da Força Motriz do Crescimento de Trincas por Fadiga, com Ensaios em Deformação Plana e em Tensão Plana com $\Delta K$ Constante, PUC-Rio, Dissertação de Mestrado, 2015.

[53] González, J.A.O.; Castro, J.T.P.; Gonzáles, G.L.G.; Meggiolaro, M.A.; Freire, J.L.F. On DIC measurements of $\Delta$ Keff to verify if it is the FCG driving force, Frattura ed Integrita Strutturale, vol. 11, no 41. p. 227-235, 2017.

[54] Skorupa, M.; Machniewicz, T.; Skorupa, A. Applicability of the ASTM compliance offset method to determine crack closure levels for structural steel. Int. J. Fatigue. vol. 29. p. 1434-1451. 2007.

[55] Lugo, M.; Daniewicz, S.R.; Newman, J.C. A mechanics based study of crack closure measurement techniques under constant amplitude loading. Int. J. Fatigue. vol. 33, n ${ }^{\circ}$ 2. p. 186-193. 2011.

[56] Forth, S.C.; Johnston, W.M.; Seshadri, B.R. The Effect of the Laboratory Specimen on Fatigue Crack Growth Rate. 2008.

[57] Forth, S.C.; Newman, J.C.; Forman, R.G. Anomalous Fatigue Crack Growth Data Generated Using the ASTM Standards. Fatigue Fract. Mech. 35th Vol. vol. 3, no 3. p. 244-244-12. 2009. 